University of South Florida

DIGITAL COMMONS Digital Commons @ University of @ UNIVERSITY OF SOUTH FLORIDA South Florida

$1-1-2016$

\title{
Safe and Accessible Pedestrian Facility Inventory Model (SAPFIM)
}

CUTR

Follow this and additional works at: https://digitalcommons.usf.edu/cutr_nctr

\section{Recommended Citation}

"Safe and Accessible Pedestrian Facility Inventory Model (SAPFIM)," National Center for Transit Research (NCTR) Report No. CUTR-NCTR-RR-2016-15, Center for Urban Transportation Research, University of South Florida, 2016.

DOI: https://doi.org/10.5038/CUTR-NCTR-RR-2016-15

Available at: https://scholarcommons.usf.edu/cutr_nctr/21

This Technical Report is brought to you for free and open access by the National Center for Transit Research (NCTR) Archive (2000-2020) at Digital Commons @ University of South Florida. It has been accepted for inclusion in Research Reports by an authorized administrator of Digital Commons @ University of South Florida. For more information, please contact digitalcommons@usf.edu. 


\title{
Safe and Accessible Pedestrian Facilities Inventory Model (SAPFIM): Development
}

\author{
Submitted by: \\ Fabian Cevallos, Ph.D. \\ Transit Program Director \\ Lehman Center for Transportation Research (LCTR) \\ Florida International University (FIU) \\ 10555 West Flagler Street, EC 3609 \\ Miami, FL 33174 \\ Phone: (305) 348-3144 \\ Email: fabian.cevallos@fiu.edu
}

\author{
Submitted to: \\ Robert Bertini, Director \\ National Center for Transit Research \\ Center for Urban Transportation Research \\ University of South Florida \\ 4202 E. Fowler Avenue, CUT 100 \\ Tampa, FL 33620 \\ Phone: (813) 974-9797 \\ Email: rbertini@usf.edu
}

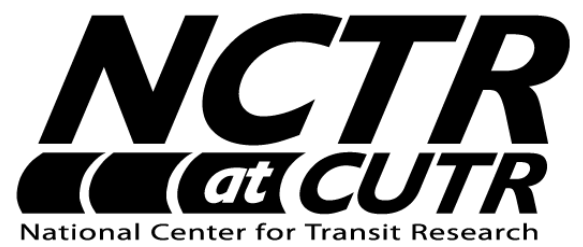

April 2018

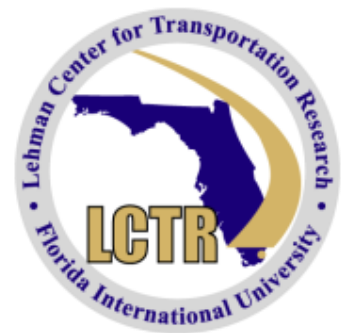




\section{DISCLAIMER}

The contents of this report reflect the views of the authors, who are responsible for the facts and the accuracy of the information presented herein. This document is disseminated under the sponsorship of the U.S. Department of Transportation's University Transportation Centers Program, in the interest of information exchange. The U.S. Government assumes no liability for the contents or use thereof. 


\section{ACKNOWLEDGMENT}

We would like to thank Mr. Haifeng Wang, Senior Programmer at the Lehman Center for Transportation Research (LCTR) at Florida International University (FIU), for the software development and database setup; Ms. Thalia Pickering, LCTR Web Designer, for the design of the user interface and for her assistance with the documentation; and Ms. Shirin Noei, Ph.D. student, for helping with the literature review.

The project team would also like to recognize the following individuals: Mr. Carey Shepherd with FHWA for his leadership and support of the SAPFIM project; Mr. Dean Perkins with FDOT for his expertize, guidance, and assistance on the development of the SAPFIM data criteria; Ms. Gabrielle Matthews with FDOT for the management and guidance on the matching project and her assistance with the different meetings and events; and Mr. Peter Gies with the Broward MPO for his participation and for agreeing to coordinate the testing of SAPFIM. Finally, the project team would like to thank Dr. Fabian Cevallos, LCTR Principal Investigator, for his direction and management of this project.

This work was supported by the National Center for Transit Research, a program of the Center for Urban Transportation Research at the University of South Florida and funded by the U.S. Department of Transportation. 


\section{LIST OF FIGURES}

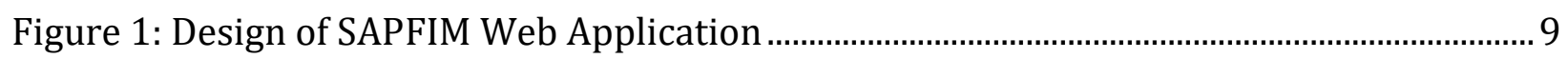

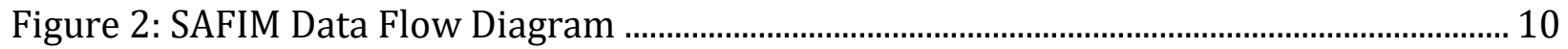

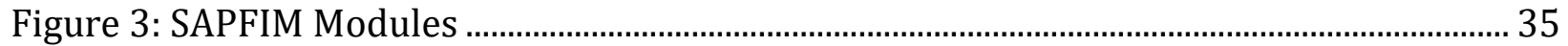

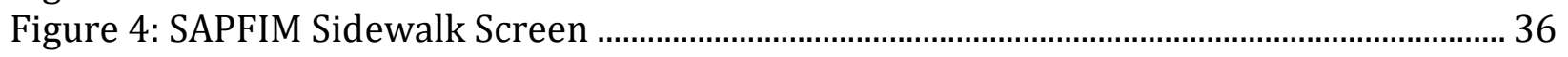

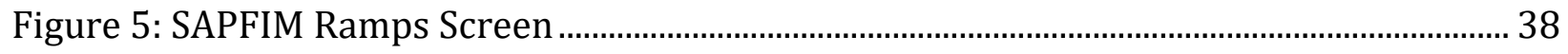

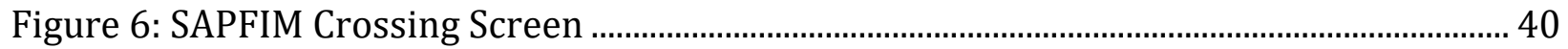

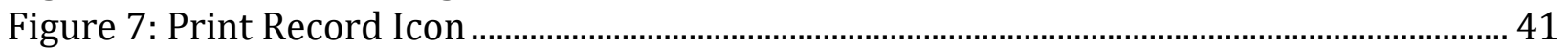

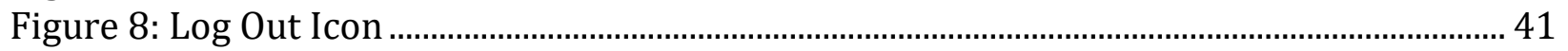

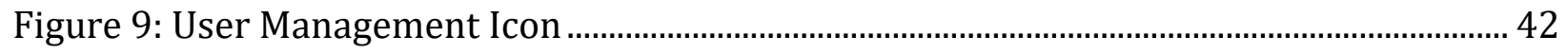

Figure 10: User Management Screen ........................................................................................... 42

Figure 11: User Management Add/Edit Screen.............................................................................. 43

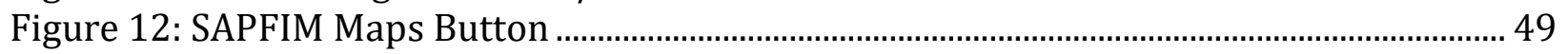

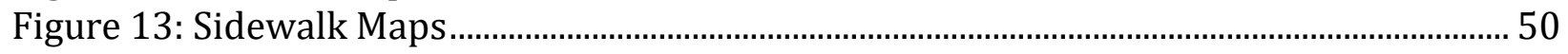

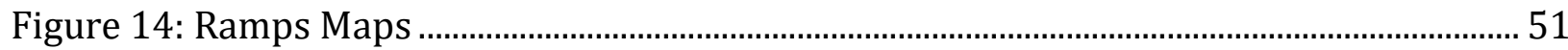

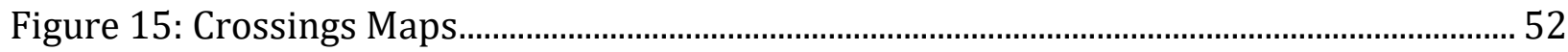

Figure 16: SAPFIM Data Management Button ................................................................................ 53

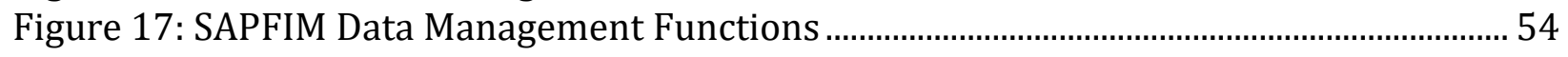

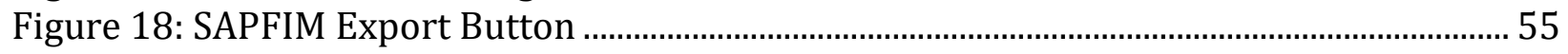

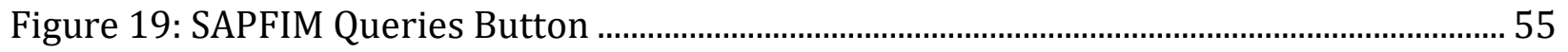

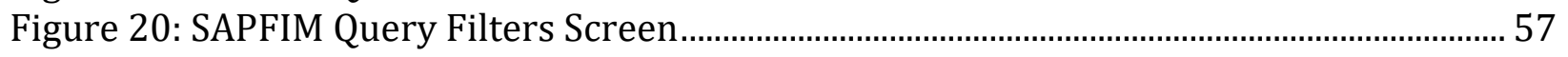

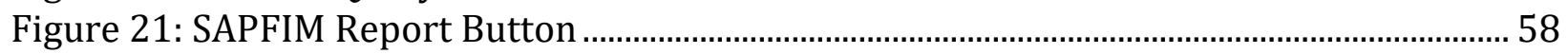

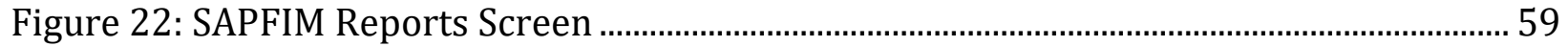

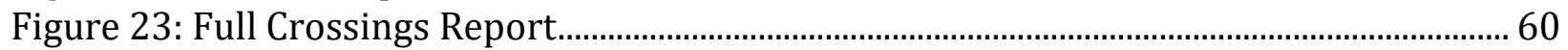

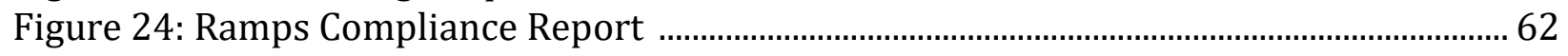




\section{LIST OF TABLES}

Table 1: SAPFIM Criteria..................................................................................................... 3

Table 2: Curb Ramps \& Blended Transition Criteria ....................................................... 6

Table 3: Street Crossing Criteria........................................................................................ 7

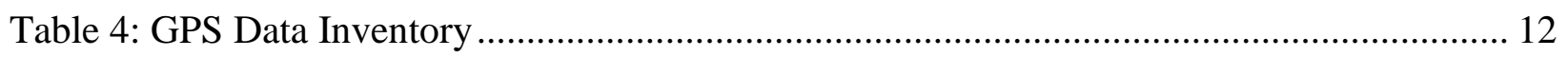

Table 5: Example of State DOT Pedestrian Inventories ......................................................... 19

Table 6: Example of Local Jurisdiction Pedestrian Inventories .............................................. 19

Table 7: Pedestrian Characteristics by Age Group ............................................................... 24

Table 8: Characteristics of Pedestrian-Friendly Communities .................................................. 25

Table 9: Common Residential Traffic Management Program Actions ..................................... 29

Table 10: Common Types of Traffic Calming Methods .......................................................... 30

Table 11: Work Zone Maintenance ...................................................................................... 32 


\section{TABLE OF CONTENTS}

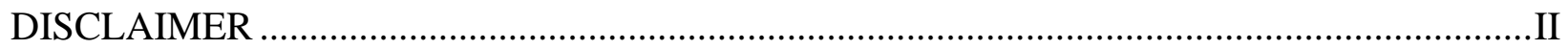

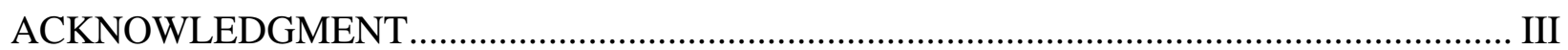

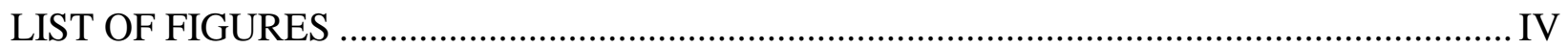

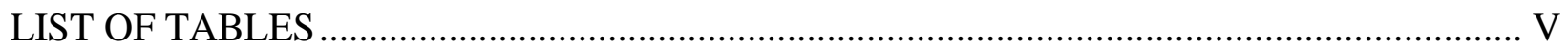

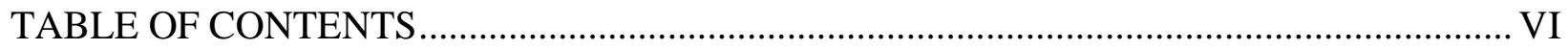

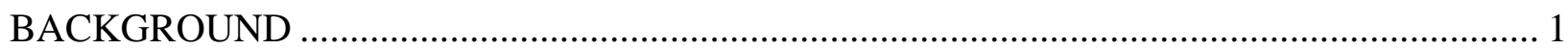

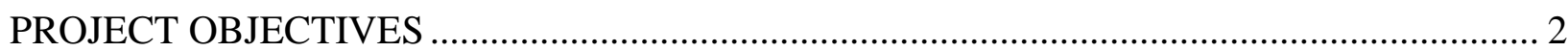

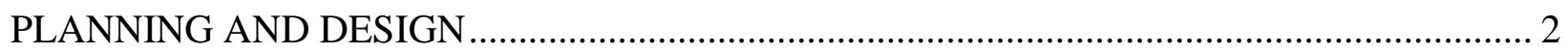

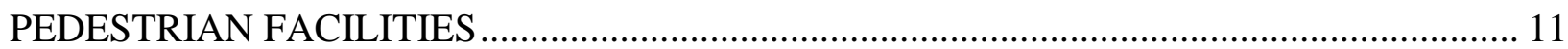

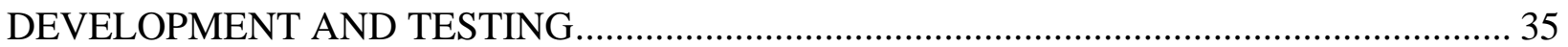

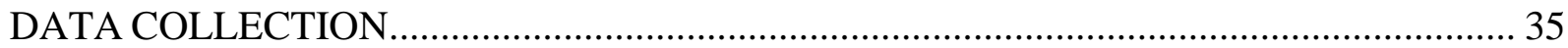

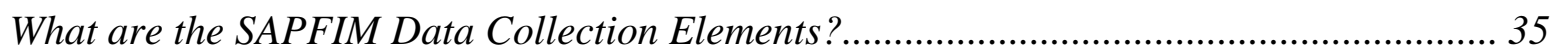

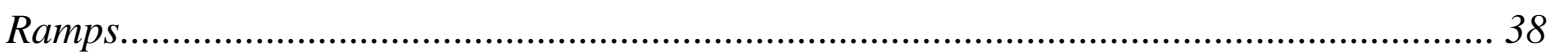

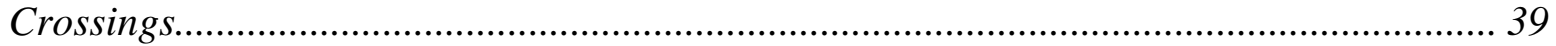

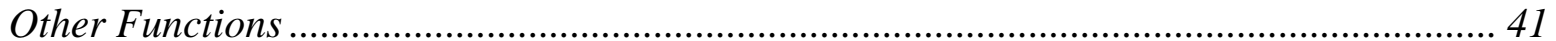

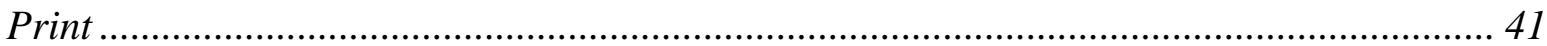

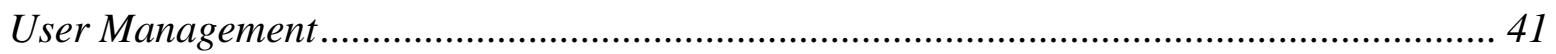

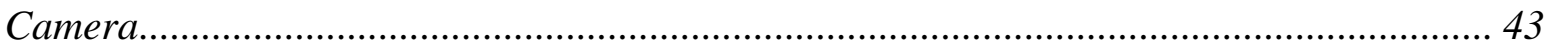

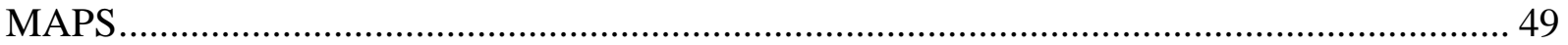

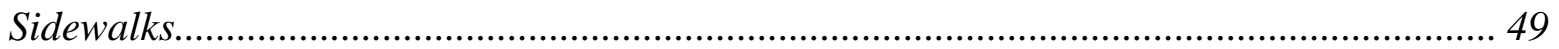

Ramps

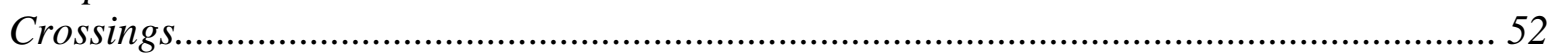

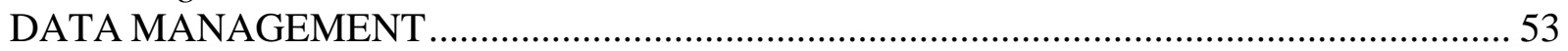

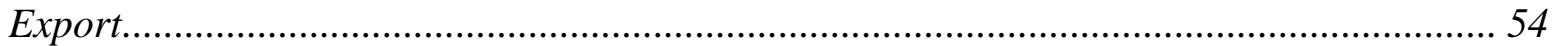

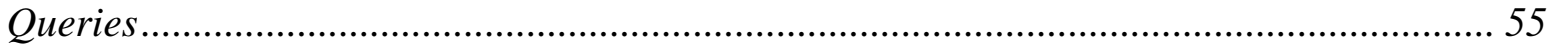

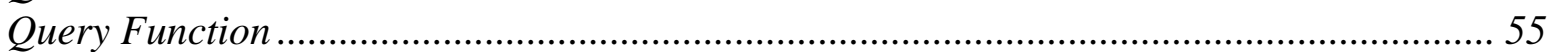

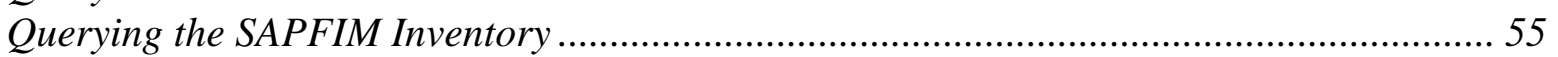

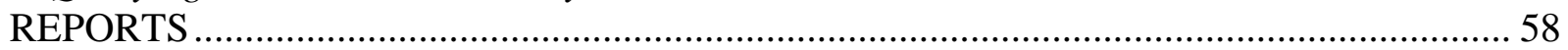

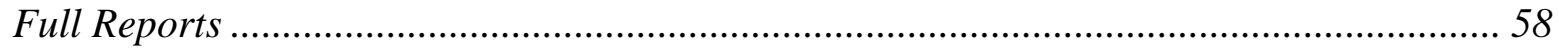

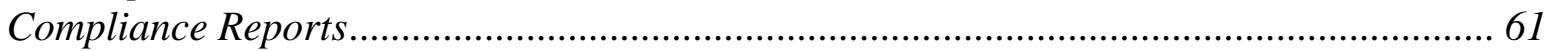

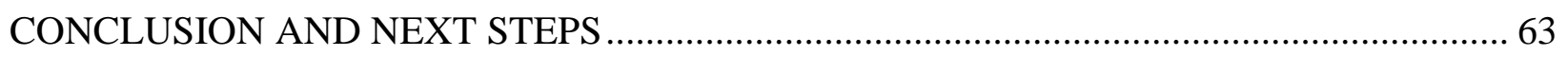

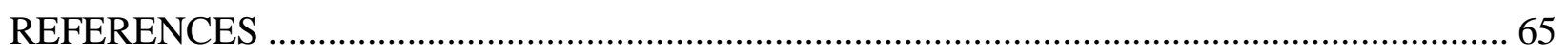

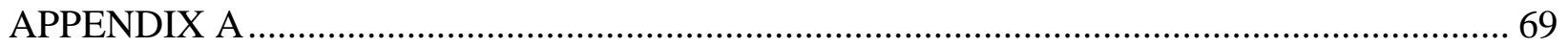




\section{BACKGROUND}

Pedestrian facilities like sidewalks, curb ramps, and crosswalks are critical elements that play a vital role in the life of a community. According to the American Association of Retired Persons (AARP), 8 out of 10 Americans prefer being in a community that offers sidewalks, which provides pedestrians with an accessible and safe path to walk within the public right-of-way separated from motor vehicles and on-road bicycles. Six out of ten prefer a neighborhood that features a mix of residential, commercial, and activities or services within easy access instead of a neighborhood that requires a car for every errand. AARP states that "People who live in neighborhoods with sidewalks are $47 \%$ more likely than residents of areas without sidewalks to be active at least 39 minutes a day".

As pedestrian facilities are critical for pedestrian movement and access, they enhance livability, connectivity, and promote a healthier lifestyle. Further, they benefit communities by promoting social economic activities. Therefore, safe, accessible, and well-maintained pedestrian facilities are a fundamental community investment that enhances public health and maximizes social capital.

Continuous and accessible pedestrian networks improve mobility and livability for all pedestrians and are particularly important for seniors and pedestrians with disabilities. Pedestrians who use sidewalks may have disabilities and may use mobility aids such as wheelchairs, scooters, walkers, canes, etc. Others may have visual impairments (blind or low vision) or have hearing impairments (deaf or hard-of-hearing). According to the Americans with Disabilities Act (ADA) regulations, 28 CFR Part 35, services provided by state and local governments, including features and devices along roadside pedestrian facilities must be "accessible to and useable by" all users, including people with disabilities.

It is often a big challenge for large urban areas to maintain and redesign or repair pedestrian facilities to comply with the Americans with Disabilities Act (ADA). It requires a tremendous effort to ensure accessibility for seniors and people with disabilities when these facilities are substandard or poorly maintained. Based on these challenges, agencies are required to develop transition plans to plan and schedule corrections to identified deficiencies. However, planning for the best provisions for accessibility during the process of redevelopment and construction in a number of communities can be challenging. Without readily available and accurate information, pedestrian improvements cannot be easily prioritized.

Pedestrian facilities are instrumental in encouraging walkability, which can help improve the quality of life of our citizens and the livability of our communities. Therefore, it is critical that local agencies have access to detailed information of pedestrian facilities to be able to make intelligent decisions. For example, a computerized pedestrian facilities inventory can easily help identify areas with no sidewalks and document the conditions of existing sidewalks, the level of 
accessibility, and the existence of obstacles or deficiencies that prevent pedestrians to take full advantage of these facilities.

A tool to keep track of pedestrian facilities can assist local agencies in prioritizing investments for pedestrian improvements: repairs, improvements, and new construction projects. To accomplish this, there is a need to develop a software tool that can facilitate this effort. Having a tool available to local agencies can help improve the livability of communities. It can also help identify any safety and accessibility deficiencies that are barriers to senior and pedestrians with disabilities.

\section{PROJECT OBJECTIVES}

The main objective of this scope of work is to develop the SAPFIM tool: a web-based software application that local agencies can use for the collection, storage, querying, and reporting of pedestrian facilities.

The Lehman Center for Transportation Research (LCTR) at Florida International University (FIU) has expertize developing web-based systems in the field of transportation. This project is intended to develop a software tool that can be used by local agencies for the assessment of pedestrian facilities. It will include accessible and safety features associated with sidewalks, curb ramps, roadway crossings, pedestrian signals, etc. Data will be collected using field devices (i.e., tablets with GPS, camera, and wireless capability) which can be uploaded directly into the web server.

To achieve this, the FIU research team proposes a series of work tasks that include software development, testing, deployment, and producing the training materials and User's Guide.

\section{PLANNING AND DESIGN}

The planning and design of the SAPFIM application starts with the creation of the SAPFIM Criteria. The data elements identified in the criteria will help identify the data fields that will need to be collected and measured using both the ADA and PROWAG standards. Further, these data fields will be used in the development of the SAPFIM web application. The development of the SAPFIM Criteria was based on the work of Dean Perkins (2015), information gathered by the research team, and the feedback from the stakeholders involved in this research project.

Tables 1, 2, and 3 list the pertinent criteria for the three selected categories: Sidewalks, Curb Ramps \& Blended Transition, and Street Crossing. These tables include the following elements: Name, Description, Detail, Measurement, and ADA and PROWAG Standards. The information provided in each of the elements will help with the field data collection and the understanding of the associated safety and accessibility features. 
Table 1: SAPFIM Criteria

\begin{tabular}{|c|c|c|c|c|c|}
\hline \multicolumn{6}{|c|}{ Sidewalks (Street Name, Side) (Photos) } \\
\hline Name & Description & Detail & $\begin{array}{c}\text { Measuremen } \\
t\end{array}$ & $\begin{array}{c}A D A \\
\text { Standard }\end{array}$ & $\begin{array}{c}\text { Public } \\
\text { Rights-of- } \\
\text { Way } \\
\text { Accessibility } \\
\text { Guidelines } \\
\text { (PROWAG) }\end{array}$ \\
\hline Sidewalk & Sidewalk & $\begin{array}{l}\text { Is there a } \\
\text { Sidewalk? }\end{array}$ & Yes/No & & \\
\hline $\begin{array}{l}\text { Sidewalk } \\
\text { Width }\end{array}$ & General Width & & $\begin{array}{l}<36^{\prime \prime} \\
\geq 36^{\prime \prime}<48^{\prime \prime} \\
\geq 48^{\prime \prime}\end{array}$ & $\geq 36 "$ & $\geq 48^{\prime \prime}$ \\
\hline $\begin{array}{l}\text { Running } \\
\text { Slope }\end{array}$ & Running Slope & & $\begin{array}{l}\leq 8.3 \% \text { or } \\
>8.3 \%\end{array}$ & $\leq 8.3 \%$ & $\leq 8.3 \%$ \\
\hline Cross Slope & Cross Slope & & $\leq 2 \%$ or $>2 \%$ & $\leq 2 \%$ & $\leq 2 \%$ \\
\hline \multirow[t]{2}{*}{$\begin{array}{l}\text { Vertical } \\
\text { Change }\end{array}$} & \multirow{2}{*}{$\begin{array}{l}\text { Vertical } \\
\text { Change in } \\
\text { Level } \\
\text { (Joint or } \\
\text { Crack) } \\
\text { Tripping } \\
\text { Hazzard }\end{array}$} & \multirow[t]{2}{*}{ Across path } & $\begin{array}{l}\leq 1 / 4^{\prime \prime} \text { or } \\
>1 / 4^{\prime \prime}\end{array}$ & $\begin{array}{c}\leq 1 / 4^{\prime \prime} \\
\text { Vertical }\end{array}$ & $\begin{array}{c}\leq 1 / 4^{\prime \prime} \\
\text { Vertical }\end{array}$ \\
\hline & & & $\begin{array}{l}\leq 1 / 2^{\prime \prime} \text { or } \\
>1 / 2^{\prime \prime}\end{array}$ & $\leq 1 / 2 "$ Sloped & $\leq 1 / 2^{\prime \prime}$ Sloped \\
\hline $\begin{array}{l}\text { Horizontal } \\
\text { Opening }\end{array}$ & $\begin{array}{l}\text { Horizontal } \\
\text { Opening } \\
\text { (Joint or Grate) }\end{array}$ & $\begin{array}{l}\text { Perpendicular } \\
\text { to path }\end{array}$ & $\begin{array}{l}\leq 1 / 2^{\prime \prime} \text { or } \\
>1 / 2^{\prime \prime}\end{array}$ & $\begin{array}{c}\leq 1 / 2^{\prime \prime} \\
\text { Opening }\end{array}$ & $\begin{array}{c}\leq 1 / 2^{\prime \prime} \\
\text { Opening }\end{array}$ \\
\hline \multirow[t]{3}{*}{$\begin{array}{l}\text { Protruding } \\
\text { Object }\end{array}$} & \multirow[t]{3}{*}{$\begin{array}{l}\text { Protruding } \\
\text { Object } \\
\text { (Horizontal } \\
\text { offset) }\end{array}$} & $\begin{array}{l}\text { Sign Panel } \\
\text { (On Post, } \\
\text { Wall, Other) }\end{array}$ & $\begin{array}{l}\geq 27 " \leq 80 " \\
\text { AWS } \\
(\text { Yes/No) } \\
\leq 4 " \\
>4 " \leq 12 " \\
>12 "\end{array}$ & \multirow[t]{3}{*}{$\begin{array}{c}\geq 27 " \leq 80 " \\
\text { Above } \\
\text { Walking } \\
\text { Surface } \\
\text { (AWS) } \\
\leq 12^{\prime \prime} \text { on Post } \\
\leq 4 " \text { on Wall }\end{array}$} & \multirow[t]{3}{*}{$\begin{array}{c}\geq 27^{\prime \prime} \leq 80 " \\
\text { Above } \\
\text { Walking } \\
\text { Surface } \\
\text { (AWS) } \\
\leq 4 " \text { on Post } \\
\leq 4 " \text { on Wall }\end{array}$} \\
\hline & & $\begin{array}{l}\text { Landscape } \\
\text { Material } \\
\text { (On Post, } \\
\text { Wall, Other) }\end{array}$ & $\begin{array}{l}\geq 27 " \leq 80 " \\
\text { AWS } \\
(\text { Yes/No) } \\
\leq 4 " \\
>4 " \leq 12 " \\
>12 "\end{array}$ & & \\
\hline & & $\begin{array}{l}\text { Other } \\
\text { (On Post, } \\
\text { Wall, Other) }\end{array}$ & $\begin{array}{l}\geq 27^{\prime \prime} \leq 80 " \\
\text { AWS } \\
(\text { Yes/No) } \\
\leq 4 " \\
>4 " \leq 12^{\prime \prime} \\
>12^{\prime \prime}\end{array}$ & & \\
\hline
\end{tabular}




\begin{tabular}{|c|c|c|c|c|c|}
\hline \multirow[t]{3}{*}{$\begin{array}{l}\text { Physical } \\
\text { Constraint }\end{array}$} & \multirow[t]{3}{*}{$\begin{array}{l}\text { Physical } \\
\text { Constraint }\end{array}$} & Building & $\begin{array}{l}<36 " \text { clear } \\
\text { width } \\
\geq 36 "<48 " \\
\text { clear width } \\
\geq 48 \text { " clear } \\
\text { width }\end{array}$ & $\geq 36^{\prime \prime}$ & $\geq 48^{\prime \prime}$ \\
\hline & & $\begin{array}{l}\text { Retaining } \\
\text { Wall }\end{array}$ & $\begin{array}{l}<36 " \text { clear } \\
\text { width } \\
\geq 36 "<48 " \\
\text { clear width } \\
\geq 48 " \text { clear } \\
\text { width }\end{array}$ & $\geq 36^{\prime \prime}$ & $\geq 48^{\prime \prime}$ \\
\hline & & Other & $\begin{array}{l}<36 " \text { clear } \\
\text { width } \\
\geq 36 "<48 " \\
\text { clear width } \\
\geq 48 " \text { clear } \\
\text { width }\end{array}$ & $\geq 36^{\prime \prime}$ & $\geq 48^{\prime \prime}$ \\
\hline $\begin{array}{l}\text { Connects } \\
\text { To Other } \\
\text { Facility }\end{array}$ & $\begin{array}{l}\text { Connects To } \\
\text { Other Facility }\end{array}$ & $\begin{array}{l}\text { To other } \\
\text { sidewalk, to } \\
\text { building } \\
\text { entrance, etc. }\end{array}$ & Yes/No & & \\
\hline $\begin{array}{l}\text { Sidewalk } \\
\text { Gap }\end{array}$ & $\begin{array}{l}\text { Discontinuity } \\
\text { of Sidewalk }\end{array}$ & Length of Gap & $\begin{array}{l}\leq 5^{\prime} \\
>5^{\prime} \leq 10^{\prime} \\
>10^{\prime}\end{array}$ & & \\
\hline Material & Material & & $\begin{array}{l}\text { Concrete } \\
\text { Asphalt } \\
\text { Brick } \\
\text { Other }\end{array}$ & & \\
\hline Condition & Condition & & $\begin{array}{l}\text { Good } \\
\text { Cracks } \\
\text { Dirt } \\
\text { Grass } \\
\text { Other }\end{array}$ & & \\
\hline \multirow{2}{*}{$\begin{array}{l}\text { Roadway } \\
\text { Cross } \\
\text { Section }\end{array}$} & \multirow[t]{2}{*}{$\begin{array}{l}\text { Roadway } \\
\text { cross-section }\end{array}$} & $\begin{array}{l}\text { Curb and } \\
\text { Gutter }\end{array}$ & Yes / No & & \\
\hline & & $\begin{array}{l}\text { Flush } \\
\text { shoulder }\end{array}$ & Yes / No & & \\
\hline $\begin{array}{l}\text { Sidewalk } \\
\text { Separation }\end{array}$ & $\begin{array}{l}\text { Sidewalk } \\
\text { Separation }\end{array}$ & $\begin{array}{l}\text { Separated } \\
\text { from road }\end{array}$ & $\begin{array}{l}\text { Curb \& } \\
\text { Gutter: } \\
\text { Utility Strip } \\
<2^{\prime} \text { or } \geq 2 \text { ' } \\
\text { Flush } \\
\text { Shoulder: } \\
\text { Utility Strip } \\
<5 \text { ' or } \geq 5 \text { ' }\end{array}$ & & $\begin{array}{l}\geq 2 \text { ' if curb \& } \\
\text { gutter, or } \\
\geq 5 \text {, if flush } \\
\text { shoulder }\end{array}$ \\
\hline
\end{tabular}




\begin{tabular}{|c|c|c|c|c|c|}
\hline & & Not separated & $\begin{array}{l}\text { Curb \& } \\
\text { Gutter: Back } \\
\text { of Curb }\end{array}$ & $\begin{array}{l}\text { Sidewalk not } \\
\text { allowed } \\
\text { adjacent to } \\
\text { flush } \\
\text { shoulder } \\
\text { roadway }\end{array}$ & $\begin{array}{l}\text { Sidewalk not } \\
\text { allowed } \\
\text { adjacent to } \\
\text { flush } \\
\text { shoulder } \\
\text { roadway }\end{array}$ \\
\hline \multirow[t]{3}{*}{$\begin{array}{l}\text { Drop-off } \\
\text { Hazard }\end{array}$} & \multirow[t]{3}{*}{$\begin{array}{l}\text { Drop-off } \\
\text { hazard }\end{array}$} & $\begin{array}{l}>10 " \text { drop } \\
\text { w/in } 24 "\end{array}$ & $\begin{array}{l}>10 " \text { drop } \\
\text { w/in 24" } \\
\text { (Yes/No) }\end{array}$ & & $\begin{array}{l}>10 " \text { drop } \\
\text { w/in } 24 "\end{array}$ \\
\hline & & $\begin{array}{l}\text { Protected by } \\
\text { railing }\end{array}$ & Yes / No & & \\
\hline & & $\begin{array}{l}\text { Other } \\
\text { protection }\end{array}$ & Yes / No & & \\
\hline \multirow[t]{8}{*}{ Obstruction } & \multirow{8}{*}{$\begin{array}{l}\text { Obstruction in } \\
\text { Sidewalk } \leq 24 \text { " }\end{array}$} & Utility Pole & $<32^{\prime \prime}$ or $\geq 32^{\prime \prime}$ & \multirow[t]{8}{*}{$\geq 32^{\prime \prime}$} & $\geq 32^{\prime \prime}$ \\
\hline & & Signal Pole & $\begin{array}{l}<32^{\prime \prime} \\
\geq 32^{\prime \prime}<48^{\prime \prime} \\
\geq 48^{\prime \prime}\end{array}$ & & $\geq 48^{\prime \prime}$ \\
\hline & & Sign Post & $\begin{array}{l}<32^{\prime \prime} \\
\geq 32^{\prime \prime}<48^{\prime \prime} \\
\geq 48^{\prime \prime}\end{array}$ & & $\geq 48^{\prime \prime}$ \\
\hline & & Fire Hydrant & $<32^{\prime \prime}$ or $\geq 32^{\prime \prime}$ & & \\
\hline & & $\begin{array}{l}\text { Furniture/Am } \\
\text { enities }\end{array}$ & $\begin{array}{l}<32^{\prime \prime} \\
\geq 32^{\prime \prime}<48^{\prime \prime} \\
\geq 48^{\prime \prime}\end{array}$ & & $\geq 48^{\prime \prime}$ \\
\hline & & $\begin{array}{l}\text { Landscaping/ } \\
\text { Hardscape }\end{array}$ & $\begin{array}{l}<32 " \\
\geq 32^{\prime \prime}<48^{\prime \prime} \\
\geq 48^{\prime \prime}\end{array}$ & & $\geq 48^{\prime \prime}$ \\
\hline & & $\begin{array}{l}\text { Trees/Vegetat } \\
\text { ion }\end{array}$ & $\begin{array}{l}<32^{\prime \prime} \\
\geq 32^{\prime \prime}<48^{\prime \prime} \\
\geq 48^{\prime \prime}\end{array}$ & & $\geq 48^{\prime \prime}$ \\
\hline & & Other & $\begin{array}{l}<32^{\prime \prime} \\
\geq 32^{\prime \prime}<48^{\prime \prime} \\
\geq 48^{\prime \prime}\end{array}$ & & $\geq 48^{\prime \prime}$ \\
\hline \multirow[t]{2}{*}{ Lighting } & \multirow[t]{2}{*}{ Lighting } & $\begin{array}{l}\text { Roadway/high } \\
\text {-level }\end{array}$ & Yes / No & & \\
\hline & & $\begin{array}{l}\text { Pedestrian/lo } \\
\text { w-level }\end{array}$ & Yes / No & & \\
\hline
\end{tabular}


Table 2: Curb Ramps \& Blended Transition Criteria

\begin{tabular}{|c|c|c|c|c|c|}
\hline \multicolumn{6}{|c|}{ Curb ramps \& Blended Transition (Intersection, Corner) (Photo) } \\
\hline Name & Description & Detail & Measurement & $\begin{array}{c}A D A \\
\text { Standard }\end{array}$ & $\begin{array}{c}\text { Public } \\
\text { Rights-of- } \\
\text { Way } \\
\text { Accessibility } \\
\text { Guidelines } \\
\text { (PROWAG) }\end{array}$ \\
\hline $\begin{array}{l}\text { Curb } \\
\text { Ramp }\end{array}$ & Curb Ramp & $\begin{array}{l}\text { Is there a Curb } \\
\text { Ramp? }\end{array}$ & Yes/No & & \\
\hline $\begin{array}{l}\text { Running } \\
\text { Slope }\end{array}$ & $\begin{array}{l}\text { Running } \\
\text { Slope }\end{array}$ & $\begin{array}{l}\text { Slope of curb } \\
\text { ramp }\end{array}$ & $\leq 8.3 \%$ or $>8.3 \%$ & $\leq 8.3 \%$ & $\leq 8.3 \%$ \\
\hline $\begin{array}{l}\text { Counter } \\
\text { Slope }\end{array}$ & $\begin{array}{l}\text { Gutter } \\
\text { Slope }\end{array}$ & Gutter slope & $\leq 5 \%$ or $>5 \%$ & $\leq 5 \%$ & $\leq 5 \%$ \\
\hline $\begin{array}{l}\text { Cross } \\
\text { Slope }\end{array}$ & Cross Slope & $\begin{array}{l}\text { Top and } \\
\text { bottom }\end{array}$ & $\leq 2 \%$ or $>2 \%$ & $\leq 2 \%$ & $\leq 2 \%$ \\
\hline $\begin{array}{l}\text { Flare } \\
\text { Slope }\end{array}$ & Flare Slope & $\begin{array}{l}\text { Both sides of } \\
\text { ramp }\end{array}$ & $\leq 10 \%$ or $>10 \%$ & $\leq 10 \%$ & $\leq 10 \%$ \\
\hline $\begin{array}{l}\text { Ramp } \\
\text { Length }\end{array}$ & $\begin{array}{l}\text { Ramp } \\
\text { Length }\end{array}$ & $\begin{array}{l}\text { From bottom } \\
\text { of ramp to top } \\
\text { of ramp }\end{array}$ & $\begin{array}{l}<72 " \\
\geq 72 "<88^{\prime \prime} \\
\geq 88^{\prime \prime}\end{array}$ & & \\
\hline $\begin{array}{l}\text { Ramp } \\
\text { Width }\end{array}$ & $\begin{array}{l}\text { Ramp } \\
\text { Width }\end{array}$ & $\begin{array}{l}\text { At narrowest } \\
\text { point }\end{array}$ & $\begin{array}{l}<36 " \\
\geq 36 "<48^{\prime \prime} \\
\geq 48^{\prime \prime}\end{array}$ & $\geq 36^{\prime \prime}$ & $\geq 48^{\prime \prime}$ \\
\hline $\begin{array}{l}\text { Top } \\
\text { Landing }\end{array}$ & $\begin{array}{l}\text { Top } \\
\text { Landing }\end{array}$ & $\begin{array}{l}\text { Landing } \\
\text { Width }\end{array}$ & $\begin{array}{l}<36 " \\
\geq 36^{\prime \prime}<48^{\prime \prime} \\
\geq 48^{\prime \prime}\end{array}$ & $\geq 36^{\prime \prime}$ & $\geq 48^{\prime \prime}$ \\
\hline $\begin{array}{l}\text { Bottom } \\
\text { Landing }\end{array}$ & $\begin{array}{l}\text { Bottom } \\
\text { Landing }\end{array}$ & $\begin{array}{l}\text { Landing } \\
\text { Width }\end{array}$ & $<48^{\prime \prime}$ or $\geq 48^{\prime \prime}$ & $\geq 48^{\prime \prime}$ & $\geq 48^{\prime \prime}$ \\
\hline \multirow[t]{2}{*}{$\begin{array}{l}\text { Detectable } \\
\text { Warnings }\end{array}$} & \multirow[t]{2}{*}{$\begin{array}{l}\text { Detectable } \\
\text { Warnings }\end{array}$} & $\begin{array}{l}\text { Truncated } \\
\text { Domes }\end{array}$ & Yes/No & & \\
\hline & & $\begin{array}{l}\text { Color: } \\
\text { - Brick Red, } \\
\text { Yellow, } \\
\text { Black, No } \\
\text { Color, Other }\end{array}$ & Yes/No & & \\
\hline $\begin{array}{l}\text { Detectable } \\
\text { Warning }\end{array}$ & $\begin{array}{l}\text { Detectable } \\
\text { Warnings } \\
\text { Placement }\end{array}$ & $\begin{array}{l}\text { Detectable } \\
\text { Warnings } \\
\text { Placement }\end{array}$ & $\begin{array}{l}\leq 2 " \text { from back of } \\
\text { curb } \\
>2 " \leq 5 \text {, from } \\
\text { back of curb } \\
>5 \text { ' from back of } \\
\text { curb }\end{array}$ & $\begin{array}{c}\leq 2 \text { " from } \\
\text { Back of curb } \\
\text { or } \\
\leq 5 \text {, from } \\
\text { Curb }\end{array}$ & $\begin{array}{c}\leq 2 \text { " from } \\
\text { Back of curb } \\
\text { or } \\
\leq 5 \text {, from Curb }\end{array}$ \\
\hline $\begin{array}{l}\text { Type of } \\
\text { Ramps }\end{array}$ & $\begin{array}{l}\text { Type of } \\
\text { Ramps }\end{array}$ & & $\begin{array}{l}\text { Perpendicular } \\
\text { Parallel }\end{array}$ & & \\
\hline
\end{tabular}


Combination

Diagonal

Other

Table 3: Street Crossing Criteria

\begin{tabular}{|c|c|c|c|c|c|}
\hline \multicolumn{6}{|c|}{ Street Crossing (Intersection, Location) (Photo) } \\
\hline Name & Description & Detail & Measurement & $\begin{array}{c}A D A \\
\text { Standard }\end{array}$ & $\begin{array}{c}\text { Public } \\
\text { Rights-of- } \\
\text { Way } \\
\text { Accessibility } \\
\text { Guidelines } \\
\text { (PROWAG) }\end{array}$ \\
\hline $\begin{array}{l}\text { Street } \\
\text { Crossing }\end{array}$ & $\begin{array}{l}\text { Street } \\
\text { Crossing }\end{array}$ & $\begin{array}{l}\text { Is there a } \\
\text { Marked } \\
\text { Crossing? }\end{array}$ & Yes/No & & \\
\hline $\begin{array}{l}\text { Horizontal } \\
\text { Opening }\end{array}$ & $\begin{array}{l}\text { Horizontal } \\
\text { Opening } \\
\text { (Joint or } \\
\text { Grate) }\end{array}$ & $\begin{array}{l}\text { Perpendicular } \\
\text { to path }\end{array}$ & $\leq 1 / 2^{\prime \prime}$ or $>1 / 2^{\prime \prime}$ & $\leq 1 / 2^{\prime \prime}$ & $\leq 1 / 2^{\prime \prime}$ \\
\hline \multirow[t]{2}{*}{ Median } & \multirow[t]{2}{*}{ Island/Median } & & Yes/No & & \\
\hline & & $\begin{array}{l}\text { Pedestrian } \\
\text { Refuge }\end{array}$ & $\begin{array}{l}60 " \text { deep x 60" } \\
\text { wide (Yes/No) } \\
48 " \text { deep x 60" } \\
\text { wide (Yes/No) }\end{array}$ & $\begin{array}{l}48 " \text { deep x } \\
60 " \text { wide }\end{array}$ & $\begin{array}{l}60 " \text { deep x } \\
60 \text { " wide }\end{array}$ \\
\hline \multirow[t]{6}{*}{$\begin{array}{l}\text { Pedestrian } \\
\text { Signal }\end{array}$} & \multirow[t]{6}{*}{$\begin{array}{l}\text { Pedestrian } \\
\text { Signal }\end{array}$} & $\begin{array}{l}\text { Is there a } \\
\text { push-button? }\end{array}$ & Yes/No & & \\
\hline & & Push-button & $\begin{array}{l}\text { 2" dia. raised } \\
\text { (Yes/No) }\end{array}$ & & 2" dia. raised \\
\hline & & $\begin{array}{l}\text { Accessible } \\
\text { Features }\end{array}$ & $\begin{array}{l}\text { Audible } \\
\text { Tactile } \\
\text { Other } \\
\text { None }\end{array}$ & & \\
\hline & & $\begin{array}{l}\text { Height of } \\
\text { Button }\end{array}$ & $\begin{array}{l}\leq 42 " \text { AWS } \\
>42^{\prime \prime} \leq 48 " \\
\text { AWS } \\
>48^{\prime \prime} \text { AWS }\end{array}$ & $\leq 48 "$ AWS & $\leq 42 " \mathrm{AWS}$ \\
\hline & & $\begin{array}{l}\text { Level Clear } \\
\text { Space }\end{array}$ & $\begin{array}{l}\geq 30 " x 48 " \\
\text { (Yes/No) }\end{array}$ & $\geq 30 " x 48 "$ & $\geq 30 " x 48 "$ \\
\hline & & $\begin{array}{l}\text { Number of } \\
\text { Lanes to } \\
\text { Cross }\end{array}$ & $\begin{array}{l}1,2,3,4,5,6 \\
7,8,9,10\end{array}$ & & \\
\hline
\end{tabular}




\begin{tabular}{|c|c|c|c|}
\hline & & $\begin{array}{l}\text { Total Time to } \\
\text { Cross }\end{array}$ & Seconds \\
\hline & & $\begin{array}{l}\text { Measured on } \\
\text { "Date" at } \\
\text { "Time" }\end{array}$ & $\begin{array}{l}\text { Date-Time } \\
\text { Stamp }\end{array}$ \\
\hline Material & Material & & $\begin{array}{l}\text { Concrete } \\
\text { Asphalt } \\
\text { Brick/Paver } \\
\text { Other }\end{array}$ \\
\hline Condition & Condition & & $\begin{array}{l}\text { Good } \\
\text { Cracks } \\
\text { Faded } \\
\text { Other }\end{array}$ \\
\hline
\end{tabular}

Figure 1 depicts the main elements for the design of the SAPFIM application. The development of SAPFIM starts with the planning the software application that sets the vision for the next steps and the expected outcome. As part of this effort, the SAPFIM Criteria was developed to outline the data that will be collected in the field and measured using ADA and PROWAG standards. The criteria will also be used for the development of the SAPFIM database. Once, the previous steps are completed, the web design will start. The web application will consist of four (4) sections that will be used for the data collection, reporting, and management of the pedestrian facilities. Those sections include:

1. Data Collection

2. Reports

3. Data Management

4. Maps

In the Data Collection section, users will input sidewalks, ramps, and street crossing data. Data will be collected using devices that have GPS, camera, and wireless capabilities and will be uploaded directly into the SAPFIM web server.

Under reports, users will be able to generate and print reports such as a full report for each of the three pedestrian facilities categories: sidewalks, ramps, and street crossings. In addition, a report that measures the compliance of pedestrian facilities with ADA and PROWAAG will be included in the software application.

In the data management section, users will be able to generate queries based on the data available in the database. Data can be exported in CSV format for use in other applications; pictures will be exported in JPG format. 
The Maps section will allow users to view and print the collected pedestrian facilities using Google Map. Users will also be able to navigate on the map to get information by clicking on the appropriate icons that represent the sidewalks, ramps, and street crossings data collected.

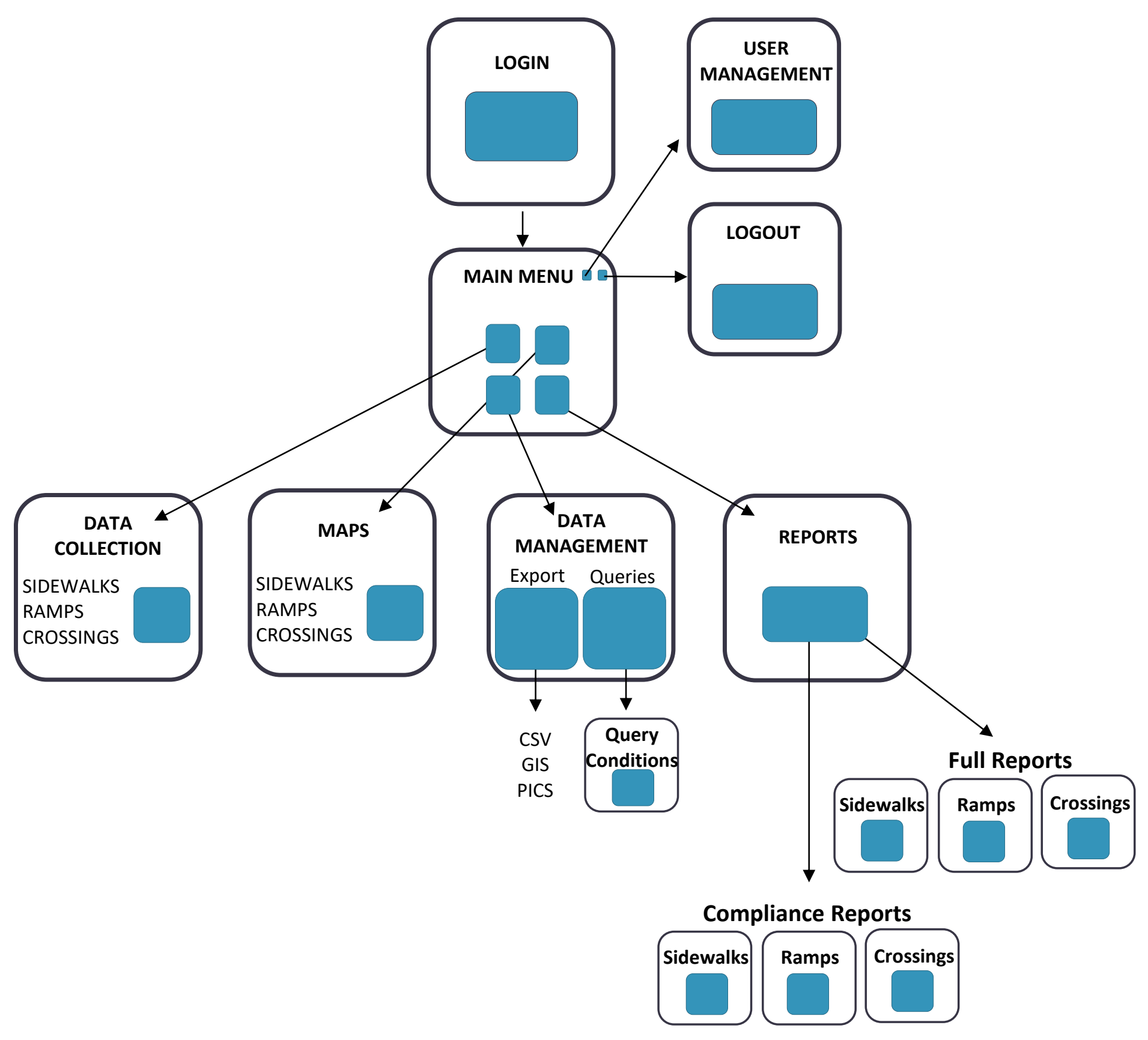

Figure 1: Design of SAPFIM Web Application 


\section{DATA FLOW OF SAPFIM}

This section describes the SAPFIM process and data flow. Users can access SAPFIM through a web browser using a computer, tablet, smartphone, or laptop. In the field, users can collect new data, modify, or view a particular pedestrian data point from the database. Once a record is retrieved, it can be edited. After the sidewalk information has been updated, a user can save it to the database.

Figure 2 shows the process and data flow functions of SAPFIM. It depicts how users using various devices or computers can upload data or retrieve information through the internet by accessing the database by means of the SAPFIM user interface hosted in the web server.

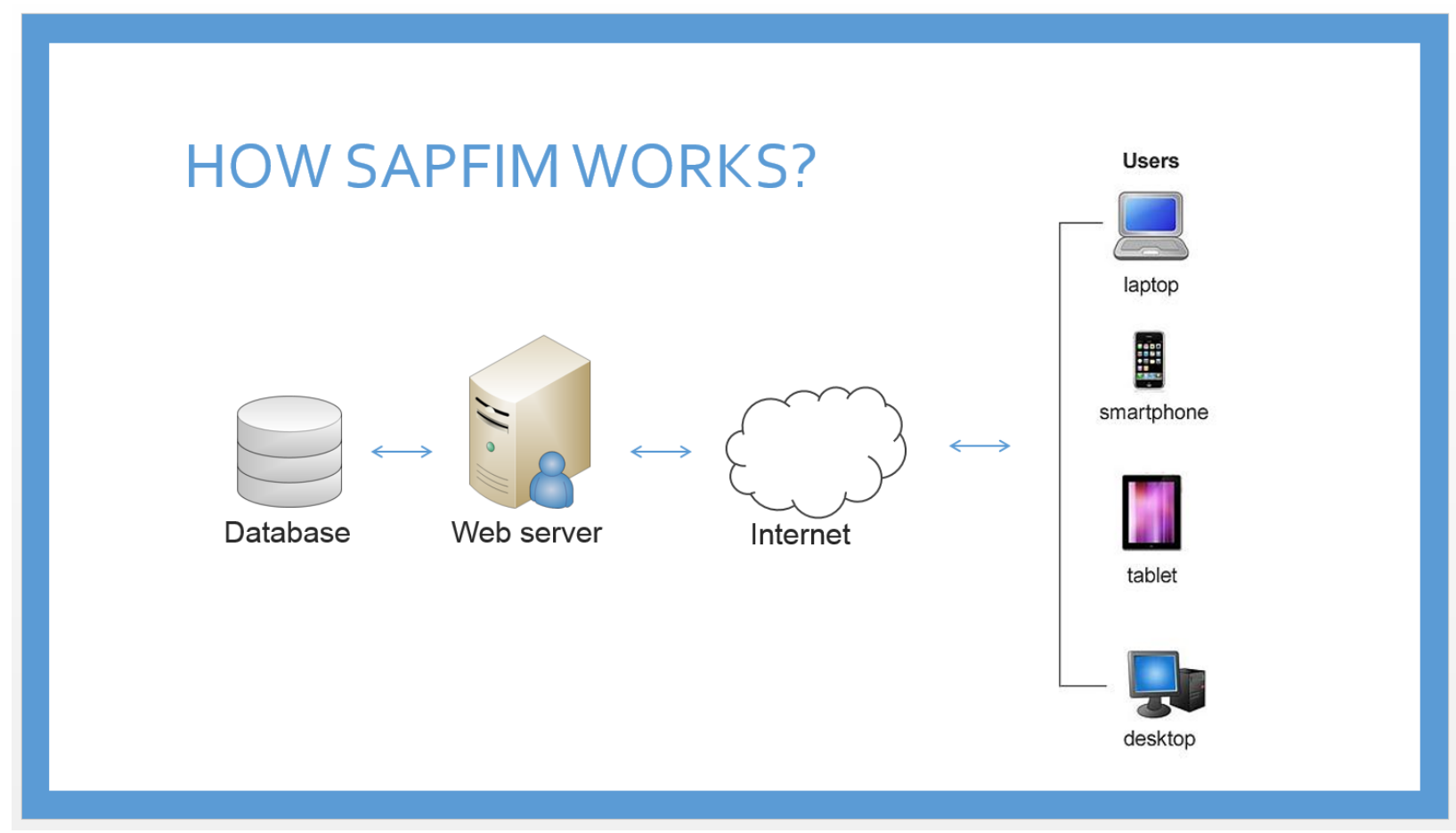

Figure 2: SAFIM Data Flow Diagram 


\section{PEDESTRIAN FACILITIES}

People's abilities vary in agility, balance, cognition, coordination, endurance, flexibility, hearing, problem solving, strength, vision, and walking speed. The design of sidewalk environments is important to all pedestrians, but is particularly important to those with disabilities who have limited travel options and depend on the pedestrian environment.

Barriers restrict the movement of persons to easily navigate within the pedestrian environment. In addition, lack of information makes it difficult for pedestrians to maneuver in this environment. The barriers within a pedestrian environment include curbs, steep slopes, obstacles, and limitations in the design of sidewalks such as widths being too narrow to walk; information barriers include complex intersections, detours, and general lack of street crossing information.

Assistive technologies enhance the ability of people with disabilities to move freely within the pedestrian environment. Technology can be used to reduce limitations that may exist in the sidewalk environment and include features such as accessible pedestrian signals and engineering treatments like curb ramps, detectable warnings, or push buttons at traffic signals to assist with intersection crossing.

Good sidewalk design should consider the following attributes: accessibility for all users, including those with disabilities; safety, so users don't feel threatened by the adjacent traffic or the pedestrian environment; adequate sidewalk design with landscaping that creates a buffer space between pedestrians and traffic and also provides shade; and a social public space to allow people interaction.

In downtown areas, sidewalks need to be designed to accommodate a larger number of pedestrian traffic than in other surrounding areas. Inclusion of streetscapes in downtowns can serve multiple purposes that need to consider the following zones: the building frontage zone, the pedestrian zone, the planter and furniture zone, and the curb zone. The building frontage zone is the area between the building and the pedestrian zone. The pedestrian zone is the area that is specifically reserved for the pedestrian walking activity. The planter and furniture zone is between the curb and the pedestrian travel zone and provides a buffer from the street traffic and allows for the consolidation of elements like utilities poles, hydrants, telephone kiosks, etc. as well as street furniture such as benches, shelters, signs. Lastly, the curb zone is the six inches of the sidewalk corridor that is adjacent to the roadway and that also discourages motor vehicles from entering/exiting the sidewalk area.

In reference to sidewalk grades and cross slopes, steep grades and cross slopes should be avoided whenever possible as they can present a problem for wheelchairs and pedestrians with disabilities. There are many factors that play a role on the usability of sidewalks such as the materials used for the surface that also have an impact on firmness, stability, and slip resistance; changes in direction 
and elevation, and dimensions of gaps, grates, and openings. Further, obstacles that protrude into the sidewalk corridor and that are difficult to detect can be problematic for blind pedestrians. Therefore, designers need to keep in mind that as they change the grade of driveway crossings to allow cars to effectively negotiate the grade change between the street and the sidewalk, they must also follow good pedestrian design practices and not compromise the accessibility and safety of sidewalk environments.

Curb ramps can help eliminate the vertical edge of the curb and, with detectable warnings, they can mark the boundary between the sidewalk and street. This can be useful for pedestrians with vision impairments and pedestrians who use walking aids such as canes, walkers, or crutches. Wider crosswalks can also enhance the use of curb ramps for all users.

To assist with safe street crossing, audible tones and speech messages at traffic signals can provide WALK, DON'T WALK information to pedestrians. Infrared or Light Emitting Diodes (LED) transmitters can send speech messages in multiple formats to personal receivers including information on the location, direction of travel, and the name of the street to be crossed. In addition, the physical design, placement, and location of the pedestrian signal devices need to be taken into consideration so that the signal device is accessible to pedestrians with vision and mobility impairments (FHWA, 2001).

Designing an effective pedestrian crossing involves the correct layout of pedestrian elements including: information (signs, accessible pedestrian/traffic signals, markings), turning radius, visible crosswalks (including raised crosswalks), adequate crossing times, medians, refuge islands, corner islands, curb ramps with detectable warnings, and curb extensions. It also involves careful consideration of adequate sight lines, traffic patterns, and traffic signal phasing. Other techniques such as restrictions on right turns, pedestrian lead times, and traffic calming measures will benefit all pedestrians. Regulations that prohibit parking at the corner can also improve blocked sight lines (ITE, 2010).

As example of the different elements that can be collected in Pedestrian Transition Plans, Table 4 presents the GPS-based data collected by the Ada County Highway District (ACHD) in 2005.

Table 4: Data Inventory

\begin{tabular}{|l|l|}
\hline Feature & Characteristics \\
\hline Sidewalks & $\begin{array}{l}\text { Location, width, cross-slope, material, surface condition, presence of } \\
\text { heaving/cracking, type and number of fixed obstacles within sidewalk, type and } \\
\text { number of movable obstacles located on sidewalk, presence of vertical } \\
\text { obstructions, type of street lighting, type and number of driveway crossings, } \\
\text { presence and type of buffer between street and sidewalk, presence and type of } \\
\text { foliage (trees, shrubs, grasses, etc.), type of street curb }\end{array}$ \\
\hline Missing & Location, type and number of fixed obstacles in immediate area of future \\
\hline
\end{tabular}




\begin{tabular}{|l|l|}
\hline Sidewalks & sidewalk, type of street curb \\
\hline Curb Ramps & $\begin{array}{l}\text { Location, type, surface condition, material, top landing width and slope, number } \\
\text { of ramps at corner, ramp width, ramp slope, ramp cross-slope, slip-resistant } \\
\text { surface, sidewalk approach, ramp flare slope, gutter slope, crosswalk connection } \\
\text { and alignment, bottom landing width and slope }\end{array}$ \\
\hline $\begin{array}{l}\text { Missing } \\
\text { Curb Ramps }\end{array}$ & $\begin{array}{l}\text { Location, sidewalk surface condition, material, type and number of fixed } \\
\text { obstacles in immediate area of future curb ramp, location of nearby street drain }\end{array}$ \\
\hline
\end{tabular}

When dealing with pedestrian facilities, maintenance can be defined as inspecting, preserving, repairing, restoring, and keeping the facility in condition for safe, convenient, and accessible use. Maintenance includes repairing surface defects and changes in level as well as snow/ice, debris, and vegetation removal, Goldman (1968).

Many jurisdictions have laws or ordinances addressing pedestrian facility maintenance, which often require the adjacent property owner to repair deteriorated sidewalks adjacent to their property. More often ordinances require property owners to remove snow and ice and vegetation encroaching onto sidewalks. However, property owner requirements and enforcement of these regulations may vary widely from jurisdiction to jurisdiction. This is due to a variety of factors including different management structures for maintaining agencies, different legislative requirements, and different climates that require varied approaches to maintenance.

Sidewalks and shared use paths are the main types of pedestrian facilities that accommodate pedestrians. However, maintenance of shared use paths can be complicated, because the agencies that are responsible for them do not always make it a habit of monitoring them to make sure they are in safe and travelable condition.

Access and mobility are inextricably linked. It is difficult to have mobility for a significant segment of the population without providing overall access to pedestrian facilities. Accessible designs are significantly undermined if maintenance is neglected and pedestrian facilities are allowed to degrade to a state where they cannot be used or are avoided by pedestrians. There are generally two accessibility issues related to maintenance and both require maintaining an accessible path. First, proper and routine maintenance of walkways allow access between intersections. Secondly, the maintenance of transition points (curb ramps, medians, crosswalks, etc.) ensures access at intersections.

The American Association of Highway and Transportation Officials (AASHTO) defines asset management as a strategic and systematic process of operating, maintaining, upgrading, and expanding physical assets effectively throughout their lifecycle. Asset management strategies can help improve the decision-making based on quality of information and defined objectives. 
Maintenance issues that commonly occur for pedestrian facilities can be sorted into two broad groups: those that are directly related to the pedestrian facility infrastructure itself, such as sidewalk surfacing deficiencies; and those that relate to seasonal or day-to-day maintenance which require keeping the facility clean and free of nuisance materials. This involves removal of vegetation, snow, ice, sand, and other materials. An effective pedestrian facility maintenance program needs to address both sets of issues. Infrastructure problems can be broadly categorized into two groups for sidewalks and paths: surfacing problems and structural problems. Both sets of problems cause maintenance issues. Most structural deficits will ultimately affect surface conditions.

The surface material used for these facilities can also have a significant effect on how and how often maintenance is performed. Of the hard surfaces, concrete is the most common surfacing type for sidewalks while asphalt is commonly used for shared use paths. Furthermore, asphalt pavement is often used as a temporary pavement for patching concrete sidewalks. Bricks and pavers are used to preserve a traditional material and appearance in a downtown or historic district. In some settings pavers are used to border concrete sidewalks. Although these materials tend to be very durable, they do have some unique maintenance issues. Surfaces can also be soft and composed of loose stone, compacted stone dust, or wood chips. Stone surfacing, especially crushed stone is sometimes used for paths and sidewalks. It is more likely that stone or gravel will be used for sidewalks as a temporary fix before a more permanent surface material ultimately replaces it.

Minor surface defects may only affect appearance, but moderate to severe conditions will ultimately become a safety hazard and may significantly affect the usable life of the sidewalk. The most common maintenance problems with hard surface materials result from structural conditions such as those caused by cracking, heaving, tilting, gaps (often at concrete joints), and sidewalk and path sections that either are depressed or raised.

Most of the same maintenance issues impacting sidewalks also impact curb ramps. The most frequent maintenance problem with crosswalk markings is durability. Another durability-related maintenance problem is the conspicuity of pavement markings.

The conditions of sidewalks for safe, comfortable, and accessible travel are influenced not only by infrastructure problems, but also by seasonal events such as snowfall, the accumulation of leaf debris, and the overgrowth of vegetation. Maintenance activities to remove obstacles to safe walking are needed to keep sidewalks accessible and hazard-free year-round.

Following a snowfall, snow and ice must be cleared from sidewalks, paths, curb ramps, and crosswalks to provide safe and accessible passage for pedestrians. Most of the problems caused by extreme heat manifest themselves as serious structural problems. Another problem in hot climates is associated with markings. Markings on newly paved streets can be degraded with vehicles tracking over them. 
Street trees and other plants adjacent to the sidewalk are a beneficial amenity for a variety of reasons including provision of shade, carbon dioxide reduction, increased property value, storm water control, and visual interest. However, vegetative growth encroaching upon sidewalks or paths is a serious condition that requires maintenance. Sightlines to driveways and intersections must also be maintained for pedestrian safety.

There are many safety issues that are directly attributable to poorly maintained pedestrian facilities. Improved safety through proper maintenance can be considered in two ways: reduction of crashes with motorists; and the reduction in trips, slips, and falls.

Sidewalk and path inspection criteria serve many useful purposes, especially to reduce slips and falls based on avoidable sidewalk and path hazards. Damaged surfaces and defects can make pedestrian facilities difficult or impossible to use for everyone and also limit the accessibility of people with disabilities or mobility impairments. The inspection criteria should include guidelines to agency employees, conveying information to residents, and preventing or minimizing lawsuits and liability exposure.

The 2010 ADA Standards (United States Access Board, 2010) are the measure of accessibility for buildings and sites and can be enforced at the Federal level. Some agencies will use these standards for the public right of way to the extent they seem to fit, because the Public Rights of Way Accessibility Guidelines (PROWAG) is not yet a Federal standard. While this may work in limited circumstances, the 2010 ADA standards do not address the situations commonly found in the public right-of-way such as steep terrain and the constraints of being located next to roadway. They also do not address additional features such as pedestrian signals, crosswalks, refuge islands, on street parking, and the need for detectable warnings at street crossings. The Access Board also establishes the guidelines for buildings and sites, so there is consistency where it is reasonable to use the same criteria.

In the Proposed Accessibility Guidelines for Pedestrian Facilities in the Public Right-of-Way (United States Access Board, 2011), the Architectural and Transportation Barriers Compliance Board proposes accessibility guidelines for the design, construction, and alteration of pedestrian facilities in the public right-of-way. The purpose of these guidelines is to ensure that sidewalks, pedestrian street crossings, pedestrian signals, and other facilities for pedestrian circulation and use constructed or altered in the public right-of-way by state and local governments are readily accessible to and usable by pedestrians with disabilities. The guidelines cover pedestrian features in public right-of-ways, including sidewalks and other pedestrian ways, street crossings, medians and traffic islands, overpasses, underpasses and bridges. It applies to permanent as well as temporary facilities provides provisions to address Pedestrian Access Routes including Sidewalks, Curb Ramps/Blended Transitions, and Street Crossings.

The Access Board's proposed guidelines address access to newly constructed and altered public streets and sidewalks covered by the American with Disabilities Act (ADA) and the Architectural 
Barriers Act (ABA) or the Rehabilitation Act. The guidelines also refer to requirements in the Federal Highway Administration's Manual on Uniform Traffic Control Devices (MUTCD) for Streets and Highways to ensure consistency and to avoid redundancy. Specifically, the guidelines invoke MUTCD definitions and technical criteria for temporary alternate pedestrian routes and pedestrian signals and push buttons. Many of these provisions are designed to ensure that the public rights-of-ways contain a continuous accessible route that accommodates all pedestrians, including those who need mobility aids. These requirements are also expected benefit many other users.

Communities should develop and adopt inspection and maintenance criteria in order to keep the sidewalk facilities in good conditions. The inspections should consider cracks, changes in grade, cross-slopes, vertical clearances, maximum running grades, minimum clear width, and the distance protruding objects extend into the pedestrian path.

Generally, there are two broad accessibility categories related to maintenance and both require maintaining an accessible path. First, proper and routine maintenance of walkways allow access between intersections while the maintenance of intersections (curb ramps, medians, crosswalks, etc.) ensures access at street crossings. Communities will need to balance their needs with the available funding for maintaining pedestrian facilities. A data collection and assessment plan can assist with the prioritization of activities and the decision to either repair or replace the sidewalk facilities. The plan should establish procedures for the public to understand and follow. This should cover how a community repairs facilities, pays for them, informs affected residents, does inspections, establishes projects annually, and schedules repairs.

Routine maintenance consists of day-to-day activities that are scheduled by maintenance personnel to maintain and preserve the condition of facilities at a satisfactory level of service. Corrective maintenance is described as activities that are performed in response to the development of a deficiency or deficiencies that negatively impact the safe, efficient operations of the facility, and future integrity of the pavement section.

Corrective maintenance activities are generally reactive, not proactive, and performed to restore a pavement to an acceptable level of service due to unforeseen conditions. Preventive maintenance consists of treatments to extend the functional condition of a facility. It is typically applied to pavements in good condition having significant remaining service life and is commonly done by applying treatments to the surface or near surface of structurally sound pavements.

Preventive measures fall into the short and long-term maintenance categories above with the best examples including: mud jacking, joint sealing, grinding, and horizontal cutting for sidewalks; and chip sealing and slurry for asphalt sidewalks and paths.

When a tripping hazard or obstacle is reported, an agency makes note of the hazard and responds quickly. Multiple falls or complaints about the same area require a city to place a particular sidewalk or street higher on the schedule for repair or replacement. The first step is to inspect the 
problem location to determine if there is a hazard as determined by the community's inspection criteria. A follow-up repair is either made on the spot, if the crew that has been sent to the location verifies the hazard and a repair can be made, or if the repair should be scheduled. A program associated with a quick response is a spot improvement program intended to respond to problems such as tripping hazards. These problems will be addressed through patching, wedging, crack filling, or even sidewalk replacement. With this program in place, tripping hazards can be responded to in the quickest possible fashion.

To address sidewalk issues in a manageable and predicable fashion, communities should sponsor sidewalk replacement programs that rotate or cycle through a community on a zone-by-zone basis. By concentrating sidewalk replacement into zones, less expensive construction bids for replacement work can typically be negotiated. Alternatively, smaller communities may be able to manage community-wide inspection and replacement programs on an annual basis without a need to split the community into zones.

All requests for sidewalk work or reported hazards should go to the same department and preferably the same person. Every community employee who observes a potential sidewalk or path problem condition should be directed to report it. It is always good policy to document reported problems and how they were resolved. If, after a complaint is received, inspection reveals that a condition does not meet the community's criteria for repair or correction, appropriate documentation should note that.

Communities that fully fund repairs have the advantage of being able to move quickly with those repairs. This is also a more equitable way to fund repairs that does not rely simply on the residents that live adjacent to older sidewalks in need of repair. Some communities are not aware of what pedestrian facilities it owns. Without knowing that, it is difficult to accept ownership for repairs. Every community should have an updated inventory of pedestrian facilities noting the general condition of each facility.

Cities should adopt and follow their own plans and policies, and ordinances for sidewalk inspection and repair. In any case, communities should define what conditions are defective and establish an approach for repair including how the repairs are going to be made and on what type of schedule. There may be times and reasons that a community cannot follow its own policy. At that point, a community should explain and support why it is not following its own established plan or policy along with how they are going to mitigate the impacts.

Initial design and construction methods greatly influence the long-term maintenance and lifespan of sidewalks. Historically concrete has been the material of choice by many jurisdictions because of its ease of installation, durability, reliability and availability of materials. The thickness of the sidewalk material, use of reinforcing bars, mesh use of aggregate base, depth of sub-base below the sidewalk, distance from trees, and other design details impact how well a sidewalk will age over time. If best practices are followed, the expected sidewalk materials service life can be as 
long as: eighty years for concrete, bricks, and interlocking concrete pavers; and forty years for asphalt.

Providing an adequate subgrade below sidewalks may deter many of failures by providing stability and good drainage, helping the sidewalk to be more resistant to seasonal changes. It is important to ensure that sidewalks are constructed with enough thickness to support expected vehicle loading. In some cases reinforcement (usually with a welded wire mesh or rebar) can be used to increase the loading capacity of sidewalks.

Proper sidewalk drainage is important for maintenance purposes and to provide a safe and comfortable experience for users. It is important to provide a slight cross slope on sidewalks to ensure proper drainage and prevent pooling of water, especially in climates where ice can form.

Control and expansion joints should be provided in all concrete sidewalks and paths to minimize cracking and guide where cracking should occur. Asphalt sidewalks typically do not need joints or scoring patterns.

Curb ramps and detectable warning surfaces present unique maintenance needs. The primary issues with detectable warning fields are debris collection, detachment from the sidewalk, or damage to the domes.

Proper site conditions, including soils, tree selection and location are all essential to ensure that the trees thrive in their location and do not interfere with nearby utilities, sidewalks or streets.

A variety of sources are available to fund pedestrian facility inspection and maintenance programs. In general, funding strategies can be split into two categories: programs that are funded by abutting property owners; and programs funded by community taxes, funds, and fees.

Many communities treat pedestrian facilities as a community-wide asset, and fund their repair and maintenance directly. Sidewalk repair and replacement is commonly paid for through the general fund, which is typically funded by property and sales tax revenues. Many communities have downtown or other business district areas that have assumed responsibility of sidewalk maintenance. These special districts may fund sidewalk maintenance through their general funds or may assess local property owners for general sidewalk maintenance as well as necessary repairs and replacements. Means of financing for homeowners association activities is similar to improvement districts or business improvement districts typically through some form of assessment based on valuation.

Assessment programs assess abutting property owners for the costs of maintaining or replacing pedestrian facilities. Property owners may be held responsible for the full cost of the maintenance or the jurisdiction may pay part of cost. If a community does not have a history of assessing property owners for pedestrian facility maintenance, it can be very difficult politically to begin an 
assessment program. An assessment program requires that the municipality have a system in place to assess property owners for the costs of maintaining abutting pedestrian facilities. In some communities, property owners are directly responsible for maintaining sidewalks, and city ordinances mandate that they schedule and pay for repairs on their own.

A review of pedestrian and bicycle infrastructure inventories carried out in various cities and states are summarized in Table 5 and Table 6.

Table 5: Example of State DOT Pedestrian Inventories

\begin{tabular}{|l|l|l|l|}
\hline Inventory & $\begin{array}{l}\text { Year } \\
\text { collected }\end{array}$ & Data recorded & $\begin{array}{l}\text { Size of } \\
\text { system }\end{array}$ \\
\hline Washington & $2002-2003$ & $\begin{array}{l}\text { Bike lanes, shoulders, shared-used pathways beside } \\
\text { the roadway, sidewalks, walking paths (not worn dirt } \\
\text { paths), signalized and un-signalized intersections, } \\
\text { roadway medians, marked crosswalks, transit stops, } \\
\text { and ADA facilities }\end{array}$ & $\begin{array}{l}7000 \\
\text { miles }\end{array}$ \\
\hline New Jersey & $2006-2007$ & $\begin{array}{l}\text { Paths (sidewalks, shared use paths, and worn paths), } \\
\text { bicycle lanes and routes, shoulders, crosswalks, curb } \\
\text { ramps, pedestrian/bicycle related signage, pedestrian } \\
\text { provisions at intersections (e.g. push-buttons and } \\
\text { pedestrian signal heads) }\end{array}$ & $\begin{array}{l}13200 \\
\text { miles }\end{array}$ \\
\hline Maryland & $2008-2009$ & $\begin{array}{l}\text { ADA Compliance of sidewalks, bus stops, curb } \\
\text { ramps, driveway crossings, and median treatments }\end{array}$ & $\begin{array}{l}874 \\
\text { sidewalk } \\
\text { miles }\end{array}$ \\
\hline
\end{tabular}

Table 6: Example of Local Jurisdiction Pedestrian Inventories

\begin{tabular}{|l|l|l|l|}
\hline City & $\begin{array}{l}\text { Year } \\
\text { collected }\end{array}$ & Data recorded & $\begin{array}{l}\text { Size } \\
\text { system }\end{array}$ \\
\hline $\begin{array}{l}\text { Rancho } \\
\text { Cucamonga, } \\
\text { CA }\end{array}$ & 2011 & $\begin{array}{l}\text { Street name and from/to limits, sidewalk presence, } \\
\text { street light presence, MicroPAVER section ID, } \\
\text { calculated length, estimated width, estimated } \\
\text { surface area, location type (e.g. hospital, library, } \\
\text { school) location proximity-500', 1000', and 1500' } \\
\text { buffers created around key locations, reasons for } \\
\text { missing sidewalk installation priority ranking }\end{array}$ & \\
\hline $\begin{array}{l}\text { Berkeley, } \\
\text { CA }\end{array}$ & 2009 & $\begin{array}{l}\text { Sidewalk presence, sidewalk width, buffer width, } \\
\text { sidewalk condition, marked crosswalk presence, } \\
\text { crosswalk color, crosswalk condition, crosswalk } \\
\text { marking type, crosswalk width, curb ramp }\end{array}$ & miles \\
\hline
\end{tabular}




\begin{tabular}{|c|c|c|c|}
\hline & & $\begin{array}{l}\text { presence, curb ramp type, curb ramp direction, } \\
\text { truncated dome presence, separated pathways, } \\
\text { pedestrian signal features }\end{array}$ & \\
\hline $\begin{array}{l}\text { Sacramento } \\
\text { County, CA }\end{array}$ & 2007 & $\begin{array}{l}\text { Sidewalk presence, intersection and street corner } \\
\text { measurements and details, mid-block crossings, } \\
\text { bike lane presence, parking type, posted speed } \\
\text { limit, sidewalk conditions, traffic direction (if one- } \\
\text { way), tree spacing in buffer, width of buffer, width } \\
\text { of sidewalk, width of pavement }\end{array}$ & $\begin{array}{l}2200 \\
\text { street/road } \\
\text { miles }\end{array}$ \\
\hline $\begin{array}{l}\text { Oakland, } \\
\text { CA }\end{array}$ & 2007 & $\begin{array}{l}\text { Sidewalk damage (type and degree), trees and tree } \\
\text { wells, land use, ADA barriers, parking restrictions } \\
\text { (curb markings), curb/gutter damage, signs, bus } \\
\text { stops }\end{array}$ & Unknown \\
\hline Marina, CA & 2003 & $\begin{array}{l}\text { Pedestrian and bicycle facility deficiencies } \\
\text { reported }\end{array}$ & Unknown \\
\hline $\begin{array}{l}\text { Rockville, } \\
\text { MD }\end{array}$ & 2009 & $\begin{array}{l}\text { Curb ramp characteristics, sidewalk locations near } \\
\text { crossings, sidewalk width, sidewalk condition } \\
\text { within crossing area, crosswalk characteristics, } \\
\text { pedestrian signals, signal push buttons, pedestrian } \\
\text { signal timing, pedestrian signing, sight distances, } \\
\text { crossing lighting }\end{array}$ & $\begin{array}{l}162 \\
\text { pedestrian } \\
\text { crossings } \\
\text { analyzed }\end{array}$ \\
\hline $\begin{array}{l}\text { Alexandria, } \\
\text { VA }\end{array}$ & 2009 & $\begin{array}{l}\text { Sidewalk typical width/typical clear width, } \\
\text { sidewalk clear width obstructions, buffer width, } \\
\text { sidewalk surface type, sidewalk surface condition, } \\
\text { driveway crossings, curb ramps (and ADA } \\
\text { compliance), curb radius, type of buffer, on-street } \\
\text { parking type, bicycle rack locations, bus stop } \\
\text { accessibility, bus stop characteristics, roadway } \\
\text { crosswalk type, roadway crosswalk condition, } \\
\text { roadway crossing length, roadway crossing traffic } \\
\text { control type, push buttons, presence of other } \\
\text { crossing facilities }\end{array}$ & 100 miles \\
\hline $\begin{array}{l}\text { Piedmont } \\
\text { Triad Rural } \\
\text { Counties, } \\
\text { NC }\end{array}$ & 2007 & $\begin{array}{l}\text { Sidewalk condition, sidewalk width, sidewalk } \\
\text { obstructions, curb ramp ADA compliance, } \\
\text { sidewalk material, }\end{array}$ & Unknown \\
\hline Tucson, AZ & 2005 & $\begin{array}{l}\text { Sidewalk category (Accessible, partially } \\
\text { accessible, partial sidewalk, shared-use path, no } \\
\text { sidewalk), roadway functional class, segment }\end{array}$ & $\begin{array}{l}4000 \\
\text { directional } \\
\text { miles }\end{array}$ \\
\hline
\end{tabular}




\begin{tabular}{|l|l|l|l|}
\hline & & priority ranking (based on variety of factors) & \\
\hline $\begin{array}{l}\text { Asheville, } \\
\text { NC }\end{array}$ & 2005 & Sidewalk presence, curb ramp ADA compliance & Unknown \\
\hline $\begin{array}{l}\text { Portland, } \\
\text { OR }\end{array}$ & 1998 & Presence of sidewalks, presence of curb ramps & Unknown \\
\hline $\begin{array}{l}\text { Lexington, } \\
\text { MA }\end{array}$ & & $\begin{array}{l}\text { Sidewalk presence, materials, conditions, major } \\
\text { obstructions }\end{array}$ & Unknown \\
\hline
\end{tabular}

All inventories reviewed have included sidewalk presence as a feature, as it can be determined reliably using aerial photography. Sidewalks are important facilities for providing pedestrian accessibility. Walking on sidewalks is generally much safer for pedestrians than walking along roadways without sidewalks. Additionally, roadway segments with sidewalks along both sides of the road experience lower rates of pedestrian crashes than segments with sidewalks along only one side.

Adequate width is required for ADA compliance. Width is also important in determining whether there is sufficient sidewalk space for the pedestrian volumes present. Wider sidewalks provide more lateral separation between pedestrians and moving vehicle traffic.

Sidewalks in poor condition can lead to impassability for pedestrians with disabilities and can pose a trip hazard for all pedestrians. Sidewalks can be ranked on a scale based on condition, but this would require a field inventory.

Utility boxes, bicycle racks, and overgrown greenery are examples of objects that may block the pedestrian right-of-way. Sidewalk obstructions can be problematic for pedestrians both in terms of inhibiting the path of travel and obscuring pedestrians from drivers' fields of view. Detecting these barriers can likely be completed with Google Street View or reviewing video imagery, or may require a field inventory.

Greater buffer space between moving motor vehicle traffic and the sidewalk or other pedestrian area increases the comfort that pedestrians experience while walking along the roadway. Buffers are typically measured from either the outside edge of the outside travel lane or the face of curb to the inside edge of the sidewalk. This measurement can usually be made through review of aerial imagery. Buffers between moving vehicle traffic and the sidewalk may include grass strips, bushes, street trees, street furniture, and parked cars. The type of buffer is important because larger objects (such as parked cars) make pedestrians feel safer with respect to adjacent traffic.

Providing accessible, affordable, reliable, and safe transportation is such an enormous challenge that some states and counties have been thinking systemically, trying to coordinate all the disparate 
transportation services and funding streams to create more efficient, cost-effective, and universally accessible transit systems. Realizing that lack of coordination is largely due to the fact that sixty two different federal programs fund transportation, not to mention the proportion of state and local taxes earmarked for transportation, several Federal agencies, including the FTA and the Departments of Health and Human Services, Labor, and Education, have launched a national fiveyear initiative to break down the barriers within human service transportation programs and encourage local partnerships to improve transportation services. One of the components of this initiative is the Framework for Action: Building a Fully Coordinated Transportation System, a comprehensive evaluation and planning tool to help state and community leaders, and agencies involved in human service transportation and transit service, along with their stakeholders, improve or start coordinated transportation systems.

The State of Florida has been working since 1979 to expand transportation services through the Florida Coordinated Community Transportation Program. Broward County, Florida, Transportation Options (TOPS) is an example of coordination at the local level under the leadership of the Florida CTD.

The JAUNT, Inc. Regional Public Transit Agency of Central Virginia was formed in 1975 to meet the transportation needs of area human service agencies. Today, JAUNT serves as a rural service provider, a leader in commuter transportation, a coordinated human service agency transporter, and an urban paratransit provider. JAUNT provides services to the citizens of Albermarle, Fluvanna, Louisa, and Nelson Counties and the City of Charlottesville with a fleet of more than 70 vehicles.

The Sweetwater County, Wyoming public transportation's transit authority (STAR) was created in 1989 and replaced a number of health and human services agency-based transportation services to form a coordinated public transportation system. STAR provides transportation to the general public and to agencies on a contractual basis, and serves the sparsely populated 10,400 square mile area of Sweetwater County in southwest Wyoming.

In a successful effort led by disability advocates, the faith community, and other CBOs, residents of six cities in Kent County, Michigan, passed a millage increase to fund expanded transportation services that benefit many segments of the population.

Inspired by a California inventor, Charlotte, North Carolina, is pilot-testing an innovative program with portable devices that use GPS satellite technology to empower people with visual impairments to better navigate the city's public transportation system.

According to the news (Boatman, 2015), the city of Los Angeles has reached a tentative agreement with disability advocates to spend $\$ 1.4$ billion to fix crumbling sidewalks that do not provide people who use wheelchairs with the adequate public access required by the ADA. 
Communities Actively Living Independent and Free (CALIF) filed the lawsuit in August 2010 advocates. The plaintiffs alleged that Los Angeles discriminated against disabled residents by not fixing damaged sidewalks; not repairing sidewalks with curb cuts that were too steep for wheelchairs; not removing obstructions that blocked sidewalks, such as signs and trees; and not ensuring enough access to public transportation via sidewalks. It is estimated that 40 percent of the sidewalks in Los Angeles are in need of repair.

Damaged sidewalks have been a problem for disabled Los Angeles residents for decades. Many residents of Los Angeles have been involved in accidents related to broken sidewalks. The city has paid over \$6 million in damages related to trip-and-fall lawsuits since 2011.

According to the settlement, the City of Los Angeles has 30 years to repair or replace damaged sidewalks. It is required to spend \$31 million per year to improve sidewalks starting in 2016 and gradually increase it to $\$ 63$ million per year in the future. The settlement also requires the city to pay $\$ 15$ million in attorneys' fees and costs. This settlement is an important victory for disabled residents of Los Angeles. Cities and towns have a responsibility to make sure that their public spaces are accessible to individuals who use wheelchairs in accordance with the Americans with Disabilities Act.

The primary focus of Pedestrian Facilities Guidebook, Washington State DOT (1997), is to encourage good planning, design, and engineering practices related to pedestrian facilities. The guidebook also addresses important construction, ongoing maintenance, and operational aspects related to pedestrian facilities. Following is the summary of this guidebook coming in eleven design toolkits.

Common characteristics of pedestrian collisions are: driver inattention; struck by vehicle while crossing at an intersection (50 percent of all collisions); struck by vehicle while crossing mid-block (33 percent of all collisions); struck from behind while walking along the roadway in the same direction as traffic (particularly in rural areas); motorist exceeding safe speed (contributes to most pedestrian fatalities); darting out into the street at mid- block (most common type of pedestrian collision for children); vehicles backing up (difficult to see children and others walking behind); and collisions in urban areas ( 80 percent of all collisions).

Some important needs of pedestrians are: safe streets and walking areas; convenience; nearby places to walk; visibility; comfort and shelter; attractive and clean environment; access to transit; interesting things to look at while walking; and social interaction. As in Table 7, Washington State Bicycle Transportation and Pedestrian Walkways Plan of 1994, classifies common pedestrian characteristics by age group. 
Table 7: Pedestrian Characteristics by Age Group

\begin{tabular}{|c|c|}
\hline Age & Characteristics \\
\hline $0-4$ & $\begin{array}{l}\text { Learning to walk; requiring constant parental supervision; developing peripheral } \\
\text { vision; depth perception }\end{array}$ \\
\hline $5-12$ & $\begin{array}{l}\text { Increasing independence, but still requiring supervision; poor depth perception; } \\
\text { susceptible to dart out/intersection dash }\end{array}$ \\
\hline 13-18 & Sense of invulnerability; intersection dash \\
\hline $19-40$ & Active; fully aware of traffic environment \\
\hline 41-65 & Slowing of reflexes \\
\hline $65+$ & $\begin{array}{l}\text { Street crossing difficulty; poor vision ; difficulty hearing vehicles approaching from } \\
\text { behind; high fatality rate }\end{array}$ \\
\hline
\end{tabular}

Aids to older pedestrians can be: reduced roadway crossing distances (bulb-outs and curb extensions); easy-to-read signs; refuge areas in roadway crossings; traffic calming; shelter and shade; handrails; smooth surfaces and unobstructed travel ways; and signal timing at lower than average walking speed

Aids to pedestrians with disabilities can be: curb cuts and ramps; tactile warnings; easy-to-reach activation buttons; audible warnings and message systems; raised and braille letters for communication; signal timing at lower than average walking speed; roadway crossing refuges; reduced roadway crossing distances (bulb-outs and curb extensions); traffic calming; handrails; and smooth surfaces and unobstructed travel ways.

Urban areas receive high pedestrian use due to: higher densities of residences, businesses, and other origins and destinations; traffic congestion; high concentrations of origin and destination points; shopping and services are more accessible to pedestrians; average trip distances are shorter; parking is too costly or unavailable; transit service is more readily available; and more available pedestrian facilities.

According to Washington State Bicycle Transportation and Pedestrian Walkways Plan of 1994, common reasons for low levels of pedestrian travel are: poor facilities; lack of sidewalks or walkways; failure to provide a contiguous system of pedestrian facilities; concerns for personal safety; failure to provide facilities to and from popular origins and destinations; inclement weather, poor lighting; and lack of separated facilities. 
Pedestrian facilities are sidewalks; trails; curb ramps; traffic calming and control devices; gradeseparated crossings; wide shoulders and other technologies; design features; and strategies intended to encourage pedestrian travel. State policies can encouraging pedestrian travel through: addressing pedestrian issues using comprehensive planning as required by the ISTEA; considering pedestrian needs in all transportation facilities; reinforcing a sense of neighborhood and community with transportation designs that accommodate pedestrian use; ensuring a connected system of pedestrian routes in urban areas; enhancing pedestrian mobility and safety in rural areas; defining jurisdictional roles in providing pedestrian facilities; encouraging land use and transportation development that accommodates pedestrians; providing pedestrian facilities that complement local business activity and provide access for employees; enhancing intermodal access for persons with impaired mobility; and maintaining the existing transportation system adequately so pedestrian use is maximized. Some common characteristics of pedestrian-friendly communities are listed in Table 8.

Based on Revised Code of Washington (RCW) (1992), sidewalk is a property between the curb lines in the lateral line of a roadway and adjacent property, set aside and intended for the use of pedestrians or such portion of private property parallel and in proximity to public highway and dedicated to use by pedestrians.

\section{Table 8: Characteristics of Pedestrian-Friendly Communities}

\begin{tabular}{|l|l|}
\hline Coordination & $\begin{array}{l}\text { Putting pedestrian facilities in place to meet current and future needs } \\
\text { requires close coordination between jurisdictions and other modes of } \\
\text { transportation. }\end{array}$ \\
\hline $\begin{array}{l}\text { Regional } \\
\text { Connectivity }\end{array}$ & $\begin{array}{l}\text { Pedestrian circulation and access is provided to shopping malls, transit, } \\
\text { downtown, schools, parks, offices, mixed-use developments, and other } \\
\text { community origins and destinations, as well as other communities within } \\
\text { the region. }\end{array}$ \\
\hline Connectivity & $\begin{array}{l}\text { A complete system of interconnected streets, pedestrian walkways, and } \\
\text { other pedestrian facilities will increase pedestrian travel. }\end{array}$ \\
\hline Convenient access & $\begin{array}{l}\text { Connections are provided between popular origins and destinations, } \\
\text { between dead-end streets or cul-de-sacs, or as shortcuts through open } \\
\text { spaces. }\end{array}$ \\
\hline $\begin{array}{l}\text { Continuous } \\
\text { separation }\end{array}$ & $\begin{array}{l}\text { Minimized or eliminated street and driveway crossings are provided and } \\
\text { well defined. Buffers from motor vehicles and separation of uses are } \\
\text { provided }\end{array}$ \\
\hline $\begin{array}{l}\text { Pedestrian } \\
\text { supportive land- } \\
\text { use patterns }\end{array}$ & $\begin{array}{l}\text { Land use patterns, such as a grid layout or short blocks in business } \\
\text { districts and downtowns enhance pedestrian mobility. }\end{array}$ \\
\hline
\end{tabular}




\begin{tabular}{|c|c|}
\hline $\begin{array}{l}\text { Well-functioning } \\
\text { facilities }\end{array}$ & $\begin{array}{l}\text { Adequate width and sight distance, accessible grades, and alignment to } \\
\text { avoid blind corners are provided. Common problems, such as poor } \\
\text { drainage, are avoided. }\end{array}$ \\
\hline Designated space & Pedestrian facilities should be well delineated, signed, and marked. \\
\hline Security & $\begin{array}{l}\text { Design to ensure a secure environment for pedestrians is important. } \\
\text { Lighting, increased visibility, open sight lines, and access to police and } \\
\text { emergency vehicles. }\end{array}$ \\
\hline $\begin{array}{l}\text { Not only } \\
\text { automobile }\end{array}$ & $\begin{array}{l}\text { Streets are designed for all modes of transportation. Parking supply is } \\
\text { reduced or managed using methods that encourage walking. }\end{array}$ \\
\hline $\begin{array}{l}\text { Neighborhood } \\
\text { traffic calming }\end{array}$ & $\begin{array}{l}\text { Narrowed streets lined with trees, traffic circles, curb bulbs, neck- downs, } \\
\text { and other techniques can lower vehicle speeds and create safer conditions } \\
\text { for pedestrians. }\end{array}$ \\
\hline Accessibility & $\begin{array}{l}\text { Siting of transit facilities adjacent to work, residential areas, shopping, } \\
\text { and recreational facilities encourages pedestrian trips. Transit stops and } \\
\text { centers should typically be located in areas of supporting densities. } \\
\text { Development of adequate pedestrian facilities to access transit is essential } \\
\text { to their success as an alternative mode of travel. }\end{array}$ \\
\hline $\begin{array}{l}\text { Lively public } \\
\text { spaces }\end{array}$ & $\begin{array}{l}\text { Secure, attractive, and active spaces provide focal points in the } \\
\text { community where people can gather and interact. Pedestrian pocket parks } \\
\text { and plazas are examples. }\end{array}$ \\
\hline Character & $\begin{array}{l}\text { Preservation of important cultural, historic, and architectural resources } \\
\text { strengthens community heritage and character. }\end{array}$ \\
\hline $\begin{array}{l}\text { Scenic } \\
\text { opportunities }\end{array}$ & $\begin{array}{l}\text { Attractive environments and scenic views encourage pedestrian use, } \\
\text { particularly when facilities are oriented toward them. }\end{array}$ \\
\hline $\begin{array}{l}\text { Pedestrian } \\
\text { furnishings }\end{array}$ & $\begin{array}{l}\text { Providing furnishings, such as benches, restrooms, drinking fountains, } \\
\text { artwork and other elements, creates a more attractive and functional } \\
\text { environment for pedestrians. }\end{array}$ \\
\hline Landscaping & $\begin{array}{l}\text { Street trees bring human scale to the street environment. Landscaping and } \\
\text { flowers in planting strips, containers, and other areas soften surrounding } \\
\text { hard edges of buildings and parking lots and add life, color, and texture } \\
\text { to the pedestrian's field of vision. }\end{array}$ \\
\hline $\begin{array}{l}\text { Design } \\
\text { requirements }\end{array}$ & $\begin{array}{l}\text { Guidelines and adopted standards are followed and, if deviated from, } \\
\text { justified and documented. }\end{array}$ \\
\hline $\begin{array}{l}\text { Proper } \\
\text { maintenance }\end{array}$ & Frequent cleanup and repair on a regular basis ensures consistent use. \\
\hline
\end{tabular}


Typical elements of pedestrian-friendly streets are: streets that are interconnected and small block patterns provide good opportunities for pedestrian access and mobility; narrower streets, scaled down for pedestrians and less conducive to high vehicle speeds; traffic calming devices to slow traffic, or reduced speed limits; median refuge islands to provide a refuge area for crossing pedestrians; public spaces and pedestrian pockets adjacent to the main pedestrian travel way, that provide a place to rest and interact (sidewalk cafes, benches, etc.); awnings/covered building entrances that shelter pedestrians from weather; planting buffers, with landscaping and street trees that provide shelter and shade without obstructing sight distances and help to soften the surrounding buildings and hard surfaces; street lighting designed to pedestrian scale (shorter light poles with attractive fixtures that are effective in illuminating the pedestrian travel way but not obtrusive or harsh); wide and continuous sidewalks or separated walkways that are fully accessible. Clear delineation and direction for the pedestrian (special paving on sidewalk or at edge of pedestrian travel area, easy-to-reach signal actuators, etc.); lively building faces with architectural relief, windows, or attractive surfacing; street furnishings, such as benches, garbage receptacles, drinking fountains, and newspaper stands, if not placed in the route of travel; public art, murals, banners, sculpture pieces and water features; colorful planters, holiday lighting and other attractive features; signs, information kiosks, maps, and other elements to help pedestrians.

Accessibility Design for All-An Illustrated Handbook, Washington State Regulations (1995), defines accessible route of travel as a continuous unobstructed path connecting all accessible elements and spaces in an accessible building or facility than can be negotiated by a person using a wheelchair and that is usable by persons with other disabilities (includes access routes across sites between building entrances and other public facilities such as parking, sidewalks, restrooms, etc.).

Most common types of pedestrian/motor vehicle collisions for children aged K-6 are: darting out; dashing across an intersection; crossing in front of a turning vehicle; crossing a multi-lane street; entering or crossing an intersection; playing in a roadway; going to or from a school bus; and crossing behind a vehicle that is backing up. In this case, recommended processes for improving student pedestrian safety are: preparing school walk route plans; providing school walk route maps and information to parents and students; identifying pedestrian safety deficiencies; and implementing remedial actions and improvements to address pedestrian safety concerns.

In addition, roadside pedestrian improvements along school walk routes can be: well-compacted crushed rock or gravel shoulders (recommended as an interim solution only; if an accessible route of travel, surface needs to be smooth and stable); separated crushed rock or gravel path (recommended as an interim solution only; if an accessible route of travel, edge treatment is necessary); paved shoulder (recommended as an interim solution only; if an accessible route of travel, edge treatment is necessary); paved walkway or sidewalk separated from roadway by ditches, swales, or planting buffer (good long-term solution; often used in rural and residential areas); and adjacent sidewalk with curb and gutter or vertical curb (good long-term solution; often 
used in urban areas). Separation treatments for multi-use pathways can be: colored paving; signing; textured paving or paving patterns; pavement markings; and striping with education program about trail use and other measures.

According to Design and Safety of Pedestrian Facilities, A Proposed Recommended Practice of the Institute of Transportation Engineers, ITE Technical Council Committee TENC 5A-5 (1998), criteria to be analyzed to determine pedestrian safety deficiencies are: roadway and traffic control device inventory; sight distance studies; adequacy of gaps in the stream of traffic for pedestrian crossings; collision summaries and diagrams; conflict analysis; pedestrian volumes and characteristics; and traffic volumes and speeds.

Based on Oregon Bicycle and Pedestrian Plan (1995), access management techniques can be: reducing the number of existing driveways or consolidating driveways to parking areas and businesses; and providing raised or landscaped medians or concrete barriers to control turning movements from the street. Furthermore, some of the access management benefits are: The number of conflict points is reduced (particularly with the use of center medians to reduce the number of conflicts between left-turning vehicles and pedestrians); pedestrian crossing opportunities are enhanced with an accessible raised median and fewer conflicts with turning cars; accommodating people with disabilities becomes easier with the reduced need for special treatments at driveway cuts; traffic volumes may decrease if local traffic can use other available routes; and improved traffic flow may reduce the need for road-widening, allowing more space within the right-of-way for use by pedestrians, bicyclists, and enhancements and maintaining fewer travel lanes to cross at intersections.

Basic principles of intersection design to accommodate pedestrians are: intersections that function well for pedestrians are typically compact; free-flowing motor vehicle movements are either eliminated or vehicles are forced to a significantly slower speed through the intersection; all legs of an intersection should be available for pedestrian use; closing a crosswalk doesn't necessarily prevent pedestrians from crossing in that direction; on some Tee intersections, it may not be desirable for pedestrians to cross in front of left turning vehicles; pedestrians need to be able to travel in a direct line across the intersection leg and the direction of travel needs to be clearly identified for all pedestrians, including those with sight impairments; and avoid increasing potential conflicts or the level of pedestrian exposure to motor vehicles.

Basic conditions that are considered in City of Kirkland for installation of pedestrian crossing improvements are: part of a school walking route; part of a route identified in the non-motorized plan; connects to significant retail; significant benefit to transit; higher level of protection or better sight distance or otherwise easier to cross; a high majority of people served by the crossing have a more difficult than average time crossing the street; a safety problem can be solved by improving the crosswalk. 
Medians and refuge islands should be a desirable width to prevent wheelchairs propelled by attendants, bicyclists, and people with strollers from projecting out into the stream of motor vehicle traffic. In some cases, smaller width medians and refuge islands may be acceptable, particularly when there is limited space in the right-of-way, depending on local requirements and existing conditions. In order to obtain appropriate median width, travel lanes can be narrowed if allowed by local standards.

Trees in medians and at the sides of streets can help to narrow the long range field of vision for approaching drivers, causing them to slow down as they near the crossing point. Landscaping in median refuge islands must be handled carefully. It is essential that landscaping not block the sight lines of pedestrians and motorists at the crossing area.

Curb ramps or full-cut through should be installed in all median refuge islands. Curb ramps are more common because the median width is sometimes not large enough to accommodate ramps that meet the $\mathrm{ADA}$ requirements.

A pedestrian push button should be placed in the median of signalized mid-block crossings where the crossing distance exceeds. The use of angled (45 degrees+) refuge areas in the island should be considered. These provide the benefit of directing and encouraging pedestrians to look in the direction of oncoming traffic, helping them to be more aware of approaching vehicles. Pedestrians are also prevented from darting directly out into traffic.

A Guidebook for Residential Traffic Management, published by Washington State DOT (1994), identified references to individual traffic control devices or measures that have been used for residential traffic management. Table 9 illustrates common actions of residential traffic management programs and Table 10 illustrates some of the most common types of traffic calming methods.

Table 9: Common Residential Traffic Management Program Actions

\begin{tabular}{|l|l|l|l|}
\hline Reducing & By what means & Examples \\
\hline Traffic volumes & Physical & Traffic circles; traffic diverters \\
\hline Vehicle noise & Psychological & Variable-spaced paint stripes \\
\hline Visual impacts & Visual & Landscaping to block through views \\
\hline Traffic speeds & Social/physical & $\begin{array}{l}\text { Neighborhood "speed watch" program; speed } \\
\text { humps/tables }\end{array}$ \\
\hline Collisions & Legal/physical & Strict speed enforcement; spot safety improvements \\
\hline
\end{tabular}




\title{
Table 10: Common Types of Traffic Calming Methods
}

\author{
Technique \\ Description \\ Traffic circles \\ Circular raised islands centered within intersections. Circles can be \\ landscaped or surfaced with special paving. Landscaping can be \\ maintained by the local jurisdiction or by neighborhood volunteers.

\begin{tabular}{l|l} 
Chicanes & $\begin{array}{l}\text { Alternately placed curb extensions into the street that force motorists } \\
\text { to drive in a serpentine pattern. Chicanes are offset from each other in } \\
\text { mid-block locations and can be used to keep through-trucks versus } \\
\text { local delivery off residential streets. }\end{array}$
\end{tabular}

Curb bulb-outs, Curb extensions placed at mid-block locations or intersections, which chokers/neckdowns narrow the street to provide visual distinction and reduce pedestrian crossing distances. Bulb-outs help to provide a clear visual signal to drivers that a crossing is approaching and makes waiting pedestrians more visible. Neckdowns are often longer than bulb-outs and often line up with and help to define parallel street parking areas. They narrow the appearance of the street and can be attractive, especially when landscaped.

Diagonal diverters

Eliminates through traffic while providing partial access in opposite directions; island can become amenity and provide refuge for pedestrians.

Forced turns and $\quad$ Truncated diagonal diverters (one end remains open) and other types partial diverters of partial diverters discourage commuter traffic by forcing turns, but provide local access opportunities.

Cul-de-sac/street $\quad$ Street is closed and turned into a cul-de-sac; end of street becomes a closures neighborhood amenity and focal point (landscaped mini park); the ongoing provision of pedestrian and bicycle access is important.

One-way entry and exit

Curb bulbs/extensions are used to close one lane of traffic at intersections; stops through traffic but allows ingress or egress depending on the direction and location of the closure.

Narrower streets $\quad$ Narrower streets limit the expanse of pavement visible to the driver and can be effective in slowing traffic, especially when lined with trees or on-street parking.

Speed humps/tables

A speed hump is wider and smoother than a speed bump, and effective in slowing cars as they approach pedestrian zones. These are most appropriately used on neighborhood streets.

Signs and neighborhood
Signs such as "Residential Street," "Local Access Only", or monuments that identify neighborhood districts can be effective, 


\begin{tabular}{|l|l|}
\hline gateways & $\begin{array}{l}\text { especially when used conjunction with other techniques, including } \\
\text { those listed above and others, such as pavement markings and textured } \\
\text { warning strips. }\end{array}$ \\
\hline Special paving & $\begin{array}{l}\text { Alternative road surfaces, such as brick, colored concrete or special } \\
\text { pavers, can be used at crossings, intersections, or along the sides of the } \\
\text { street to break up the visual expanse of pavement and define areas of } \\
\text { pedestrian travel. }\end{array}$ \\
\hline Speed watch programs & $\begin{array}{l}\text { Citizens and organizations can utilize a radar device and electronic } \\
\text { signboard to measure speeds of passing vehicles in their } \\
\text { neighborhoods. Letters of warning can be sent to the registered owners } \\
\text { of offending vehicles. These programs promote neighborhood. }\end{array}$ \\
\hline
\end{tabular}

Low-cost improvements to increase pedestrian access to transit are: pavement markings where sidewalks or other pedestrian facilities do not exist; marked crosswalks; removal of sidewalk obstructions; and changes in signal phasing at intersections and crossings near stations and bus stops.

Delineated walkways through parking lots; connections to neighborhoods and surrounding areas; easy to identify building entrances and building frontages located along streets rather than across parking lots; convenient and safe access to transit and adjacent sidewalks; alignment of walkways for convenience and reduced travel distances; accessible routes of travel to and from the site, as well as throughout the site; and no barriers (walls, ditches, landscaping, or roads without safe crossings) to pedestrian travel are common features of a pedestrian-friendly site design.

These questions should be addressed for successful mixed-use site developments: Are the uses complementary? Are the uses located within convenient walking distance of each other? Are the uses linked by sidewalks or paved paths? Are the walking routes short and direct? Do the buildings fit with and complement each other? Do the uses create activity at different times of the day? Is parking kept out of the pedestrian's path of travel? Do the uses support one another economically?

Separating pedestrians from conflicts with construction vehicles, equipment, and operations; separating pedestrians from conflicts with traffic traveling around or through the construction area; providing a safe, convenient, and accessible route that maintains the direction and character of the original route; minimizing work vehicle traffic crossing pedestrian routes by minimizing the number of construction access points; communicating construction activity and pedestrian impacts through local media and pedestrian interest groups; and avoiding using delineating materials that are difficult to recognize by people with impaired sight are common considerations for pedestrian safety in work zones. Bicycle and Pedestrian Facilities Planning and Design Guidelines, North Central Texas Council of Governments summarizes work zone maintenance issues and recommendations as in Table 11. 
Table 11: Work Zone Maintenance

\begin{tabular}{|l|l|}
\hline Issue & Recommended maintenance \\
\hline $\begin{array}{l}\text { Temporary pathways } \\
\text { constructed of inexpensive, } \\
\text { short-life materials }\end{array}$ & $\begin{array}{l}\text { Pathway surfaces should be inspected regularly; surface } \\
\text { materials should be treated with nonslip materials; surface } \\
\text { materials with holes, cracks, or vertical separation should be } \\
\text { replaced }\end{array}$ \\
\hline $\begin{array}{l}\text { Detour pedestrian paths } \\
\text { increase volumes on detour } \\
\text { roadway }\end{array}$ & $\begin{array}{l}\text { Detour pathway should be inspected regularly for adequacy of } \\
\text { signal timing, signing, and pedestrian traffic hazards }\end{array}$ \\
\hline $\begin{array}{l}\text { Construction material debris } \\
\text { on pathway }\end{array}$ & Require contractor to maintain clear pathways \\
\hline $\begin{array}{l}\text { Changing pedestrian route } \\
\text { during construction }\end{array}$ & $\begin{array}{l}\text { Inspect pedestrian signing regularly to ensure a clearly } \\
\text { understood pathway }\end{array}$ \\
\hline Damaged traffic barriers & Replace and reevaluate adequacy for pedestrian safety \\
\hline
\end{tabular}

Bicycle Facilities are limited to bicycle use only:

- Shared roadway (with limited, inconsistent, or no shoulder)

- A roadway accommodating bicyclists and motorists in the same travel lane. Typically the travel lanes are wider than what would be designed for automobile traffic only for the associated functional classification of the road and its context (e.g. rural or urban).

- Shared roadways may be a Signed Bike Route or include other indicators such as Share the Road Signs, Sharrows, or other pavement markers.

- Shared roadway with paved shoulder

- The street with a paved shoulder or wide curb lane that accommodates bicyclists adjacent to the vehicle travel lanes. A four to six foot shoulder is preferable, in conjunction with applicable municipal and PennDOT guidelines.

- Paved shoulders are separated from travel lanes by the striping representing the outside edge of the outermost travel lane.

- Bike lane

- A designated travel lane along the shoulder for exclusive use by bicyclists. Bicycle lanes are typically located on roadways in urban and suburban settings with moderate to high vehicular traffic volumes and moderate to high-posted speeds.

- PennDOT's Design Manual requires a formal bicycle lane to have a five-foot dedicated shoulder, application of pavement striping, markings, and regulatory 
signage. Bicycle lane facilities should be one-way facilities that carry traffic in the same direction as motor vehicles.

In addition to the shared roadway and bike lane facilities, supplemental signage, roadway treatments (striping, coloration, or texture) can be added to these facilities when warranted.

- Share the Road

- A supplemental signage added to a shared roadway to warn motorists of the increased likelihood of bicyclists.

- Sharrow

- A pavement marker that increases driver awareness of shared roadway arrangements.

- Signed bicycle route

- A treatment used to designate a preferential bicycle routing and provide guidance to cyclists. AASHTO's Guide for the Development of Bicycle Facilities states that the signing of shared roadways indicates to cyclists that there are particular advantages to using these routes compared to alternate routes.

- Route signs can be used to provide directional, distance, and destination information to assist bicyclists in navigation. Signed routes can also be used to direct cyclists to corridors that have existing on-road facilities, or access locations for off road facilities.

- Bicycle boulevard

- A corridor treatment that prioritizes bicycle travel via traffic calming measures, signs, pavement markings, and crossing improvements to enhance bicycle travel.

- Cycle track

- An exclusive facility for bicyclists that combines design aspects of bike lanes and shared-use trails. Shared-use facilities accommodate users of different modes on the same facility:

- Shared use/multi-use trail

- A facility that is physically separated from the roadway and typically accommodates bi-directional travel by both bicyclists and pedestrians. The trail can be located within a publicly owned right-of-way, an exclusive right-of-way, or an easement.

- Shared-use paths typically have an improved surface (e.g., asphalt, concrete, compacted gravel, etc.) and have a recommended width per AASHTO of ten feet, although a minimum width of eight feet may be used where space is constrained or in environmentally sensitive areas.

- Sidepaths are a subset of shared use paths that denote paths that run adjacent to a parallel roadway. Sidepaths can provide bicycle connections between on- and offroad facilities, but often require a more in-depth operational and safety analysis. 
- Mid-block crossing

- A mid-block crossing permits pedestrians and bicyclists to cross a road at a location other than an intersection. These crossing require special engineering analysis to determine their appropriateness and effectiveness.

Pedestrian facilities are limited to pedestrian use only:

- Sidewalks

- A pedestrian lane that provides space to travel within the public right-of-way that is separated from roadway vehicles. PennDOT's Design Manual requires sidewalks to be a minimum of five feet in width to comply with ADA requirements.

- Sidewalks are primarily for pedestrian use only; exceptions for bicycles may include use by small children or where no other option is available (such as narrow bridges where bicycles may be expressly permitted).

- Internal walkway

- A designated single-use facility with an improved surface, primarily for use by pedestrians, typically located outside of the road right-of-way and/or not directly adjacent to a street and generally used to facilitate pedestrian transportation between buildings and parking areas or sidewalks, between buildings on a parcel or within a development, or between adjacent uses, developments, or facilities.

- Social path/trail

- An informal, unimproved path typically, of bare earth worn in grassy areas formed by pedestrians repeatedly traveling between areas where no trails, sidewalks, or pedestrian paths have been installed. The point of defining social paths is to require their identification during the subdivision and land development process and requiring that consideration be given to formalizing them into sidewalks, internal walkways, or trails as a part of new development to facilitate pedestrian movement within a site and connections to adjacent areas.

- Use-restricted path

- Paths are typically unpaved trails that are primarily used for one form of travel. Most commonly, single-use paths are designated for pedestrian/hiking purposes only due to trail width, surface, topography, condition, accessibility limitations, and potential user conflict.

The ADA for Roadway Design Incorporating PROWAG presented by Dean Perkins (2015) provides a brief background of ADA and recommends using PROWAG criteria if ADA Standards do not address an issue. The document contains safety and accessibility criteria on pedestrian access routes. It also explains public services must be accessible, public sidewalks and curb ramps should be accessible routes since the public utilized them, and features on sidewalks and curb ramps must be accessible. 


\section{DEVELOPMENT AND TESTING}

The SAPFIM application includes four modules: Data Collection, Maps, Data Collection, and Reports. Figure 3 depicts the SAPFIM modules.
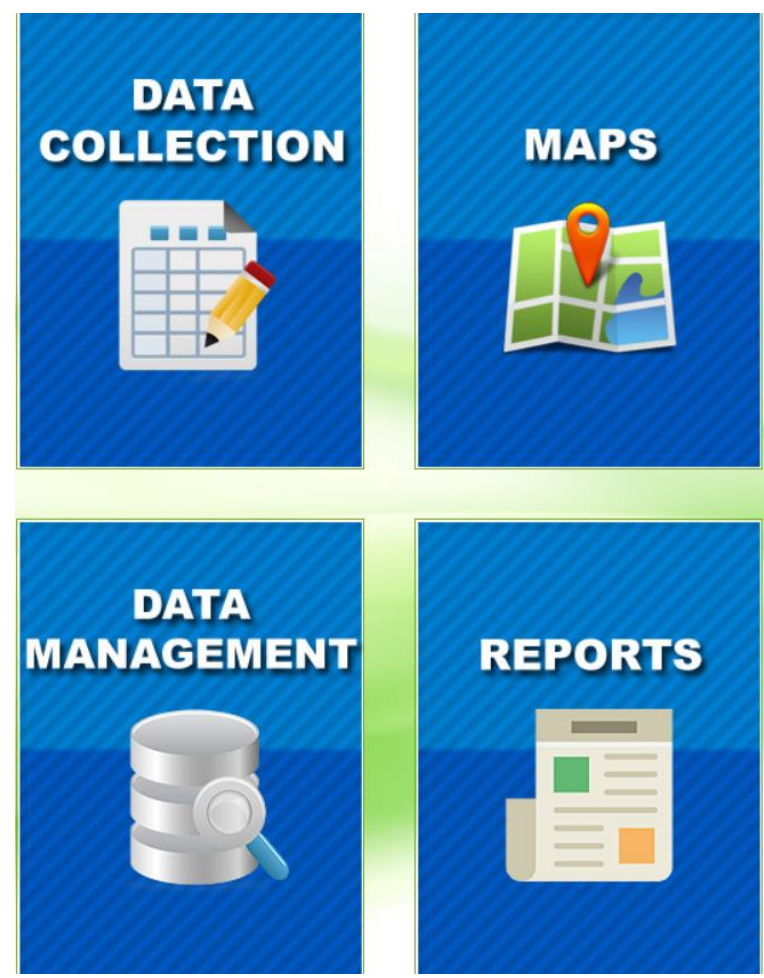

Figure 3: SAPFIM Modules

\section{DATA COLLECTION}

This section defines the main data collection elements adopted in SAPFIM. Appendix A depicts the Quick Guide with information on the main SAPFIM functions and a description of the Data Collection fields.

\section{What are the SAPFIM Data Collection Elements?}

The data collection elements were identified by the FIU research team and FDOT management team.

There are three elements in the data collection module, as follows:

1. Sidewalks

2. Ramps

3. Crossings

Each of the elements contains a series of attributes, as explained in the following sections. 


\section{Sidewalks}

The Sidewalk Attributes is the initial setting after logging in and clicking on the "Data Collection" button from the SAPFIM main menu. Figure 4 displays the sidewalk screen.

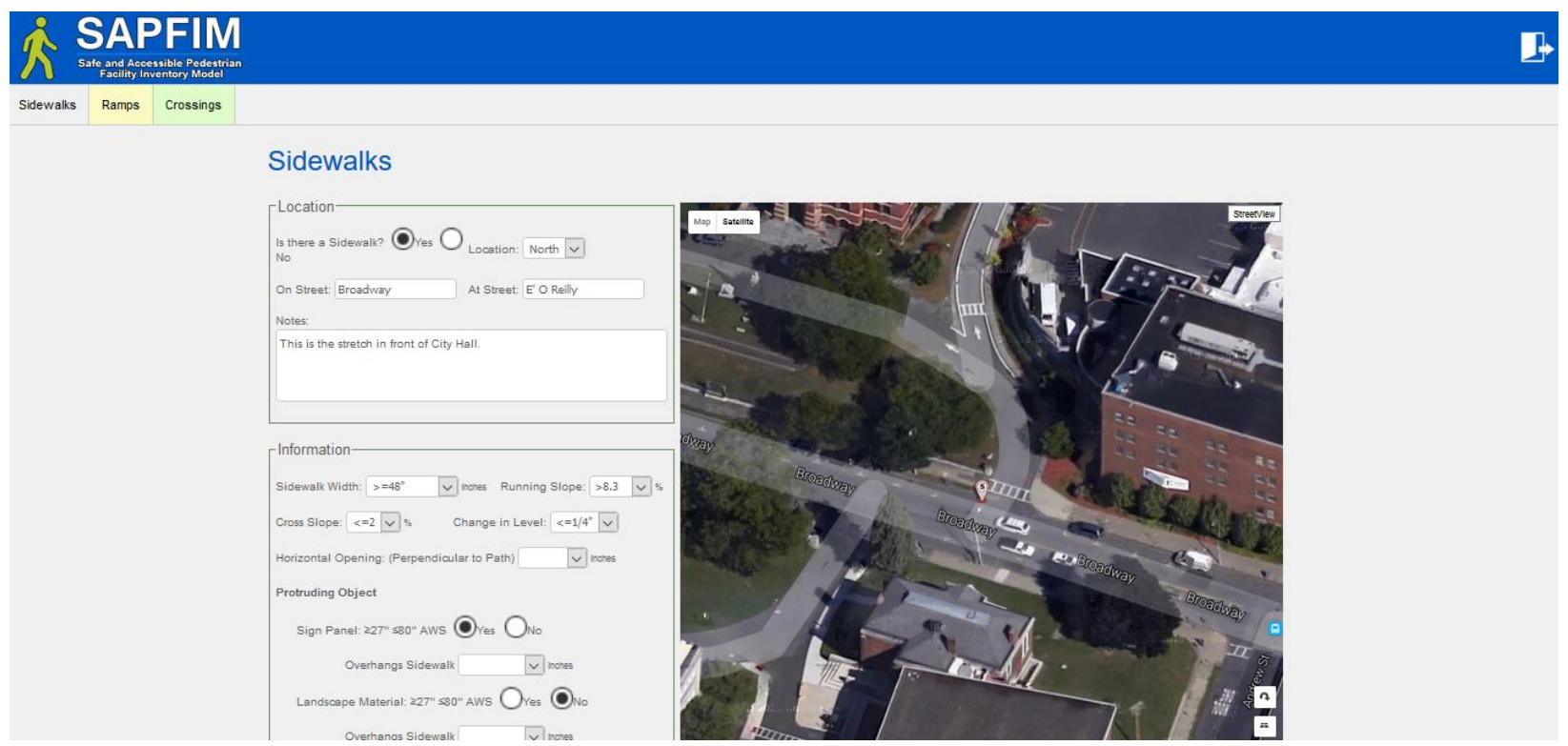

Figure 4: SAPFIM Sidewalk Screen

The Sidewalk Location and Information Attributes are described below:

1. Is there a Sidewalk? Check yes or no if there is a sidewalk or not.

2. Location: Select whether the sidewalk is located on the North, South, East, or West.

3. On Street: Enter the name of the street along the sidewalk.

4. At Street: Enter the name of the closest cross-street.

5. Note: A "note" can be included to document any special conditions that exist at the sidewalk.

6. Sidewalk Width: Select the appropriate option for the width of the sidewalk: $<36$ ", $>=36$ " $<48$ ", or $>=48$ ".

7. Running Slope: Select the percentage of the running slope of the sidewalk.

8. Cross Slope: Select the percentage of the cross slope of the sidewalk.

9. Change in Level: Select a vertical change along the sidewalk.

10. Horizontal Opening (Perpendicular to Path): Select a horizontal opening.

11. Sign Panel: $\geq \mathbf{2 7 "} \leq \mathbf{8 0 "}$ AWS: Check whether there is a sign panel between 27 " and 80 " Above Walking Surface.

12. Overhangs Sidewalk: Select the length of a protruding object that overhangs the sidewalk. 
13. Landscape Material: $\geq 27 " \leq 80 "$ AWS: Check whether there is landscape material between 27' and 80" Above Walking Surface.

14. Overhangs Sidewalk: Select the length of a protruding object that overhangs the sidewalk.

15. Other: $\geq \mathbf{2 7}$ " $\leq \mathbf{8 0 "}$ "AWS: Check whether there is an object between 27" and 80" Above Walking Surface.

16. Overhangs Sidewalk: Select the length of a protruding object that overhangs the sidewalk.

17. Building: Width of the sidewalk, at that particular location, measured from back of curb to a building.

18. Retaining Wall: Width of the sidewalk, at that particular location, measured from back of curb to a retaining wall.

19. Other: Width of the sidewalk, measured from back of curb to an infrastructure, other than building or retaining wall.

20. Connects To Other Facility: Check yes or no if the sidewalk connects to other facility (e.g., sidewalk or building entrance).

21. Sidewalk Gap: Select the length of a sidewalk gap in feet.

22. Material: Select the type of material of the sidewalk: concrete, asphalt, brick, other.

23. Condition: Select the condition of the sidewalk: good, cracks, dirt, grass, other.

24. Curb and Gutter: Select whether there is a curb and gutter.

25. Flush Shoulder: Select whether there is a flush shoulder.

26. Separated from road: Select separation distance using the Curb and Gutter or Flush Shoulder options.

27. Not separated from road: Select Curb and Gutter or Flush Shoulder options, if not separated from road.

28. >10" drop w/in 24": Check yes or no there is a 10" vertical drop within 24" horizontal distance.

29. Protected by Railing: Check yes or no if there is a protected railing.

30. Other Protection: Check yes or no there is another protection, other than railing.

31. Utility Pole: Select the smallest distance from back of curb to utility pole or from back of sidewalk to utility pole.

32. Signal Pole: Select the smallest distance from back of curb to signal pole or from back of sidewalk to signal pole.

33. Sign Post: Select the smallest distance from back of curb to sign post or from back of sidewalk to sign post.

34. Fire Hydrant: Select the smallest distance from back of curb to fire hydrant or from back of sidewalk to fire hydrant.

35. Furniture/Amenities: Select the smallest distance from back of curb to furniture/amenities or from back of sidewalk to furniture/amenities. 
36. Landscaping/Hardscape: Select the smallest distance from back of curb to landscaping/hardscape or from back of sidewalk to landscaping/hardscape.

37. Trees/Vegetation: Select the smallest distance from back of curb to trees/vegetation or from back of sidewalk to trees/vegetation.

38. Other: Select the smallest distance from back of curb to other obstruction or from back of sidewalk to other obstruction.

39. Roadway/high-level: Check whether there is a roadway/high-level lighting present.

40. Pedestrian/low-level: Check whether there is a pedestrian/high-level lighting present.

41. Upload Picture: Select to upload a picture to the database.

42. Notes: A "note" can be included to document any special conditions that exist at the sidewalk.

\section{Ramps}

The Ramps Location and Information Attributes section are described below. Figure 5 displays the Ramps screen.

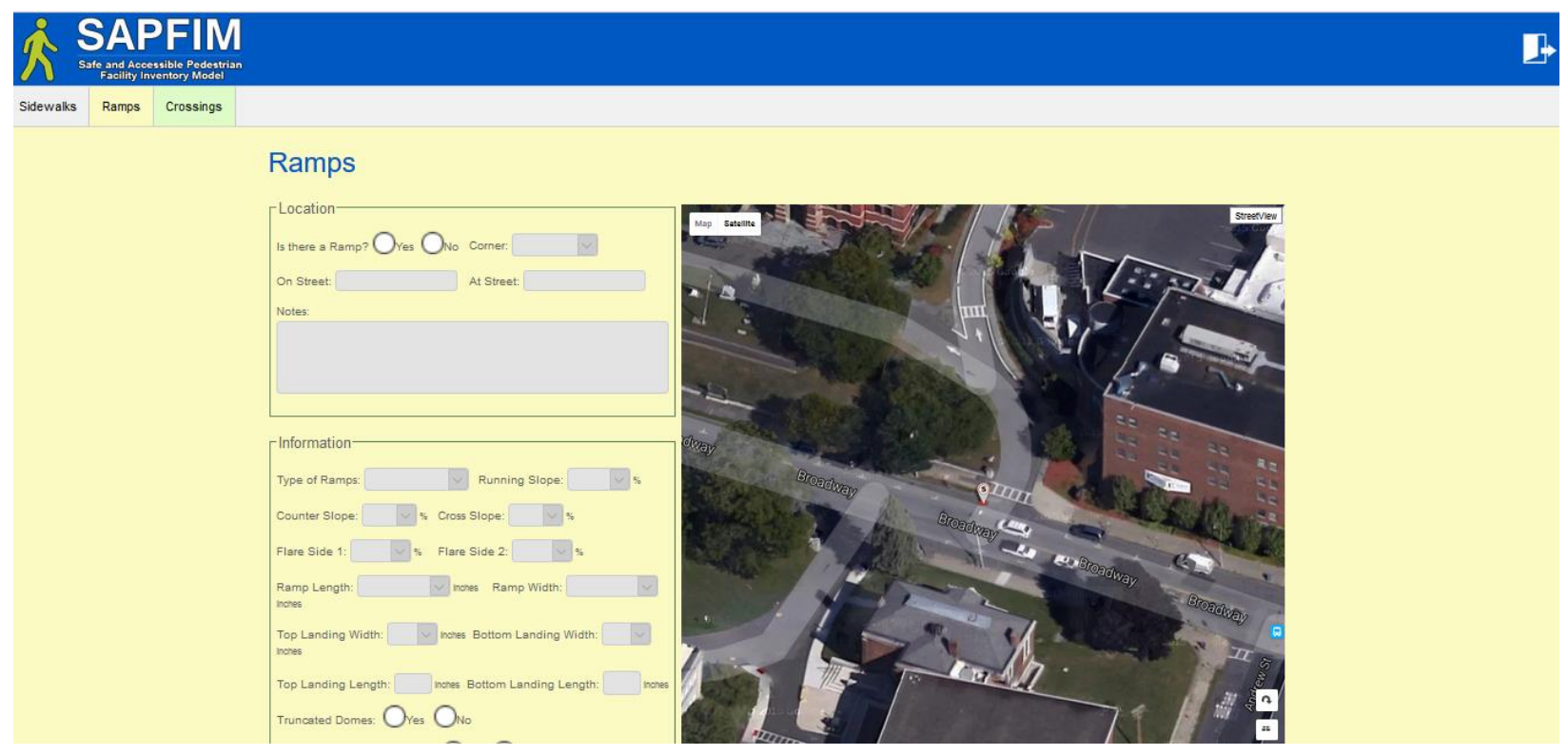

Figure 5: SAPFIM Ramps Screen

1. Is there a Ramp? Check yes or no if there is a ramp or not.

2. Corner: Select whether the corner location is Northwest, Northeast, Southwest, or Southeast.

3. On-Street: Enter the name of the street where the ramp is located.

4. At-Street: Enter the name of the closest cross-street to the ramp. 
5. Notes: A "note" can be included to document any special conditions that exist at the ramp.

6. Type of Ramps: Select whether the ramp is Perpendicular, Parallel, Combination, Diagonal, or Other.

7. Running Slope: The percentage of the slope of ramp parallel to walking direction.

8. Counter Slope: The percentage of the slope of gutter at bottom of ramp.

9. Cross Slope: The percentage of the ramp cross slope.

10. Flare Side 1: The percentage of the ramp flare slope parallel to curb.

11. Flare Side 2: The percentage of the ramp flare slope parallel to curb.

12. Ramp Length: The length of the ramp in inches.

13. Ramp Width: The width of the ramp in inches.

14. Top Landing Width: The width of the top landing in inches.

15. Top Landing Length: The length of the top landing in inches.

16. Bottom Landing Width: The width of the bottom landing in inches.

17. Bottom Landing Length: The length of the bottom landing in inches.

18. Truncated Domes: Check whether the ramp surface include truncated domes or not.

19. Detectable Warning Contrast: Select whether detectable warning contrast with surrounding surfaces.

20. Warning Placement: Select the distance of the detectable warnings from back of curb or roadway edge.

21. Is Detectable Warning Full Width? Select whether detectable warning full width of curb ramp or sidewalk.

22. Upload Picture: Select to upload a picture to the database.

23. Notes: A "note" is included to document any special conditions that exist at the ramp.

\section{Crossings}

The Crossings Location and Information section are described below. Figure 6 shows the SAPFIM Crossings screen. 


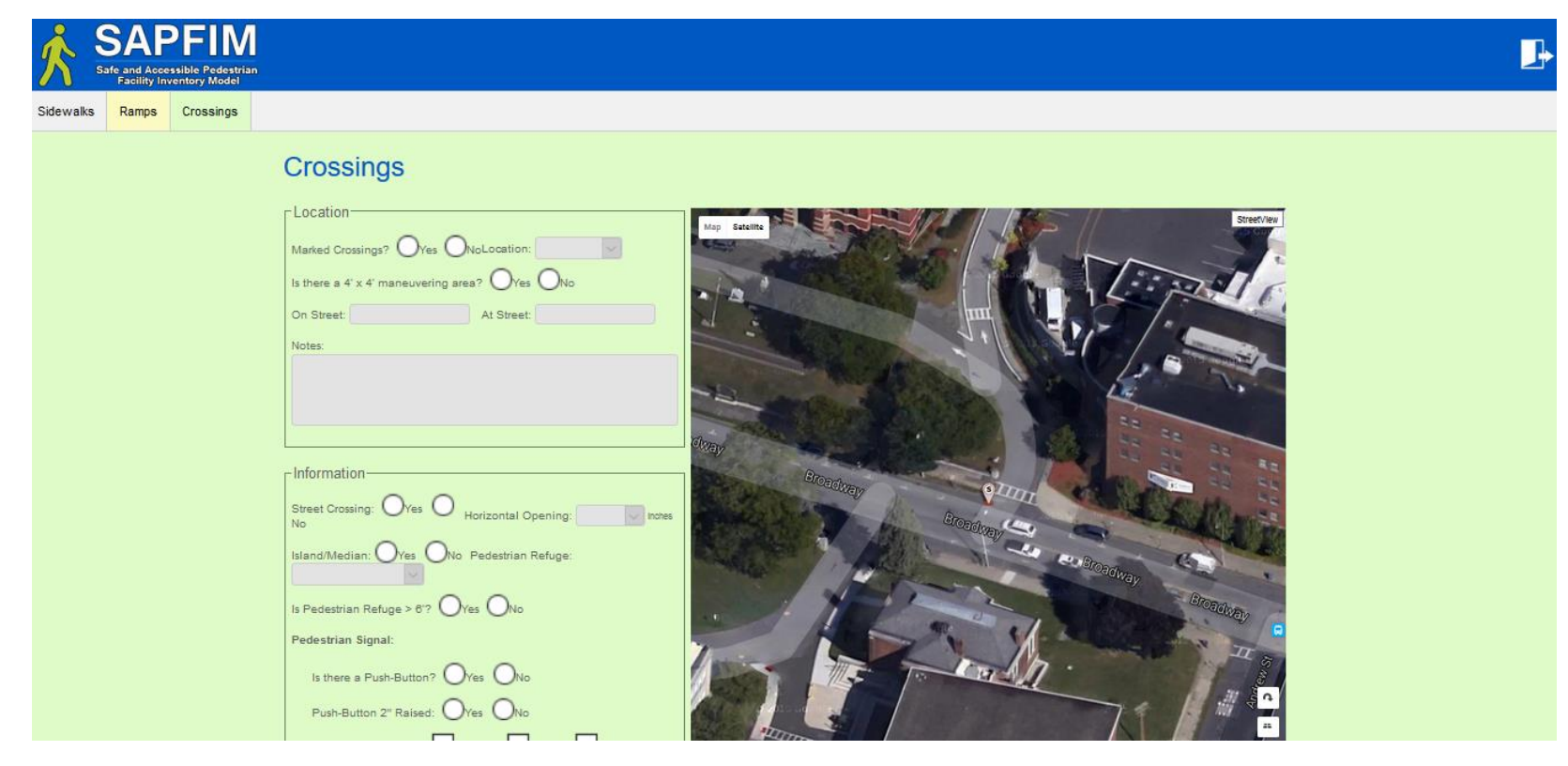

Figure 6: SAPFIM Crossing Screen

1. Is there a Marked Crossing? Check the yes or no checkbox if there is a marked crossing.

2. Is there a 4' $x$ 4' maneuvering area? Select whether there is a 4' $x 4$ maneuvering area.

3. Location: Select whether the crossing location is Northside, Northside, Westside, or Eastside.

4. On Street: Enter the name of the street where the crossing is located

5. At Street: Enter the name of the closest cross-street to the crossing.

6. Notes: A "note" can be included to document any special conditions that exist at the crossing.

7. Street Crossing: Select whether there is a street crossing.

8. Horizontal Opening: Select the appropriate distance if a horizontal opening exists.

9. Island/Median: Select whether there is an island/median or not.

10. Pedestrian Refuge: Select the appropriate distance if there is pedestrian refuge.

11. Is Pedestrian Refuge > 6? Select whether pedestrian refuge is greater than 6 inches.

12. Is there a Push-Button? Select yes or no if there is a push-button at the pedestrian signal or not.

13. Push-Button 2" Raised: Select yes or no if the pedestrian signal includes a push-button raised and 2 " in diameter.

14. Accessible Features: Select the features the pedestrian signal has: Audible, Tactile, Other, or None.

15. Height of Button: Select the height of the pedestrian signal button, measured from Above Walking Surface. 
16. Level Clear Space: Select whether there is a clear level space equal or greater than $30 " \mathrm{x}$ $48 "$.

17. Number of Lanes to Cross: Enter the number of street lanes to cross.

18. Total Time to Cross: Enter the time it takes to cross the street.

19. Measured on "Date" at "Time": Enter the date and time when the Total Time to Cross was measured.

20. Material: Select whether the crosswalk material is Concrete, Asphalt, Brick/Paver, or Other.

21. Condition: Select the crosswalk condition: Good, Cracks, Faded, Other.

22. Upload Picture: Select to upload a picture to the database.

23. Notes: A "note" can be included to document any special conditions that exist at the crosswalk.

Other Functions

\section{Print}

This function prints records, reports, etc. To print a record, click/tap the Print icon (Figure 7).

Important: Print settings will vary depending on each user's printing capabilities. Printer settings may need to be adjusted if difficulties arise when attempting to print.

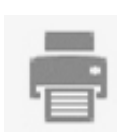

Figure 7: Print Record Icon

\section{Log Out}

This function allows the user to log out of the SAPFIM system. To log out, simply click/tap the Log Out icon (Figure 8) to exit the system.

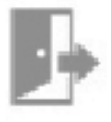

Figure 8: Log Out Icon

\section{User Management}

This function allows the administrator to create usernames and passwords. To create a user account, simply click/tap the User Management icon (Figure 9) to view the User Management page. 


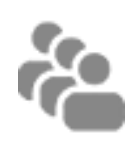

Figure 9: User Management Icon

To add a user, simply click the "Add New User" button and fill out the information. Once done, click "Add" at the bottom of the web page. To edit a user, simply click the "Edit" button on the right hand side of the web page and then click Save or Cancel the edits. Figures 10 and 11 depict some of the functionality within the User Management module.

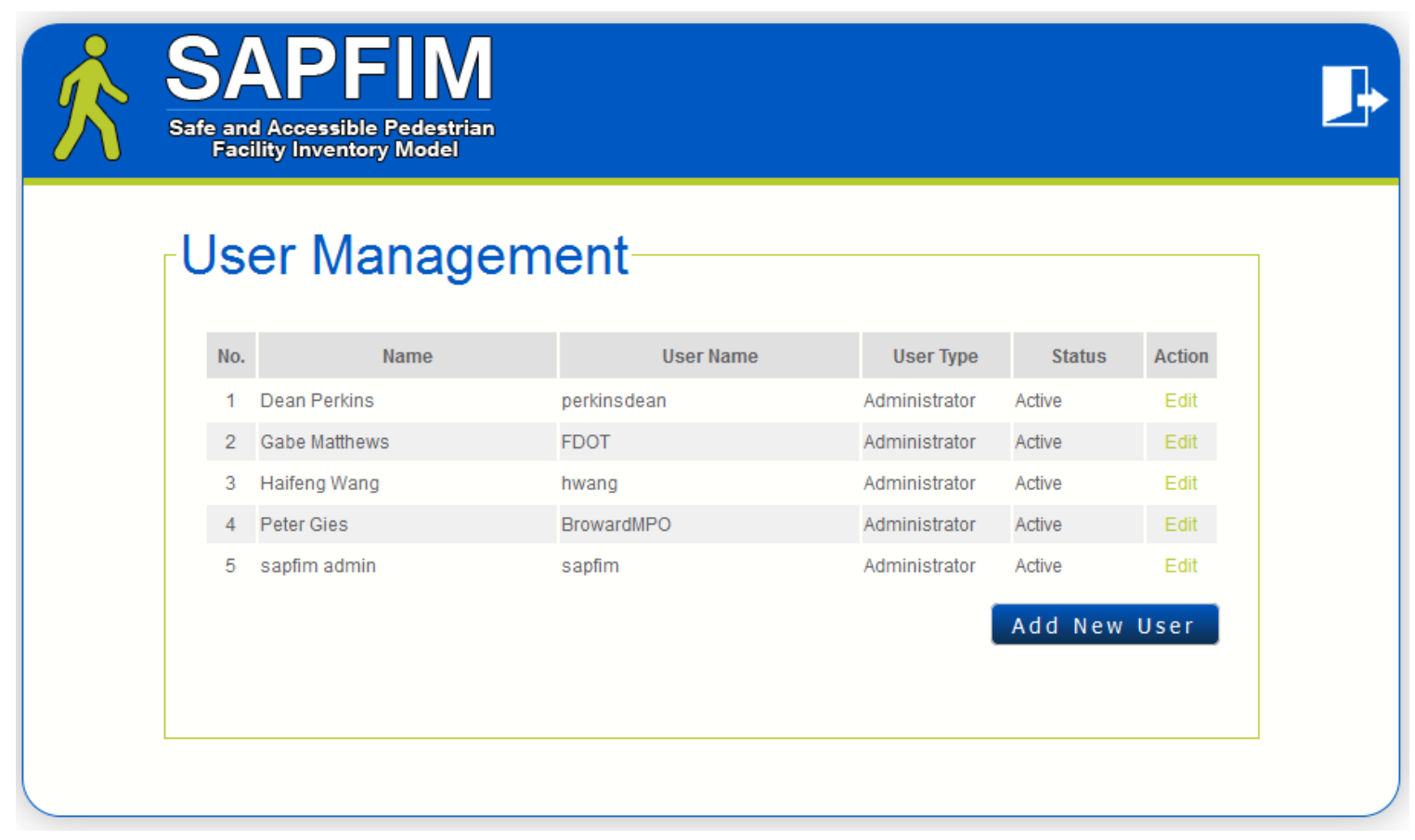

Figure 10: User Management Screen 


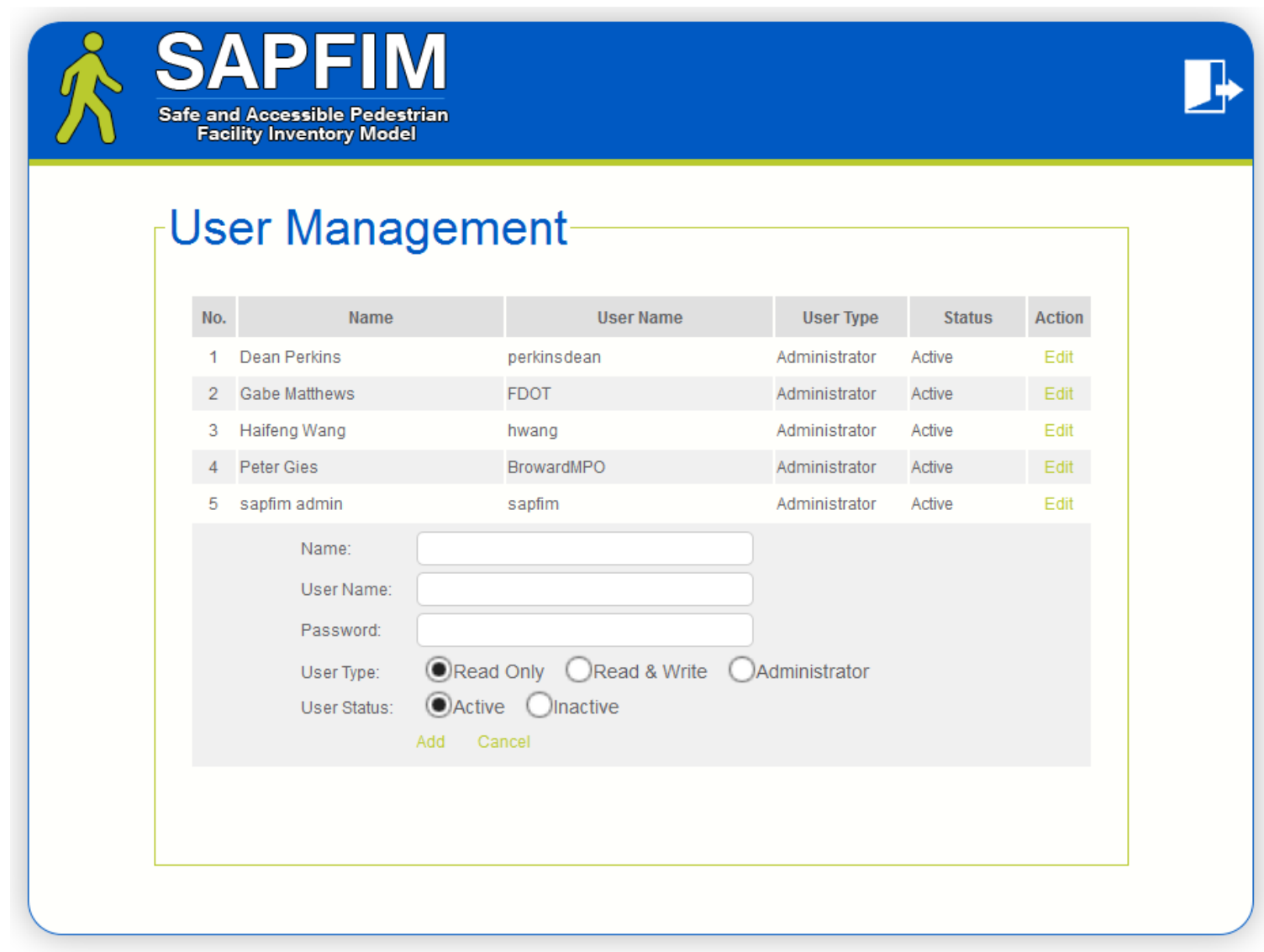

Figure 11: User Management Add/Edit Screen

\section{Camera}

In order to use SAPFIM effectively, the data collection device should have a camera with access to a wireless network. Therefore, a data plan ( $4 \mathrm{G}$ recommended) should be purchased from an Internet Service Provider (ISP) such as AT\&T, Verizon, Sprint, T-Mobile, or other company.

A camera can be used to take pictures of the pedestrian facilities of interest. A picture or pictures can enhance the data collected in the field and can help office personnel with the decision making for the improvements of pedestrian facilities. The following pages shows images of bad and good pedestrian facilities such as sidewalks, ramps, and crossings. 


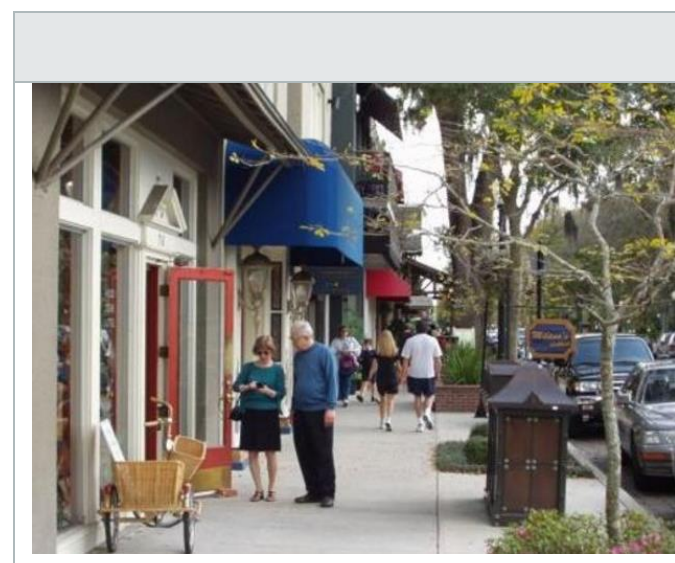

This picture shows a sidewalk in good condition.

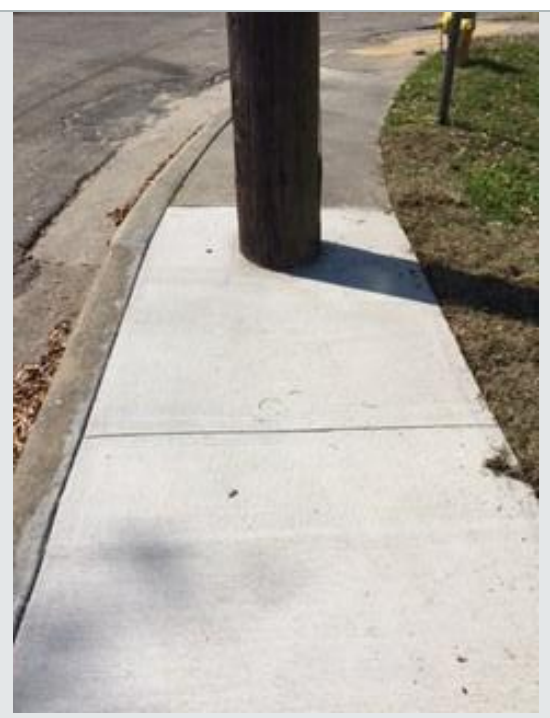

This picture shows a pole in the middle of a sidewalk, which is an accessibility issue.

\section{SIDEWALKS}

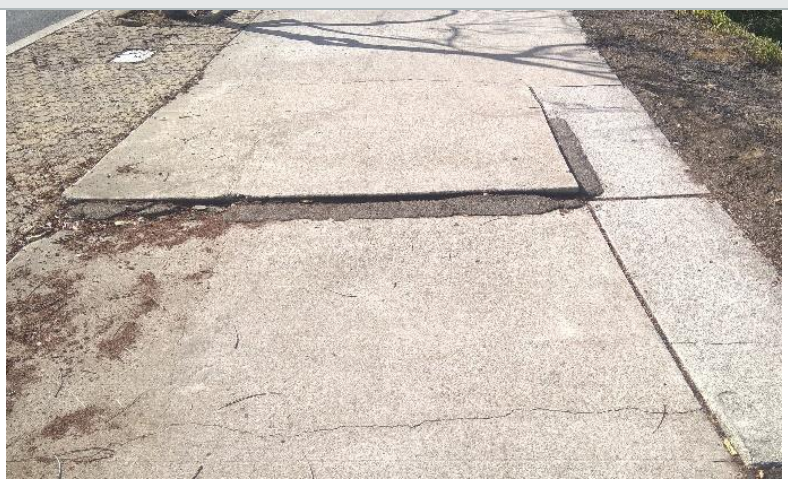

This picture shows a sidewalk with a change in level, which is a pedestrian hazard.

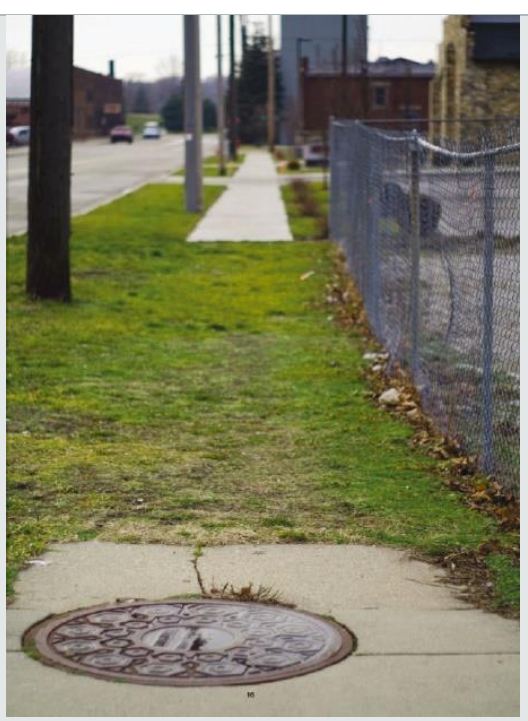

This picture depicts a huge gap along the sidewalk. Missing pieces of sidewalk make it difficult for people with disabilities to use the facility and poses a safety problem. 


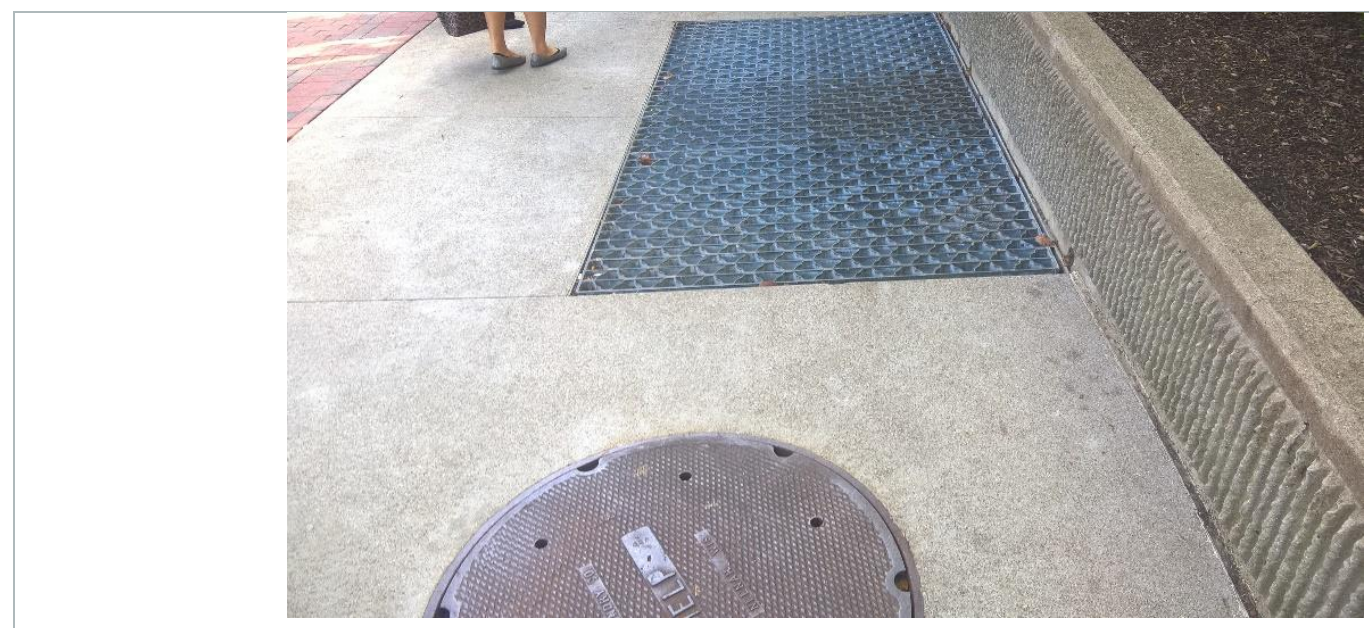

This picture shows a grate in the sidewalk.

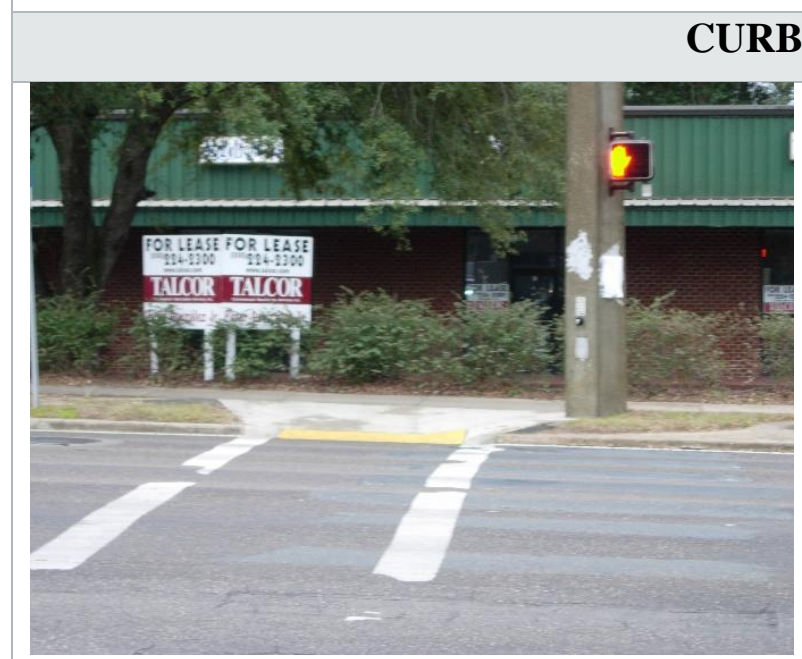

This picture shows a curb ramp in good condition.

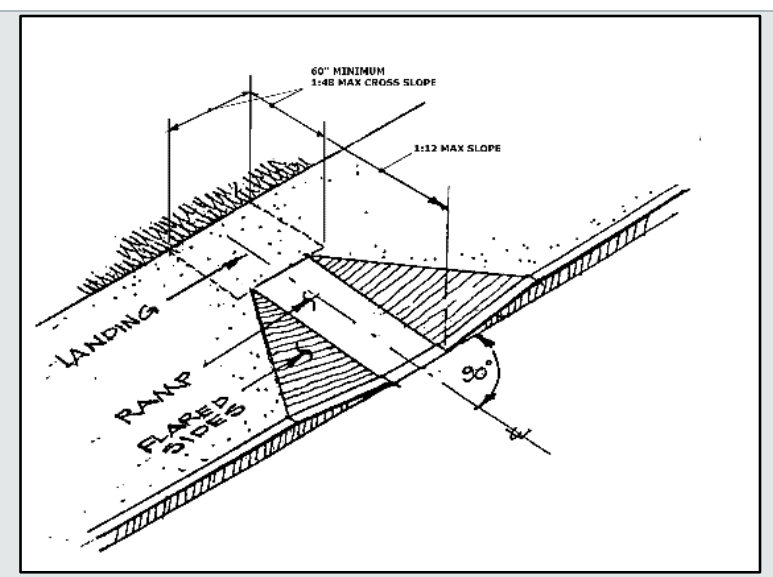

This picture show an accessible parts of a curb This picture shows a missing curb ramp.

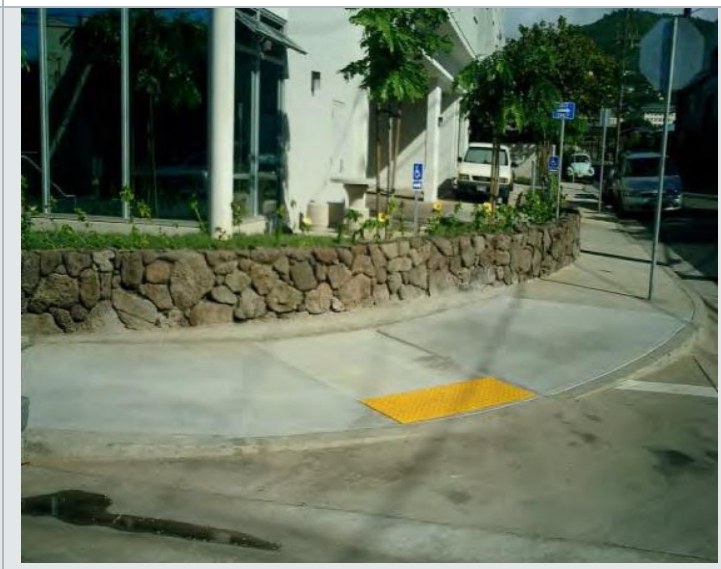

This is an example of a good parallel ramp. ramp. 


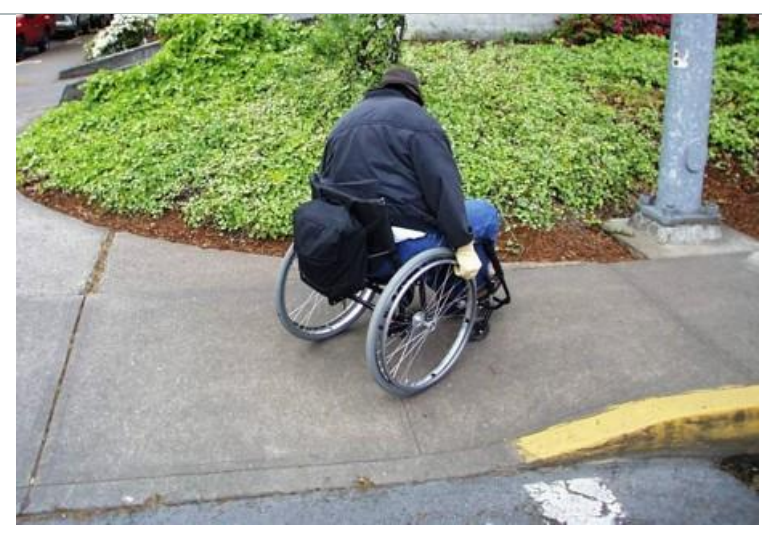

This is a bad example of a no top landing.

\section{Detectable warnings}

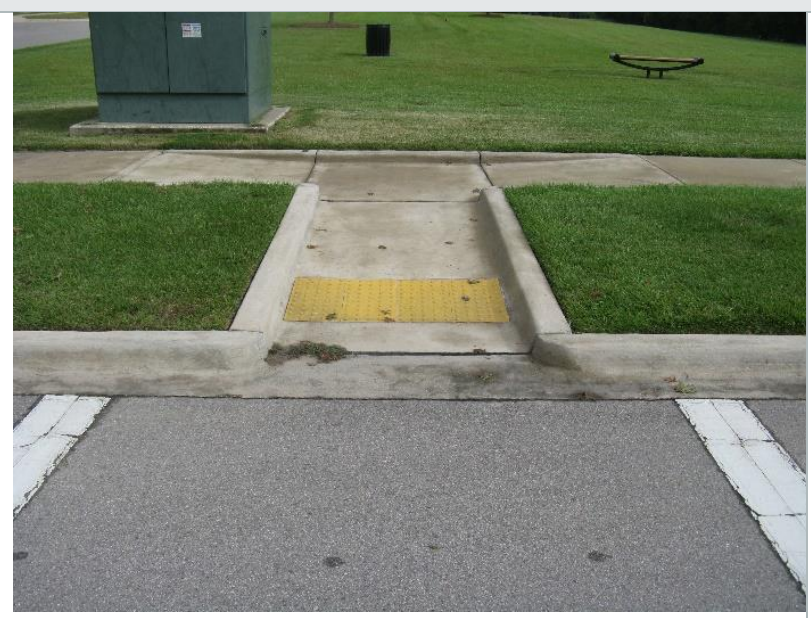

This is an good example of a detectable warning.

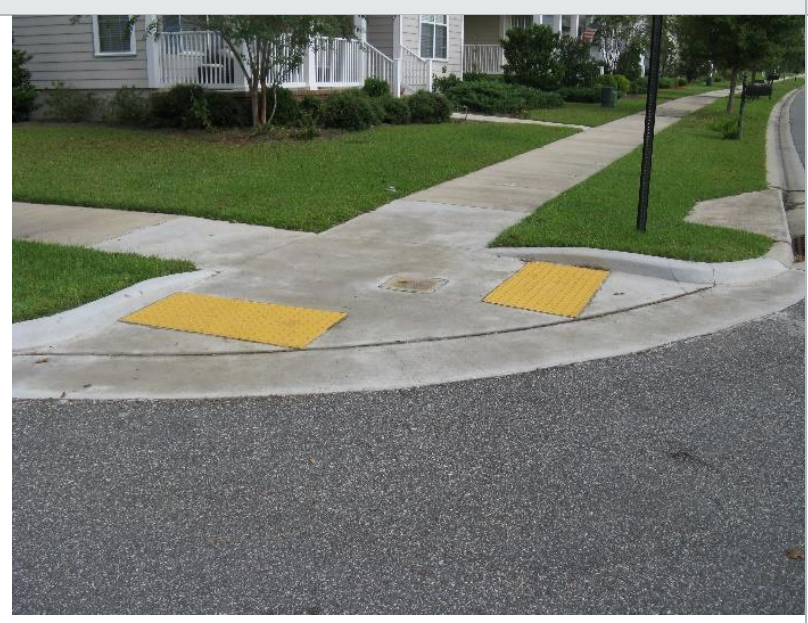

This is an bad example of an incomplete detectable warning.

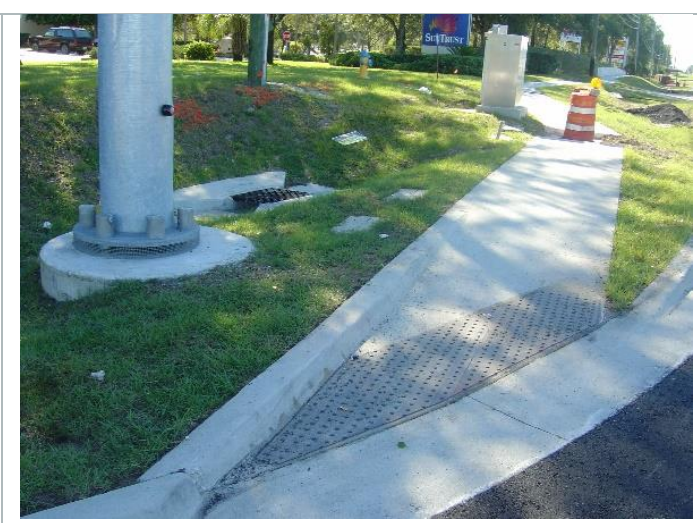

This is an example of a good linear ramp.

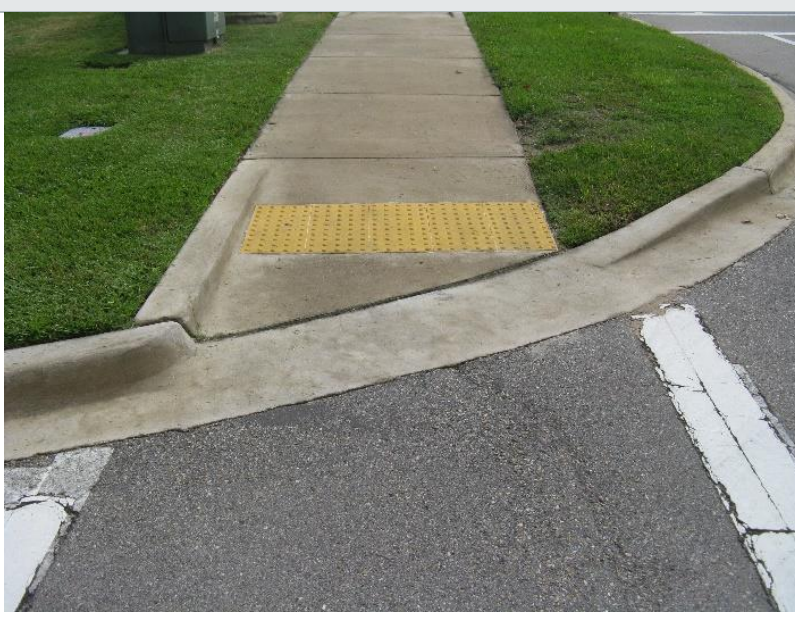

This is another good example of a detectable warning.

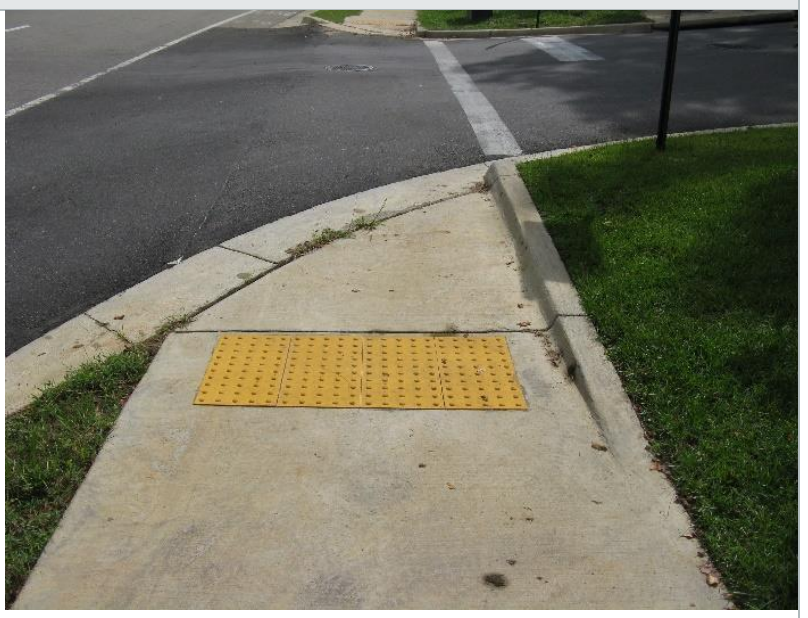

This is another bad example of an incomplete detectable warning. 


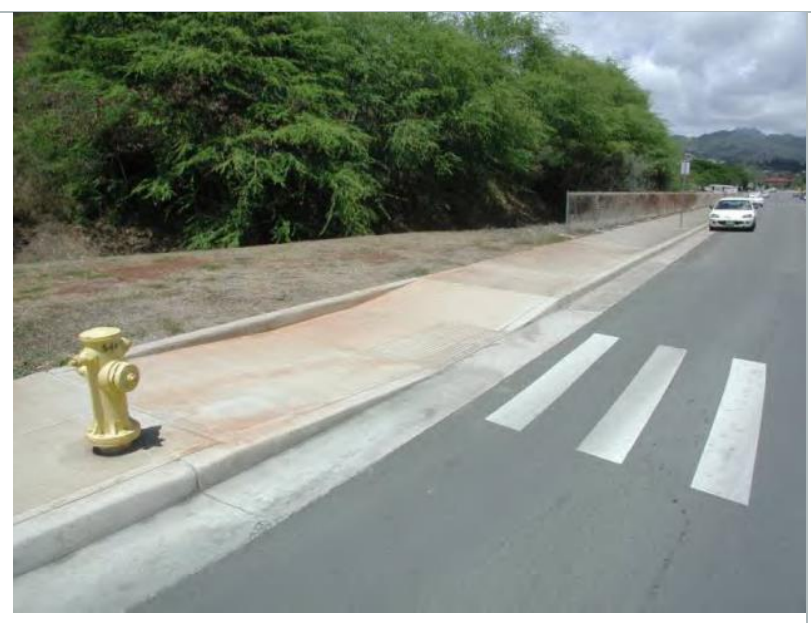

This is a bad example of a missing detectable warning.

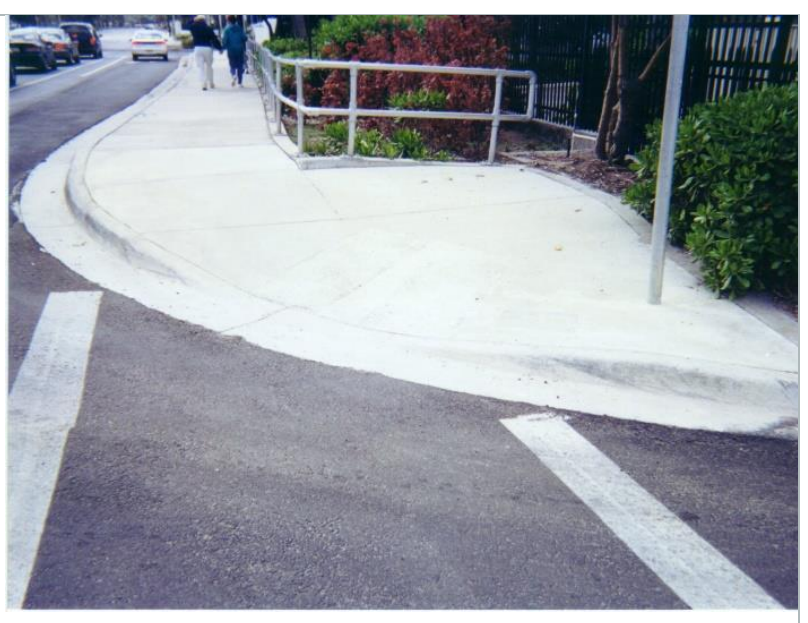

This is another bad example of a missing detectable warning.

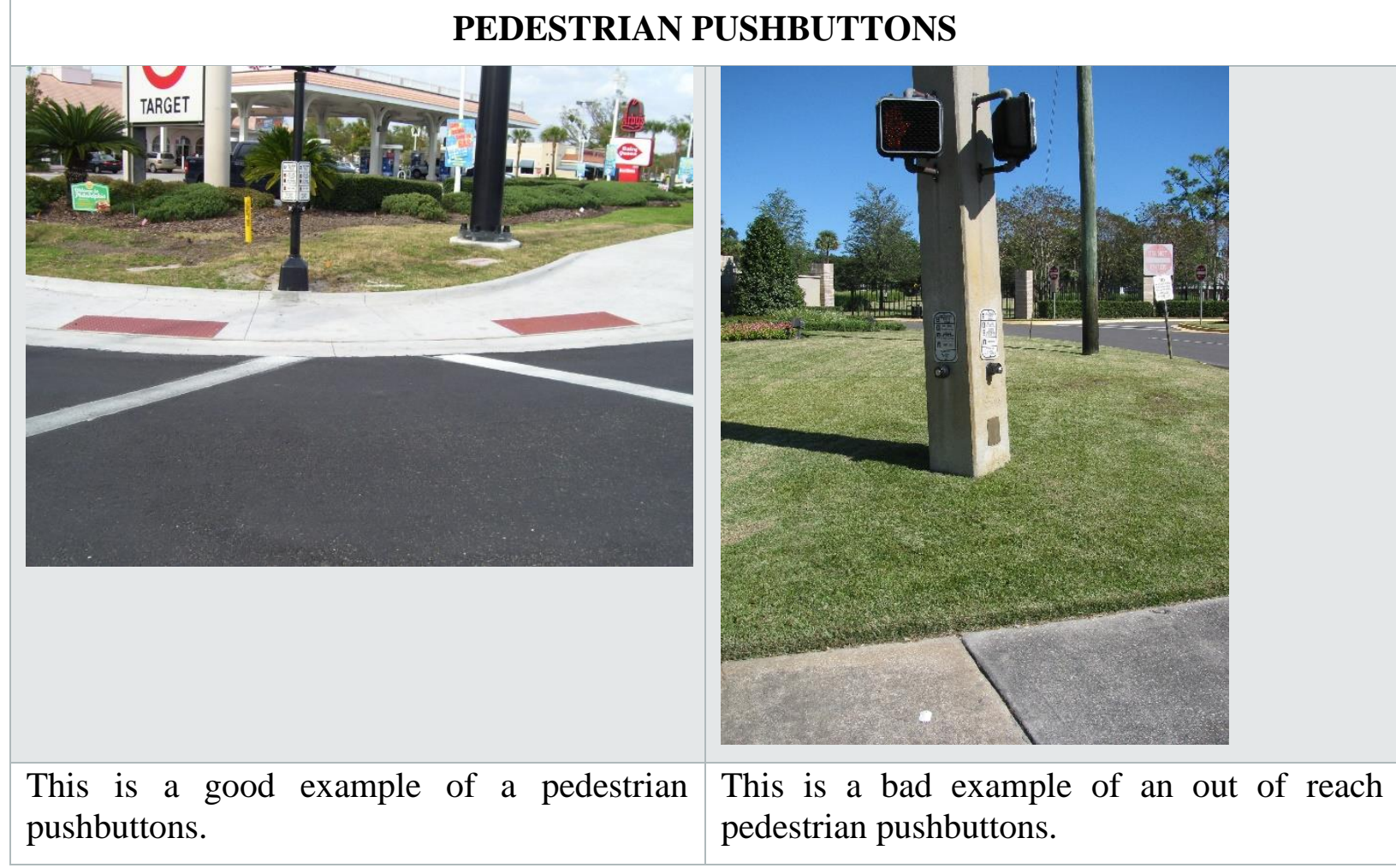




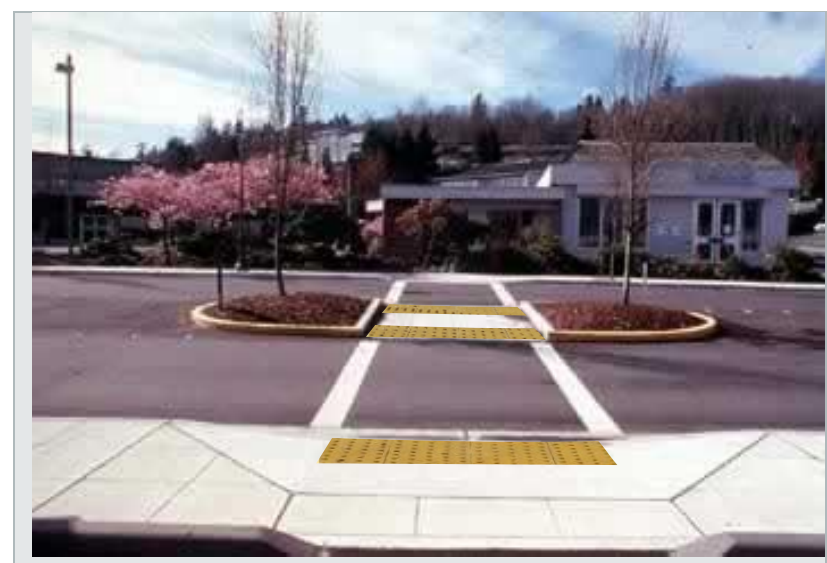

This is a good example of a median cutthrough.

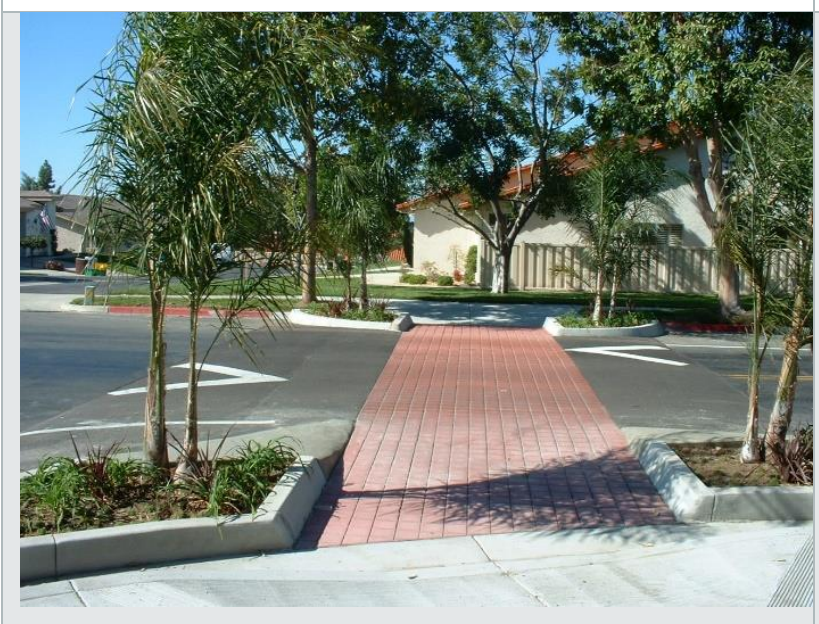

This is a good example of a raised crossing.

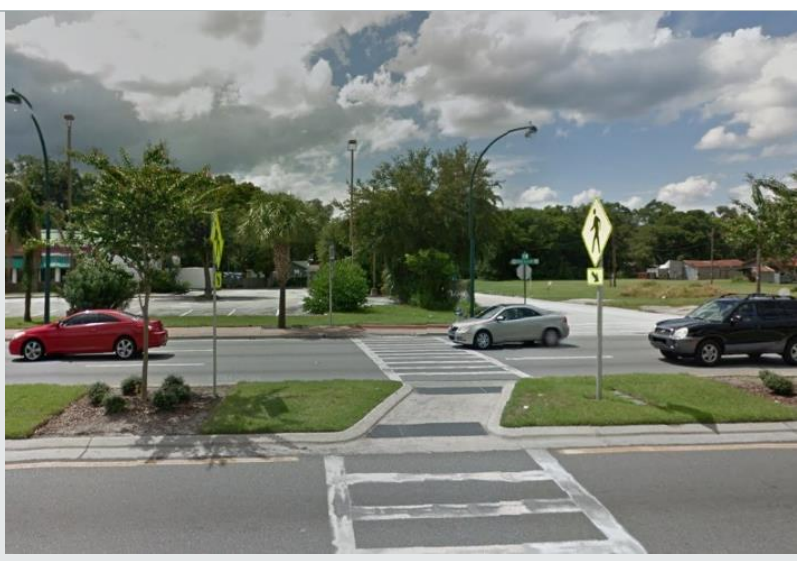

This is a good example of a diagonal median cut-through.

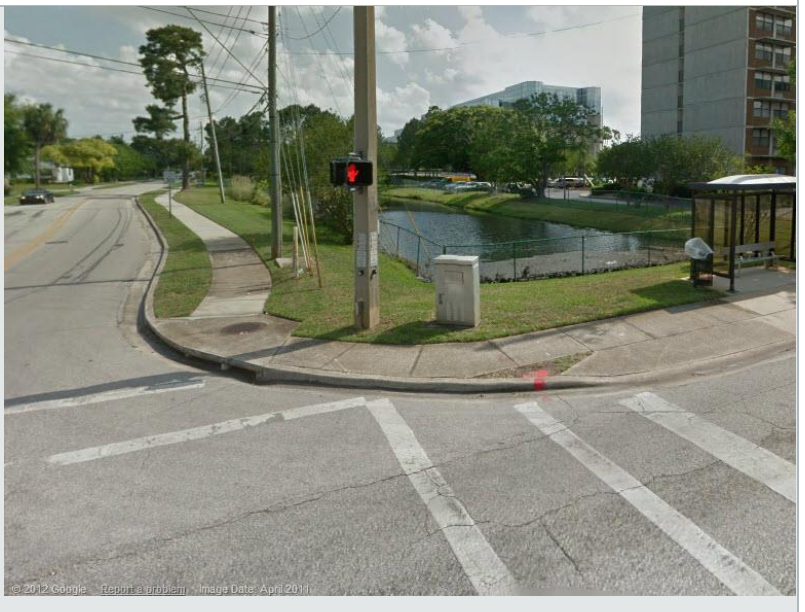

This is a bad example of no curb ramps at crossing. 


\section{MAPS}

The Google Maps function allows users to view and print a map along with the collected data. To access Google Maps, click the "Maps" button from the main menu. Figure 12 displays the SAPFIM "Maps" button and Figures 13 through 15 show the maps for Sidewalks, Ramps, and Curbs.

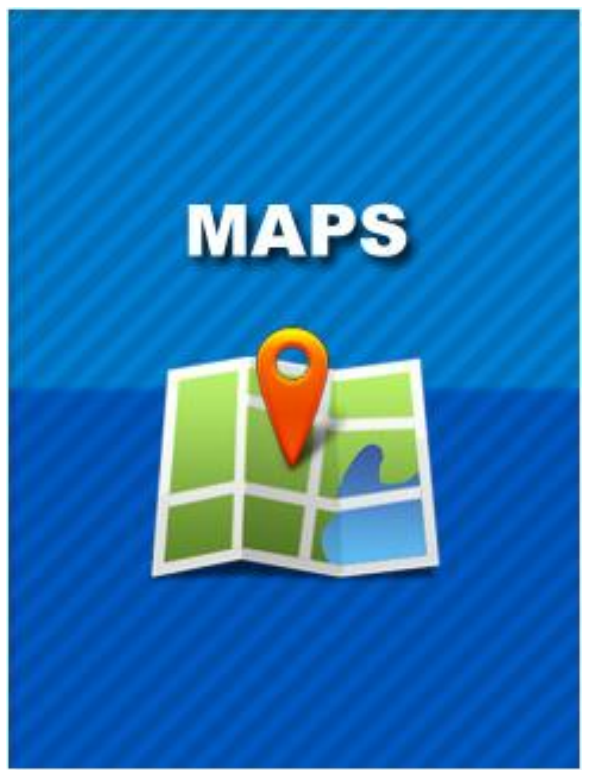

Figure 12: SAPFIM Maps Button

\section{Sidewalks}

The sidewalk information will display on the right after the user clicks on any location icons (labeled S, R, C for Sidewalk, Ramp, and Crossing) in the map. 


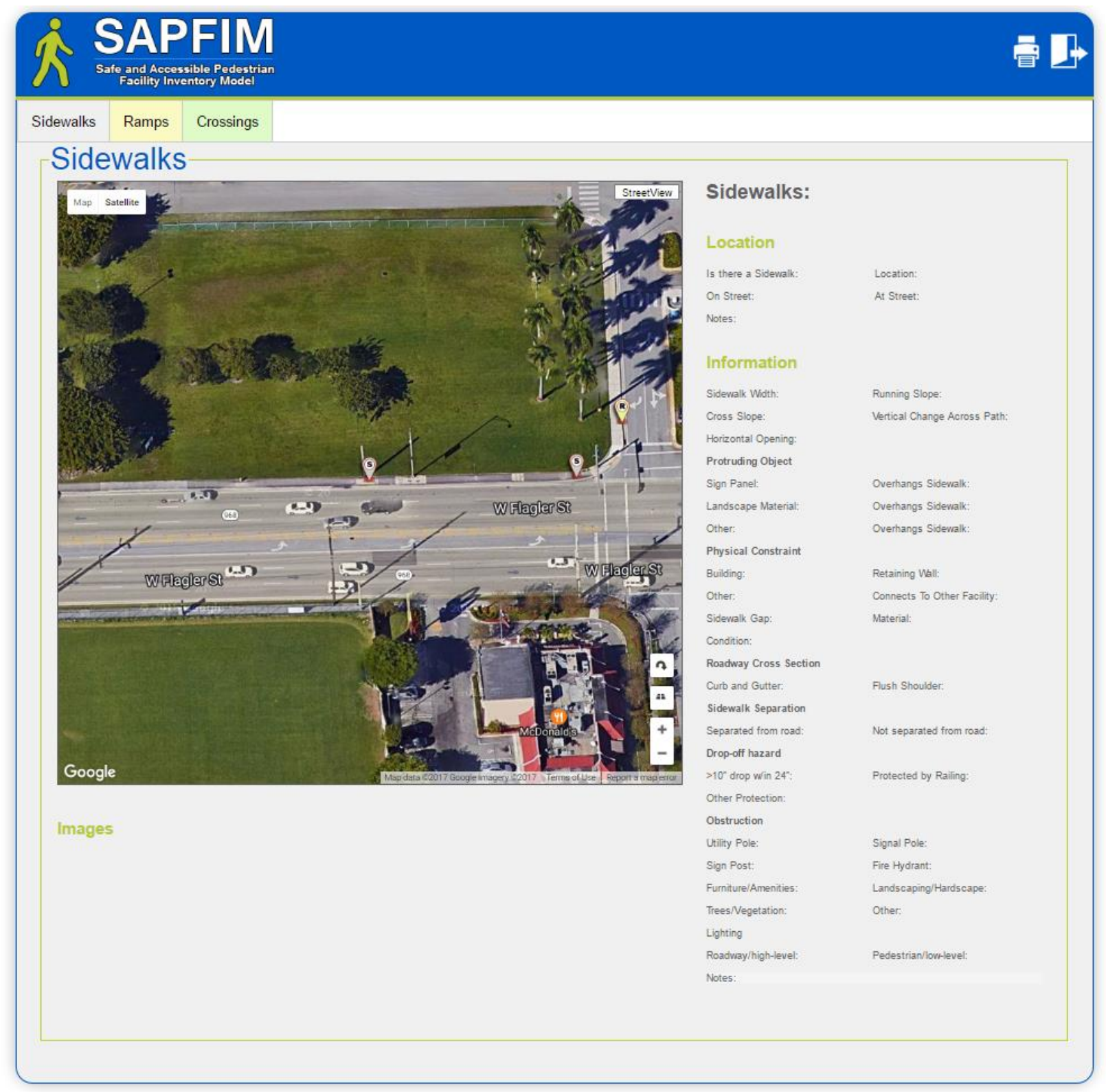

Figure 13: Sidewalk Maps 


\section{Ramps}

The sidewalk information will display on the right after the user clicks on any location icons (labeled S, R, C for Sidewalk, Ramp, and Crossing) in the map.

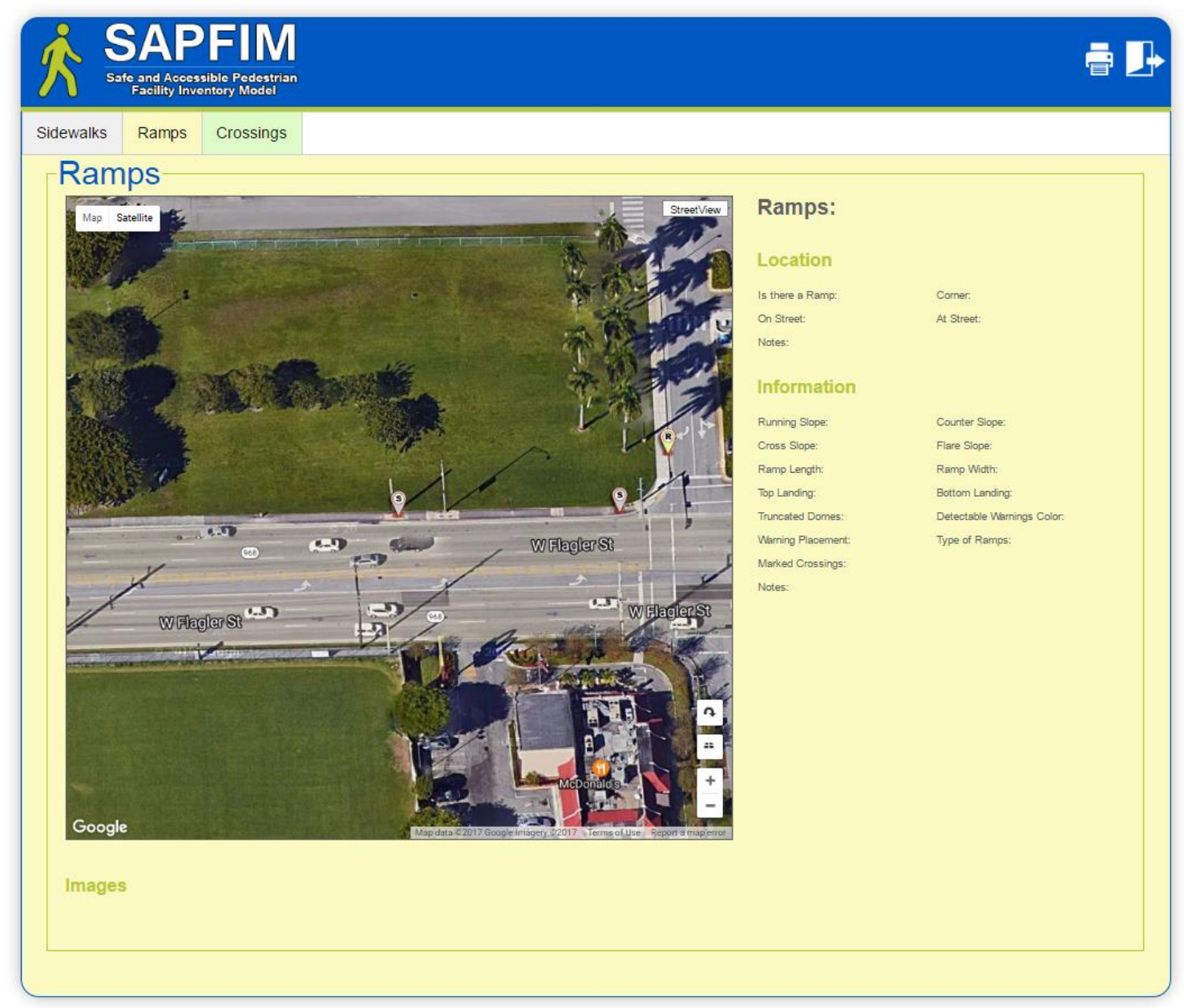

Figure 14: Ramps Maps 


\section{Crossings}

The sidewalk information will display on the right after the user clicks on any location icons (labeled S, R, C for Sidewalk, Ramp, and Crossing) in the map.

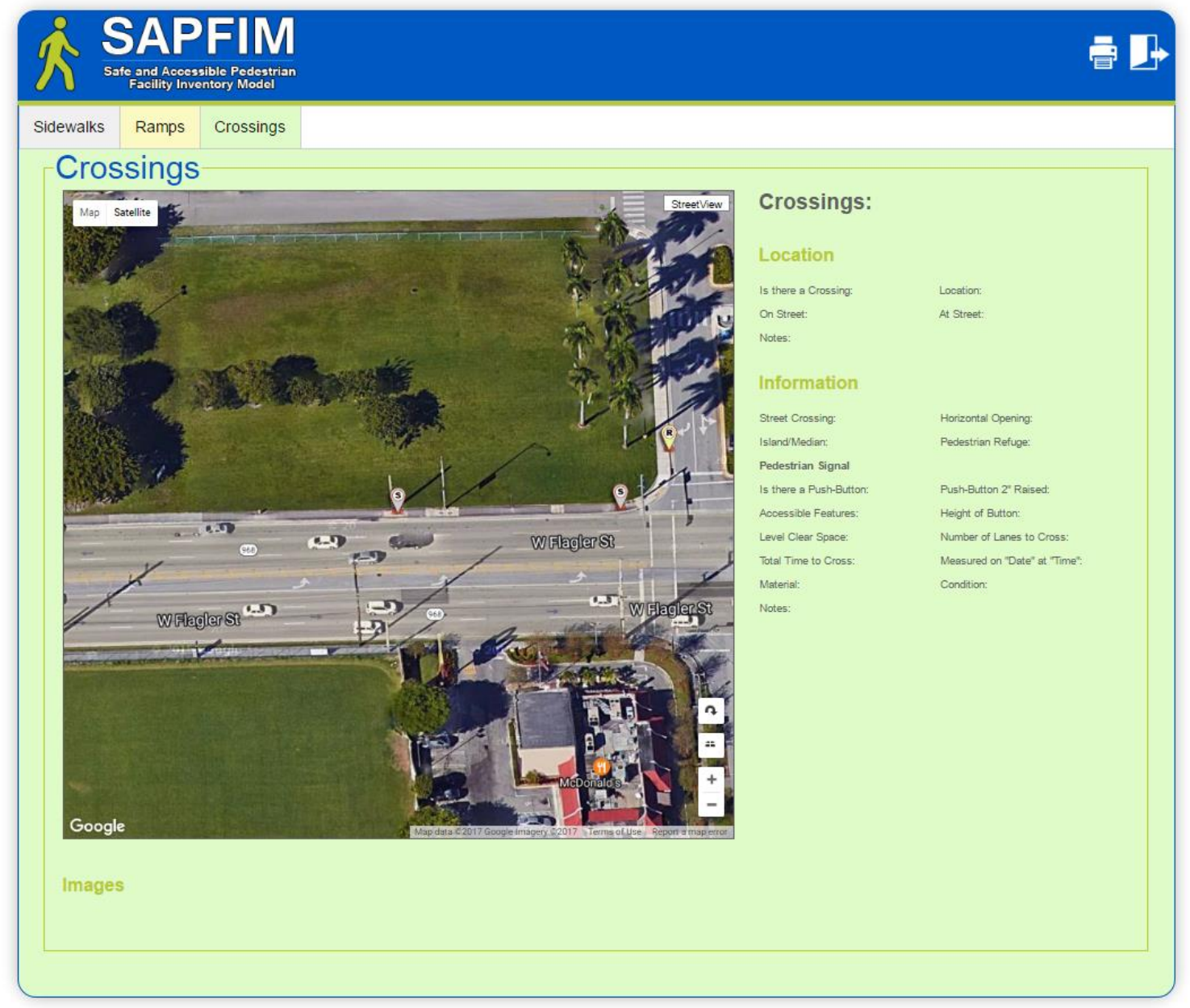

Figure 15: Crossings Maps 


\section{DATA MANAGEMENT}

The Data Management button allows users to Export and Query the data stored in the SAPFIM database. The Export function exports all the data in different formats: CSV (text file), GIS (shapefiles), and Pictures (jpg) with Sidewalks, Ramps, and Crossing information. The Queries section allows users to quickly retrieve information on a specific request or Query Condition (e.g., select locations where the sidewalk width is less than 36"). To access the Data Management component, click the "Data Management" button from the main menu. Figure 16 shows the SAPFIM "Data Management" button; Figure 16 shows the SAPFIM Data Management button and Figure 17 shows the two functions within the Data Management module.

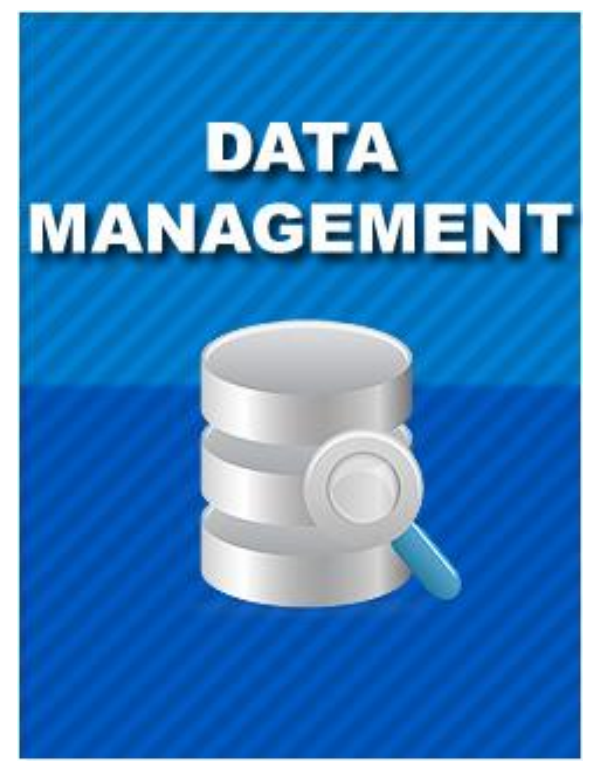

Figure 16: SAPFIM Data Management Button 


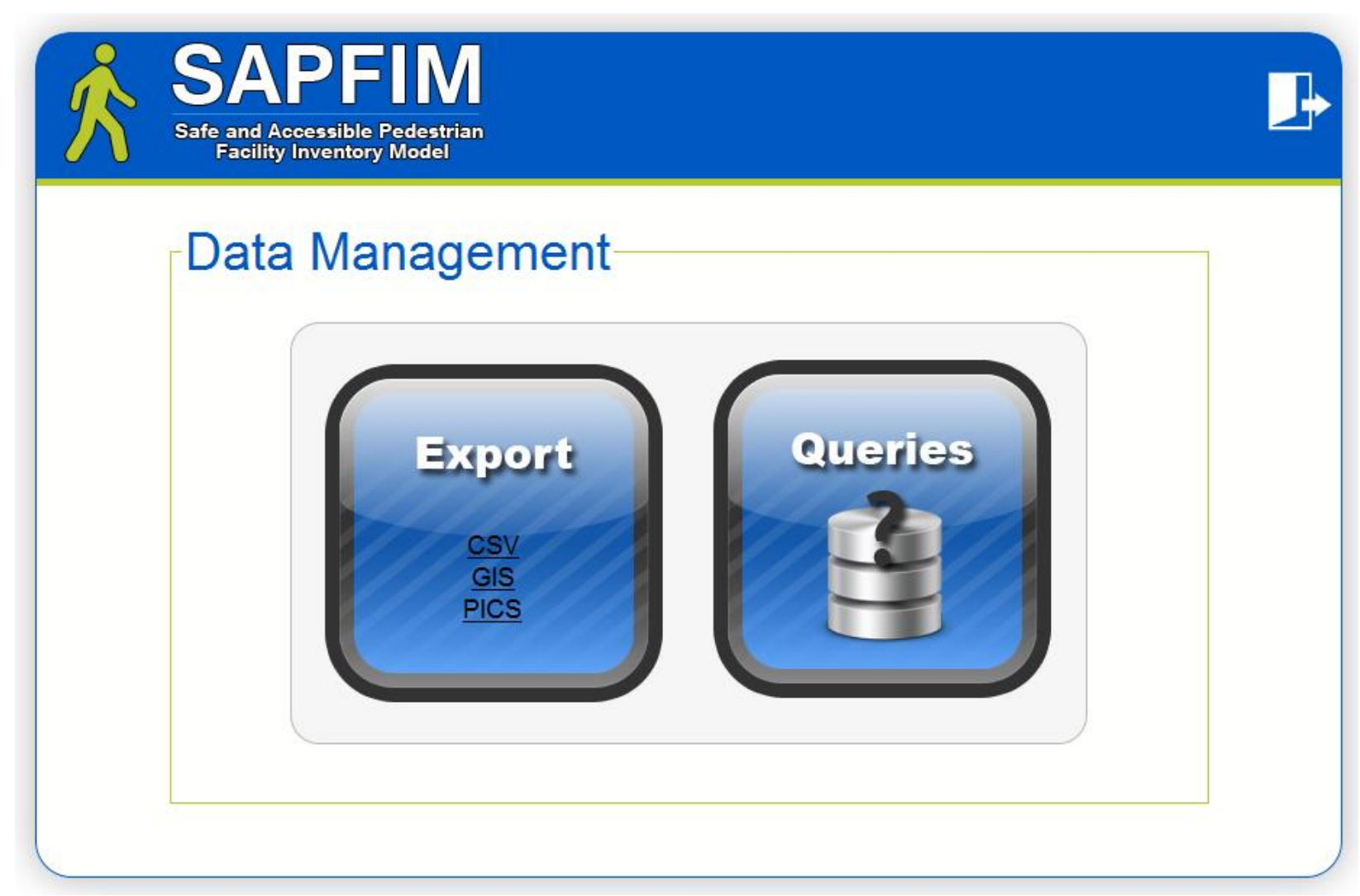

Figure 17: SAPFIM Data Management Functions

\section{Export}

The first function in Data Management is the Export function. This function allows users to export data in three different formats (CSV, GIS, PICS). Figure 18 displays the SAPFIM "Export" button.

- CSV (Comma Separated Value): CSV will save as a text file, which can be opened in Microsoft Excel.

- GIS (Geographic Information Systems): GIS will save as a zip file, which contains the three main GIS shapefiles (.dbf, .shp, shx).

- PICS: PICS will save as a zip file, which contains JPEGs or images for all stops. 


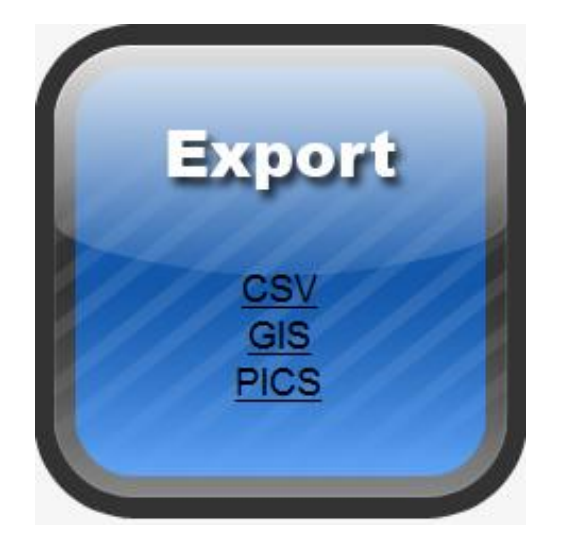

Figure 18: SAPFIM Export Button

\section{Queries}

The Queries function allows users to quickly retrieve pedestrian facilities based on specific criteria. The function is accessible by clicking the "Data Management" button from the SAPFIM main menu, then selecting the "Queries" button. Figure 19 displays a screenshot, as well as more detailed information on accessing Queries.

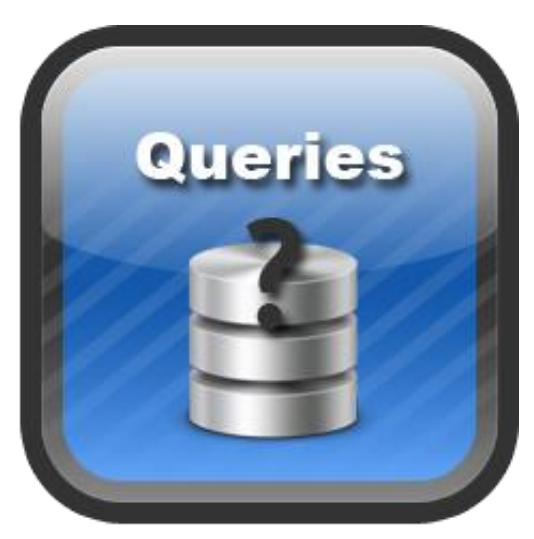

Figure 19: SAPFIM Queries Button

\section{Query Function}

SAPFIM includes a query function that quickly identifies pedestrian facility possessing a specific set of features. The function is accessible by selecting "Data Management" from the SAPFIM main menu.

\section{Querying the SAPFIM Inventory}

After selecting Data Management from the main menu, choosing the Queries option will bring up the screen shown in Figure 20. The query conditions act as filters for the pedestrian facilities attributes and only retrieve information that meet the specified condition(s), in which the following rules apply: 
- By default, the "Query Condition" and the "Query Condition Text" are empty. Selecting the "Search" button while these fields are empty will retrieve all stop records in the database.

- Specific query conditions are chosen by selecting an option from the drop-down menu.

- Multiple query conditions may be specified using the AND/OR operators.

- When multiple conditions are specified for an attribute, the "OR" logical operator is applied. For example, when "Material" and "Condition" are selected for crossings, the query will return pedestrian facilities that has either materials or conditions populated in the database.

- When conditions are specified for more than one attribute, the "AND" logical operator is applied. For example, checking Ramp Type = Parallel in the query condition, and adding Ramp Type $=$ Perpendicular will cause the query to only return pedestrian facilities that have ramp types with parallel and perpendicular.

- For query applications that require other combinations of "OR" and "AND" logical operators, users should click the "Add to Query Condition" button after each condition to construct the query.

- The operator "=" should be used when the data to be retrieved is based on an exact match (e.g., Location='North'). This will retrieve records where the pedestrian facilities locations are on "North" side.

- The operator "Like" can be used to retrieve data that contains a specific/s characters (e.g., ON_STREET Like '\%Flagler\%'). This will retrieve records where the word "Flagler" exists in the ON_STREET data field. 


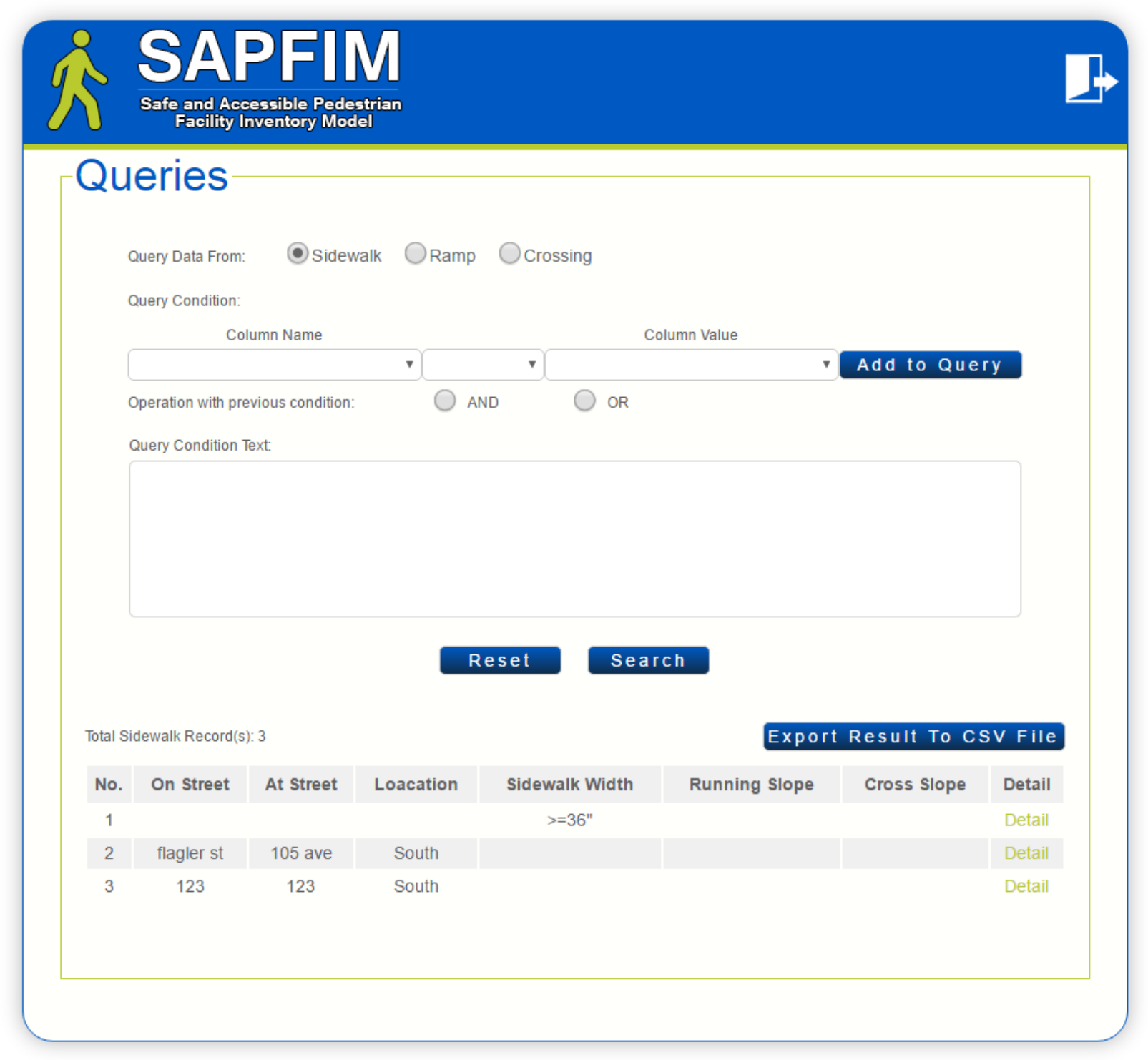

Figure 20: SAPFIM Query Filters Screen

Once the query specifications are completed, click the "Search" button to execute the query. All pedestrian facilities that satisfy the query conditions will be listed at the bottom of the screen. The next step will be to export the search result by clicking "Export Search Result To CSV File," which can be used for analysis data in Excel. 


\section{REPORTS}

The Reports function allows users to generate and print reports based on information from the collected data. To access the reports, click/tap the "Reports" button from the main menu. Figure 21 displays the SAPFIM "Report" button.

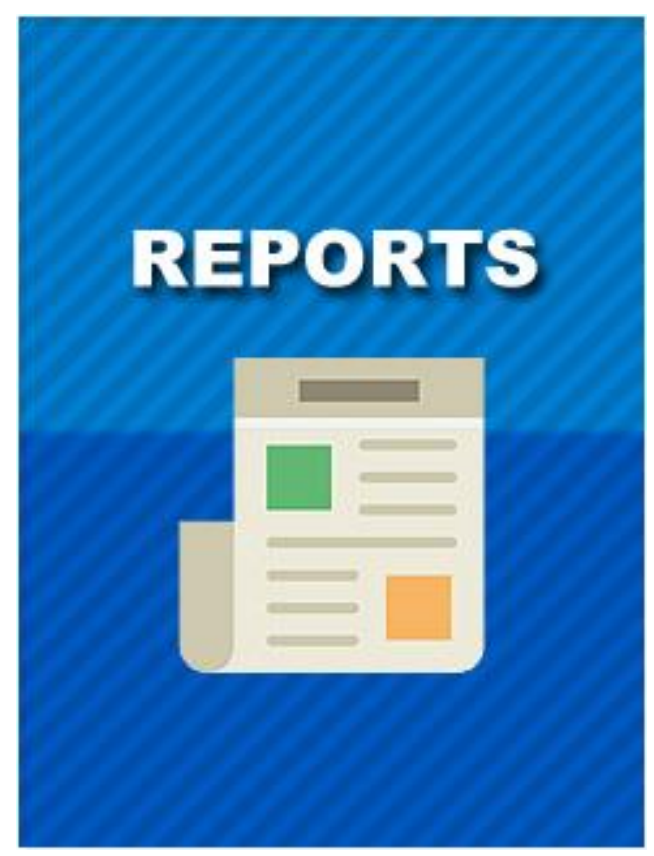

Figure 21: SAPFIM Report Button

\section{Full Reports}

SAPFIM includes full reports of all the data collection fields to quickly obtain important pedestrian facility information. This feature is accessible by selecting the "Full Report" radio button on top of the page. By default, the "Full Report" is already selected (see Figure 22). Then click on any location icons (labeled S, R, C for Sidewalk, Ramp, and Crossing) in the map to display the full report. The browser will then ask if the report should be saved or opened. Figure 23 shows an example of a Crossings report. 


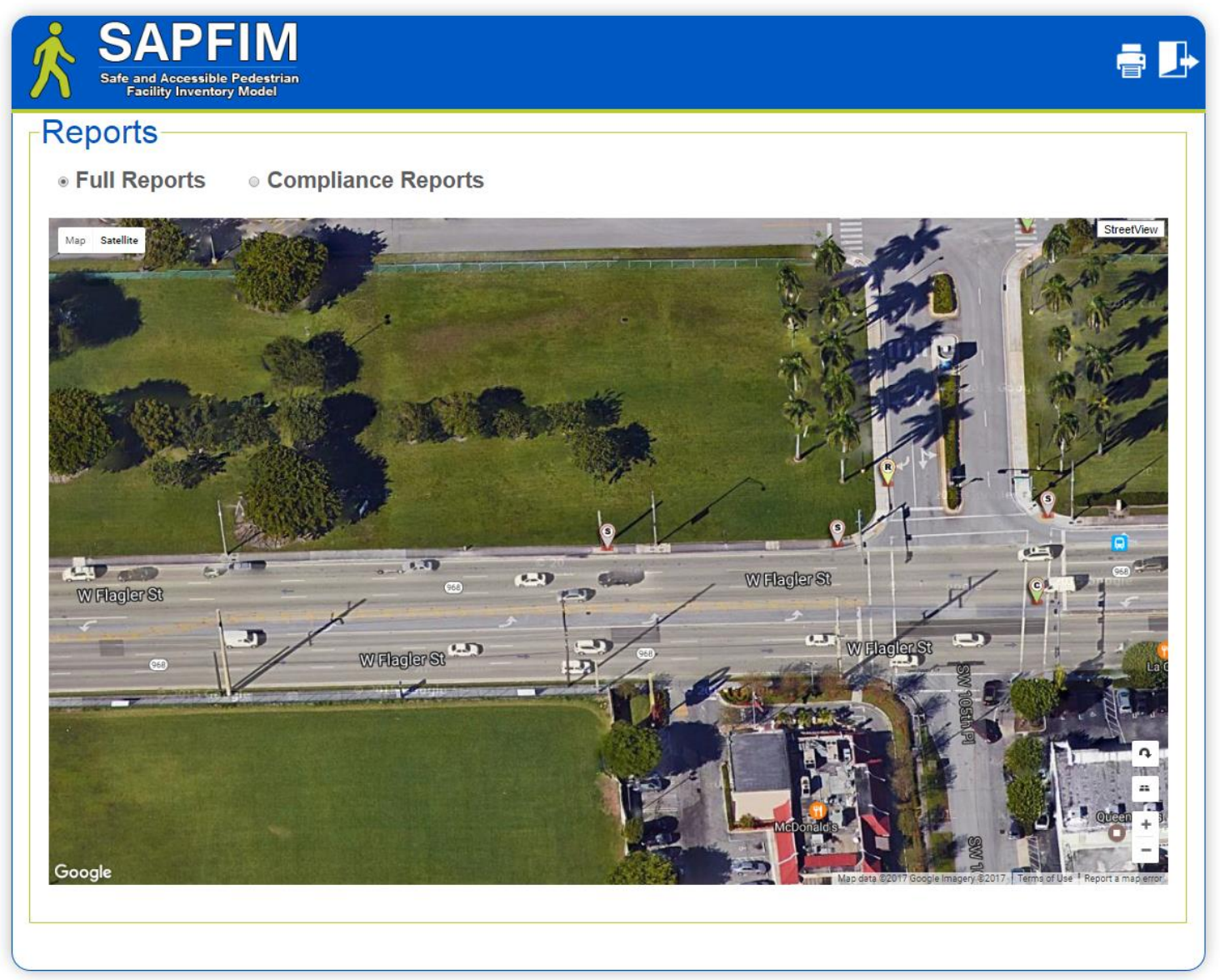

Figure 22: SAPFIM Reports Screen 


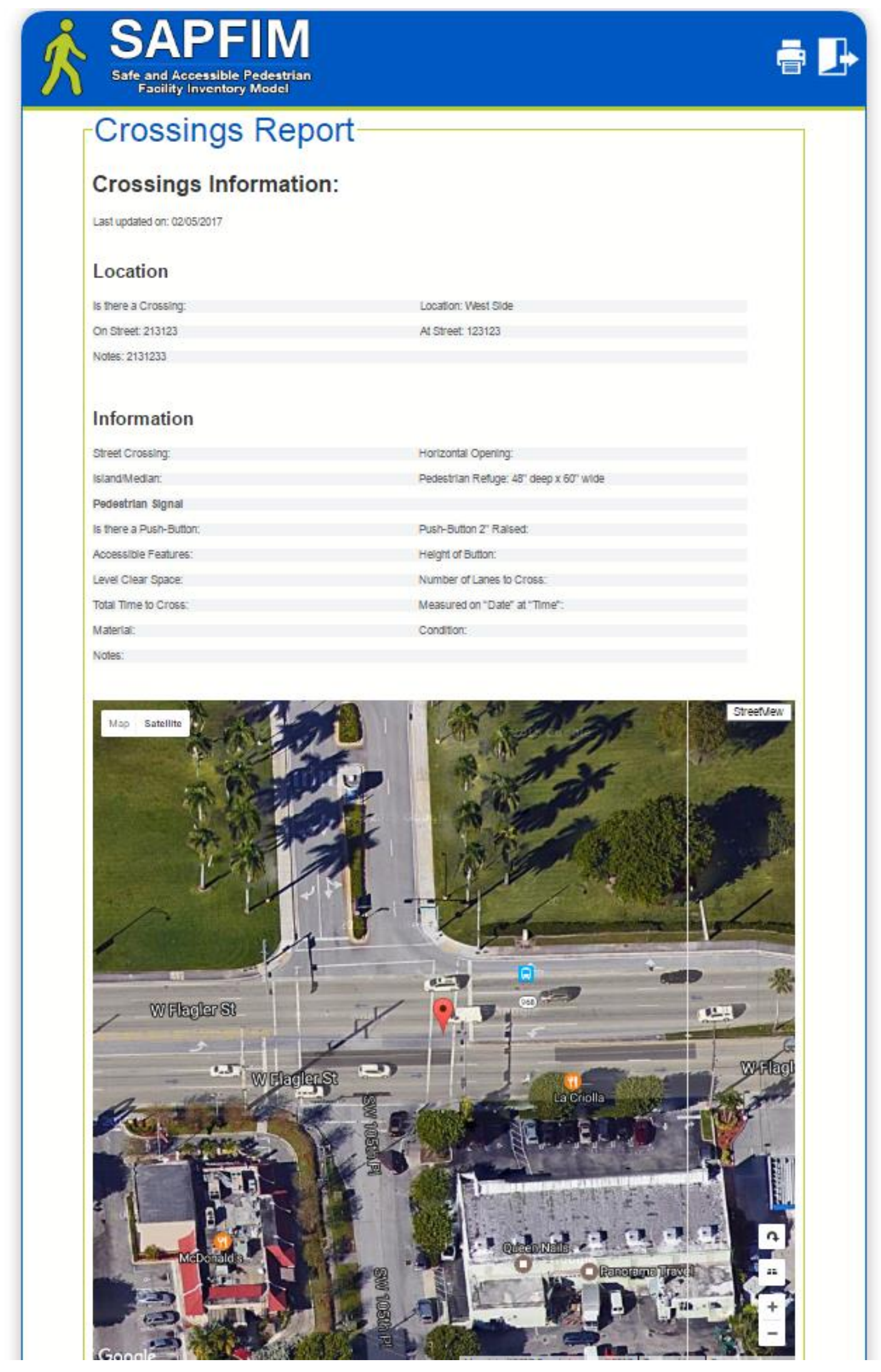

Figure 23: Full Crossings Report 


\section{Compliance Reports}

SAPFIM includes compliance reports of all the data collection fields to quickly assess whether the fields are in compliance with ADA and PROWAG or not. This feature is accessible by selecting the "Compliance Report" radio button on top of the page (see Figure 22). Then click on any location icons (labeled S, R, C that for Sidewalk, Ramp, and Crossing) in the map to display the compliance report. The browser will then ask if the report should be saved or opened. Figure 24 depicts an example of the full Compliance report. 


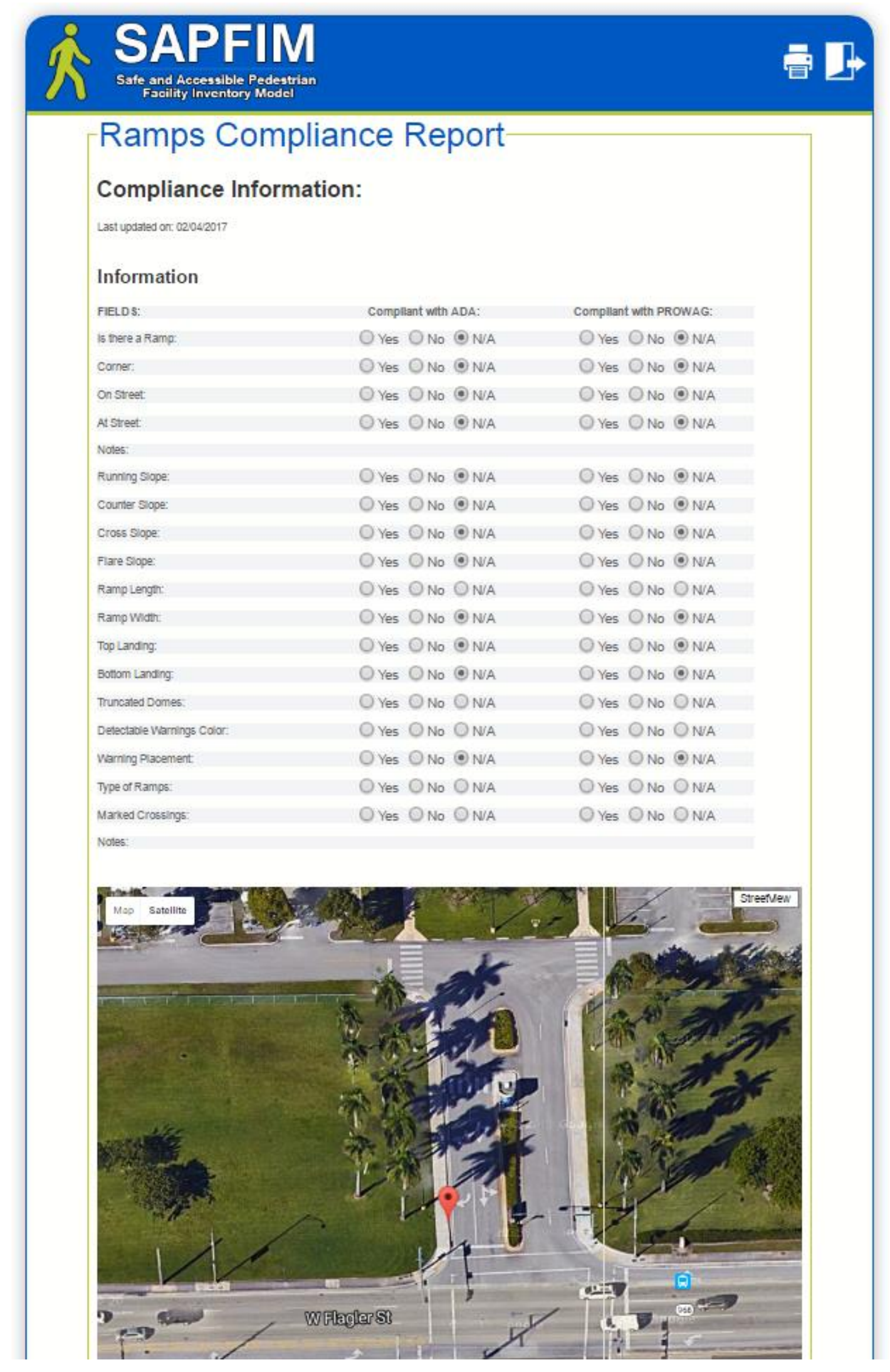

Figure 24: Ramps Compliance Report 


\section{CONCLUSION AND NEXT STEPS}

This section presents the conclusion and the next steps for the SAPFIM web-based application, as presented in the scope of work of the "Safe and Accessible Pedestrian Facilities Inventory Model (SAPFIM): Development" project funded by the National Center for Transportation Research (NCTR) and additional elements to be taken into consideration for the future of the SAPFIM application.

The main objective of the SAPFIM project was to develop a web-based software application that local agencies could use for the collection, storage, querying, analysis, and reporting for the assessment of pedestrian facilities. It included accessible and safety features associated with sidewalks, curb ramps, and street crossings. The user interface enables users to collect data in the field with wireless devices that allows the data to be uploaded directly into the SAPFIM web server. In the office, the data can be exported in different formats for further analysis and the reports can be used to assess whether the collected data fields are in compliance with the ADA and PROWAG standards or not.

To accomplish what it was proposed in the scope of work, the FIU research team concentrated on the following work tasks:

\section{- Prepare the Project Work Plan for the Development of SAPFIM}

This task served as a general guideline for all the milestones according to the proposed schedule.

\section{- Develop the SAPFIM Software}

As part of this task, a web-based pedestrian facility application was developed using Microsoft Visual Studio. This was used to develop the SAPFIM software application.

\section{- Database}

This included the creation and setup of the SQL server database using Microsoft SQL Server, which is the back end of the SAPFIM software application.

\section{- User Interface}

In this step, the user interface of the web application was created. The SAPFIM interface allows the users to collect and upload field data from pedestrian facilities. The software application can also assist local agencies with efficiently assessing the conditions of pedestrian facilities such as sidewalks, ramps, and crosswalks along public rights of way. 


\section{- Test and Troubleshoot the web application}

This task ensured that the application worked as intended. It included an overall testing of all the software elements and external components such as the user interface and database testing as well as the device testing and the wireless communication testing. This task assured that the software was free of bugs and provided opportunities to improve the application.

\section{NEXT STEPS}

After the development and deployment of SAPFIM, the next steps include a series of tasks that can help with the use and further development of the application. This includes three elements: marketing, technical assistance, and proposed future development.

Marketing - this task is being carried out by representatives of FHWA and FDOT who are promoting the software application as a means for local agencies to develop system-wide plans for transitioning noncompliant pedestrian rights of way as required by the Americans with Disabilities Act (ADA). The SAPFIM application is being promoted in national webinars and conferences throughout the country.

Technical Assistance - this task is supported by FIU to assist the agencies that want to use the SAPFIM application. As funding for the creation of individual databases for local agencies, web hosting, and server maintenance can be challenging, the best model for providing support is still under investigation. Nevertheless, FIU is willing to provide full support and technical assistance to the agencies for a nominal fee or to support the agencies that want to install SAPFIM in their servers.

Future Development - as not every possible ADA or safety feature was included in SAPFIM, new features can be added or modified in future. This could be based on users' request and the availability of funds for future development. In addition to more data fields, the user experience can also be enhanced by adding new computer features such as a Search function to find a particular address or to add a Locate button to find the current location on a map. Future versions of the SAPFIM application will depend on the users' demand and financial support. 


\section{REFERENCES}

AARP, WALC (2014). Sidewalks: A Livability Fact Sheet. American Association of Retired Persons and Walkable and Livable Communities Institute. http://www.aarp.org/content/dam/aarp/livable-communities/documents2014/Livability\%20Fact\%20Sheets/Sidewalks-Fact-Sheet.pdf

AASHTO Executive Committee. (1999). "Guide for the Development of Bicycle Facilities." American Association of State Highway and Transportation Officials, Washington, DC.

AASHTO (2004). Guide for the Planning, Design, and Operation of Pedestrian Facilities. American Association of State Highway and Transportation Officials.

AASHTO (2012). Guide for the Development of Bicycle Facilities. American Association of State Highway and Transportation Officials.

ACHD (2005). Pedestrian-Bicycle Transition Plan. Ada County Highway District (ACHD), Idaho. Report prepared by the Transpo Group. http://www.achdidaho.org/Documents/ TitleVI/BikePed2005/ch.2_Inventory.pdf

Allan, B., \& Moffett, F. C. (1998). Accessibility Design for All: An Illustrated Handbook: Washington State regulations (WAC 51-40). Olympia, WA (Capitol Court, Suite 237, 1110 Capitol Way, S., Olympia 98501-2272): A.I.A., Washington Council.

American National Standards Institute (ANSI) (1998). Accessible and Usable Buildings and Facilities. The Council.

Americans with Disabilities Act of 1990: Law and Explanation. (1990). Chicago, Ill. (4025 W. Peterson Ave., Chicago 60646): Commerce Clearing House.

Bicycle, Oregon, and Pedestrian Plan. "Oregon Department of Transportation." Salem, OR (1995).

Boatman|, B. M. (2015). Los Angeles Will Fix Crumbling, Inaccessible Sidewalks - New Mobility. Retrieved October 18, 2016, from http://www.newmobility.com/2015/04/los-angeleswill-fix-crumbling-inaccessible-sidewalks/

Designing Walkable Urban Thoroughfares: A Context Sensitive Approach. (2010). Washington, DC: Institute of Transportation Engineers.

Federal Highway Administration (FHWA) (2001). Accessible Sidewalks and Street Crossings: An Informational Guide. 1200 New Jersey Avenue, SE Washington, DC 20590 USA. http://www.bikewalk.org/pdfs/sopada_fhwa.pdf

Federal Highway Administration (FHWA) (2013). A Guide for Maintaining Pedestrian Facilities for Enhanced Safety. No. FHWA-SA-13-037. 
Federal Highway Administration (FHWA). Designing Sidewalks and Trails for Access https://www.fhwa.dot.gov/environment/bicycle_pedestrian/publications/sidewalks/contents.cfm

Goldman, Charles D. Architectural Barriers: A Perspective on Progress. W. New England Law Review 5 (1968): 465.

Florida Department of Transportation. (2016). FDOT Americans with Disabilities Act (ADA): ADA / Accessibility Program. http://www.fdot.gov/designsupport/ADA/

International Code Council, Inc. (2016). ICC A117.1 Standard Fourth Public Review Draft Background Report. ICC/ANSI A117.1 Standard Development - 2015 Edition http://productionpullzone.umz7izwbxixtqs4tn8wkvgdcktq5y5tafr.netdna-cdn.com/wpcontent/uploads/asc_a117/A117-1-Fourth-Public-Review-Draft.pdf

ITE (1998). Design and Safety of Pedestrian Facilities. Institute of Transportation Engineers. Traffic Engineering Council Committee TENC 5A-5.

ITE (2010). Designing Walkable Urban Thoroughfares - A Context Sensitive Approach: An ITE Recommended Practice. Institute of Transportation Engineers.

Keim, Donald W. (1976). "Education of all Handicapped Children Act of 1975, University of Michigan, JL Reform 10: 110.

Kockelman, K., Zhao, Y., Heard, L., Taylor, D., \& Taylor, B. (2000). The Nature of ADA's Sidewalk Cross-Slopes Requirements: A Review of the Literature. Transportation Research Record, 1705, 53-60.

LaPlante, J. N., and Short, T. R. (2000). AASHTO GUIDE FOR THE PLANNING, DESIGN AND OPERATION OF PEDESTRIAN FACILITIES. Institute of Transportation Engineers.

NACTO (2010). Urban Bikeway Design Guide. National Association of City Transportation Officials

NACTO (2014). Urban Bikeway Design Guide, Second Edition. National Association of City Transportation Officials.

National Council on Disability (2004). Livable Communities for Adults with Disabilities.

Oberlink, M. "Livable communities for adults with disabilities." Policy brief (Center for Home Care Policy and Research (US)) 29 (2005): 1-6.

PACTS (2014). Regional Bicycle and Pedestrian Facility Design Guidance for the PACTS Metropolitan Planning Area. Portland Area Comprehensive Transportation System. Report prepared by Alta Planning + Design. http://www.pactsplan.org/plans-studies/2013-plans-studiescompleted/ 
Pedestrian Guidebook Facilities. (1997). Incorporating Pedestrians into Washington's Transportation System. Prepared by Otak for Washington State DOT, Olympia, WA.

PennDOT (2016). Design Manual Part 2 Highway Design. Publication 13M, 2015 Edition Change No. 1. Pennsylvania Department of Transportation. https://www.dot.state.pa.us/public/ pubsforms/Publications/PUB\%2013M.pdf

Perkins, Dean. (2015). ADA for Roadway Design: Incorporating PROWAG. Design Training Expo. http://www.fdot.gov/design/Training/DesignExpo/2015/presentations/ADAandPROWAGDeanPerkins.pdf

Rehabilitation Act of 1973 (1998). https://www.disability.gov/rehabilitation-act-1973/ Revised Code of Washington. Vol RCW 70.010 (1992). Washington Electronic Authentication Act.

Savage, Joseph P., MacDonald, David R., and Ewell John. (1994). A Guidebook for Residential Traffic Management. Olympia, WA: Washington State Department of Transportation.

United States Access Board (1991). The Americans with Disabilities Act Accessibility Guidelines (ADAAG). Amended in 2002. https://www.access-board.gov/guidelines-andstandards/buildings-and-sites/about-the-ada-standards/background/adaag

United States Access Board (2004). Americans with Disabilities Act and Architectural Barriers Act Accessibility Guidelines. Amended in 2014. https://www.access-board.gov/attachments/ article/412/ada-aba.pdf

United States Access Board. (2006). ADA Standards for Transportation Facilities. https://www.access-board.gov/guidelines-and-standards/transportation/facilities/ada-standardsfor-transportation-facilities

United States Access Board. (2006). Americans with Disabilities Act (ADA) Standards for Transportation Facilities. https://www.accessboard.gov/attachments/article/1417/ADAdotstandards.pdf

United States Access Board (2010). Guide to the ADA Standards. https://www.accessboard.gov/guidelines-and-standards/buildings-and-sites/about-the-ada-standards/guide-to-theada-standards

United States Access Board (2011). Proposed Accessibility Guidelines for Pedestrian Facilities in the Public Right-of-Way. https://www.access-board.gov/attachments/article/743/nprm.pdf

United States Congress. "Intermodal surface transportation efficiency act of 1991." Public Law (1991): 102-240.

United States Congress. "Transportation Equity Act for the 21st Century." Public Law (1998): 105-178. 
United States Department of Justice Civil Rights Division. (2016). Information and Technical Assistance on the Americans with Disabilities Act. https://www.ada.gov/

United States Department of Transportation. Accessibility: Equal Access to Transportation. https://www.transportation.gov/accessibility

WALC (2014). Observations and Recommendations: The Built Environment. Albuquerque, New Mexico. Walkable and Livable Communities Institute.

Zhang, Y., Proulx, F. R., Ragland, D. R., Schneider, R. J., \& Grembek, O. (2014). Develop a Plan to Collect Pedestrian Infrastructure and Volume Data for Future Incorporation into Caltrans Accident Surveillance and Analysis System Database. State of California Department of Transportation. 


\section{APPENDIX A}

(SAPFIM Quick Guide) 
Safe and Accessible Pedestrian Facility Inventory Model

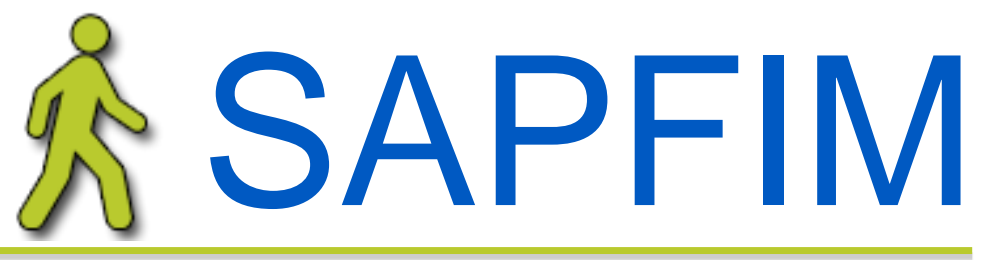

Quick Guide

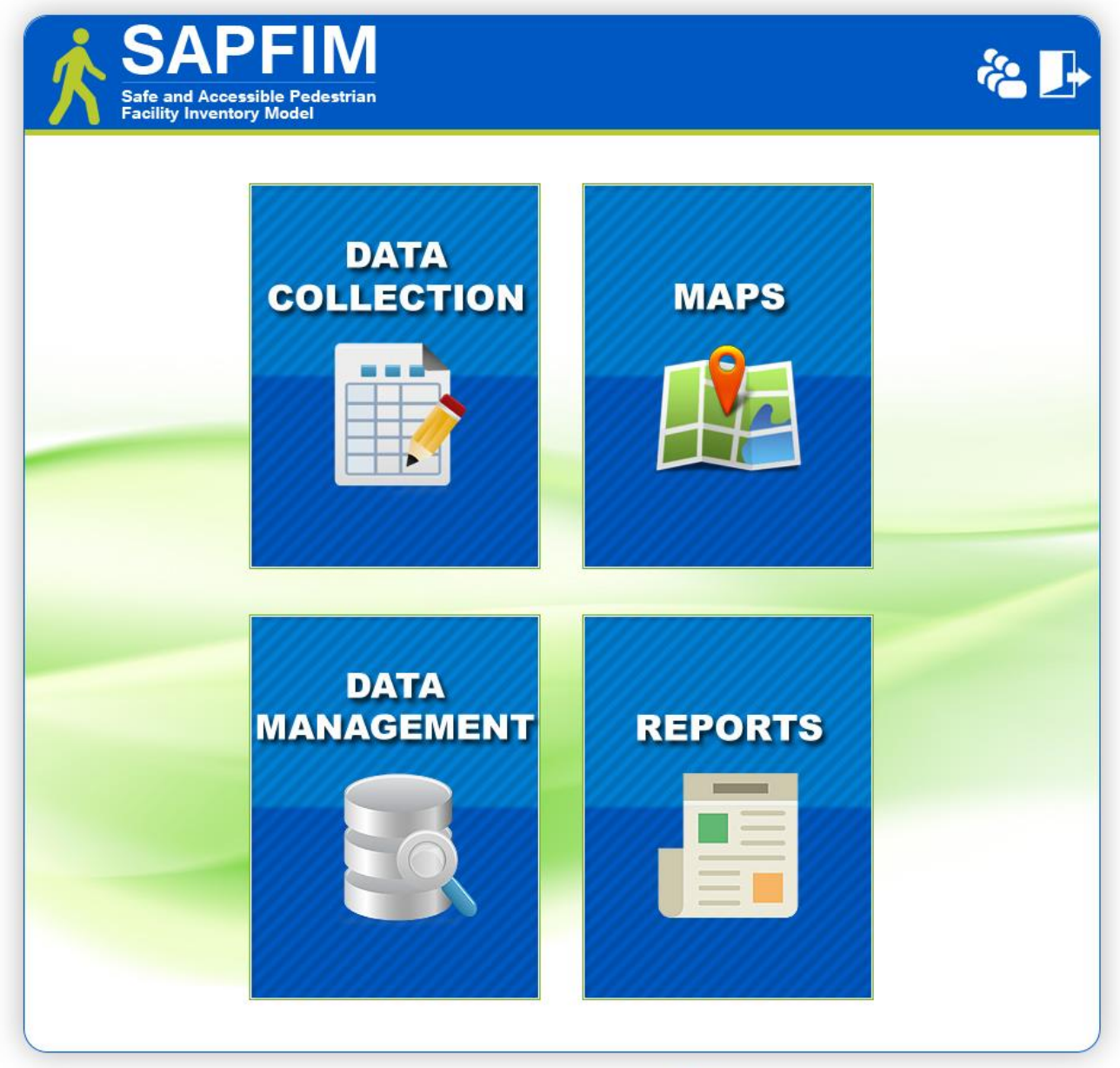




\section{DISCLAIMER}

While every effort was made to ensure that this software is of the best quality and free of defects, some errors may be unavoidable. No warranty, expressed or implied, and no warranty of merchantability or fitness, is given. Neither the Florida Department of Transportation, nor Florida International University, will assume any liability for results obtained or losses incurred from the use of this software. The opinions, findings, and conclusions expressed in this publication are those of the authors and not necessarily those of the Florida Department of Transportation.

Use this guide as much as possible to insure accurate data collection. If something is unclear or for more information, please contact the following person below:

Fabian Cevallos, Ph.D.

Transit Program Director

Lehman Center for Transportation Research

Florida International University

Email: fabian.cevallos@fiu.edu

Office: (305) 348-3144

Cell: (954) 234-4183 
The SAPFIM main menu consists of four components:

1. Data Collection

2. Maps

3. Data Management

4. Reports

The SAPFIM main menu provides a gateway to accessing the various functions of SAPFIM. This section presents a description of the Data Collection fields for the Sidewalk, Ramps, and Crossing elements.

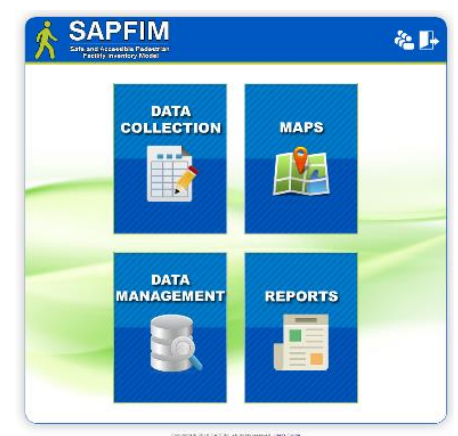

\section{Field/Inventory Staff}

\section{Sidewalks}

The Sidewalk fields are described below:

43. Is there a Sidewalk? Check yes or no if there is a sidewalk or not.

45. On Street: Enter the name of the street along the sidewalk.

47. Notes: A "note" can be included to document any special conditions that exist at the sidewalk.

49. Running Slope: Select the percentage of the running slope of the sidewalk.

51. Change in Level: Select a vertical change along the sidewalk.

53. Sign Panel: $\geq \mathbf{2 7} " \leq \mathbf{8 0}$ " AWS: Check whether there is a sign panel between 27" and 80" Above Walking Surface.

55. Landscape Material: $\geq 27$ " $\leq \mathbf{8 0}$ " AWS: Check whether there is landscape material between 27" and 80 " Above Walking Surface.

57. Other: $\geq \mathbf{2 7} " \leq \mathbf{8 0}$ " AWS: Check whether there is an object between 27" and 80" Above Walking Surface.

59. Building: Width of the sidewalk, at that particular location, measured from back of curb to a building.

61. Other: Width of the sidewalk, measured from back of curb to an infrastructure, other than building or retaining wall.

63. Sidewalk Gap: Select the length of a sidewalk gap in feet.

65. Condition: Select the condition of the sidewalk: good, cracks, dirt, grass, other.

67. Flush Shoulder: Select whether there is a flush shoulder.

69. Not separated from road: Select Curb and Gutter or Flush Shoulder options, if not separated from road.

71. Protected by Railing: Check yes or no if there is a protected railing.
44. Location: Select whether the sidewalk is located on the North, South, East, or West.

46. At Street: Enter the name of the closest crossstreet.

48. Sidewalk Width: Select the appropriate option for the width of the sidewalk: $<36^{\prime \prime},>=36^{\prime \prime}<48$ ", or $>=48$ ".

50. Cross Slope: Select the percentage of the cross slope of the sidewalk.

52. Horizontal Opening (Perpendicular to Path): Select a horizontal opening.

54. Overhangs Sidewalk: Select the length of a protruding object that overhangs the sidewalk.

56. Overhangs Sidewalk: Select the length of a protruding object that overhangs the sidewalk.

58. Overhangs Sidewalk: Select the length of a protruding object that overhangs the sidewalk.

60. Retaining Wall: Width of the sidewalk, at that particular location, measured from back of curb to a retaining wall.

62. Connects To Other Facility: Check yes or no if the sidewalk connects to other facility (e.g., sidewalk or building entrance).

64. Material: Select the type of material of the sidewalk: concrete, asphalt, brick, other.

66. Curb and Gutter: Select whether there is a curb and gutter.

68. Separated from road: Select separation distance using the Curb and Gutter or Flush Shoulder options.

70. >10" drop w/in 24": Check yes or no there is a 10 " vertical drop within 24 " horizontal distance.

72. Other Protection: Check yes or no there is another protection, other than railing. 
73. Utility Pole: Select the smallest distance from back of curb to utility pole or from back of sidewalk to utility pole.

75. Sign Post: Select the smallest distance from back of curb to sign post or from back of sidewalk to sign post.

77. Furniture/Amenities: Select the smallest distance from back of curb to furniture/amenities or from back of sidewalk to furniture/amenities.

79. Trees/Vegetation: Select the smallest distance from back of curb to trees/vegetation or from back of sidewalk to trees/vegetation.

81. Roadway/high-level Lighting: Check whether there is a roadway/high-level lighting present.

83. Upload Picture: Select to upload a picture to the database.
74. Signal Pole: Select the smallest distance from back of curb to signal pole or from back of sidewalk to signal pole.

76. Fire Hydrant: Select the smallest distance from back of curb to fire hydrant or from back of sidewalk to fire hydrant.

78. Landscaping/Hardscape: Select the smallest distance from back of curb to landscaping/hardscape or from back of sidewalk to landscaping/hardscape.

80. Other: Select the smallest distance from back of curb to other obstruction or from back of sidewalk to other obstruction.

82. Pedestrian/low-level Lighting: Check whether there is a pedestrian/high-level lighting present.

84. Notes: A "note" can be included to document any special conditions that exist at the sidewalk.

\section{Ramps}

The Ramps fields are described below:

24. Is there a Ramp? Check yes or no if there is a ramp or not.

26. On-Street: Enter the name of the street where the ramp is located.

28. Notes: A "note" can be included to document any special conditions that exist at the ramp.

30. Running Slope: The percentage of the slope of ramp parallel to walking direction.

32. Cross Slope: The percentage of the ramp cross slope.

34. Flare Side 2: The percentage of the ramp flare slope parallel to curb.

36. Ramp Width: The width of the ramp in inches.

38. Top Landing Width: The width of the top landing in inches.

40. Bottom Landing Width: The width of the bottom landing in inches.

42. Detectable Warning Contrast: Select whether detectable warning contrast with surrounding surfaces.

44. Warning Placement: Select the distance of the detectable warnings from back of curb or roadway edge.

46. Notes: A "note" is included to document any special conditions that exist at the ramp.

25. Corner: Select whether the corner location is Northwest, Northeast, Southwest, or Southeast.

27. At-Street: Enter the name of the closest crossstreet to the ramp.

29. Type of Ramps: Select whether the ramp is Perpendicular, Parallel, Combination, Diagonal, or Other.

31. Counter Slope: The percentage of the slope of gutter at bottom of ramp.

33. Flare Side 1: The percentage of the ramp flare slope parallel to curb.

35. Ramp Length: The length of the ramp in inches.

37. Top Landing Length: The length of the top landing in inches.

39. Bottom Landing Length: The length of the bottom landing in inches.

41. Truncated Domes: Check whether the ramp surface include truncated domes or not.

43. Detectable Warning Full Width: Select whether detectable warning full width of curb ramp or sidewalk.

45. Upload Picture: Select to upload a picture to the database.

47.

\section{Crossings}

The Crossings fields are described below:

24. Is there a Marked Crossings? Check whether street crossings are marked or not.

25. Location: Select whether the crossing location is Northside, Northside, Westside, or Eastside. 
26. Is there a 4' $x$ 4' maneuvering area? Whether there is a $4^{\prime} \times 4^{\prime}$ maneuvering area within the crossing markings.

28. At Street: Enter the name of the closest crossstreet to the crossing.

30. Street Crossings: Select whether there is a street crossings.

32. Island/Median: Select whether there is an island/median or not.

34. Is Pedestrian Refuge $>6^{\prime}$ ? Select the appropriate distance if there is pedestrian refuge.

36. Push-Button 2" Raised: Select yes or no if the pedestrian signal includes a push-button raised and 2" in diameter.

38. Height of Button: Select the height of the pedestrian signal button, measured from Above Walking Surface.

40. Number of Lanes to Cross: Enter the number of street lanes to cross.

42. Measured on "Date" at "Time": Enter the date and time when the Total Time to Cross was measured.

44. Condition: Select the crosswalk condition: Good, Cracks, Faded, Other.

46. Notes: A "note" can be included to document any special conditions that exist at the crosswalk.
27. On Street: Enter the name of the street where the crossing is located.

29. Notes: A "note" can be included to document any special conditions that exist at the crossing.

31. Horizontal Opening: Select the appropriate distance if a horizontal opening exists.

33. Pedestrian Refuge: Select the appropriate distance if there is pedestrian refuge.

35. Is there a Push-Button? Select yes or no if there is a push-button at the pedestrian signal or not.

37. Accessible Features: Select the features the pedestrian signal has: Audible, Tactile, or Other.

39. Level Clear Space: Select whether there is a clear level space equal or greater than $30 " \mathrm{x} 48$ ".

41. Total Time to Cross: Enter the time it takes to cross the street.

43. Material: Select whether the crosswalk material is Concrete, Asphalt, Brick/Paver, or Other.

45. Upload Picture: Select to upload a picture to the database.

47.

\section{Office/Assessment Staff}

The Reports section allows users to generate and print reports based on information from the collected data. There are two reports a user can generate: Full Reports and Compliance Reports.

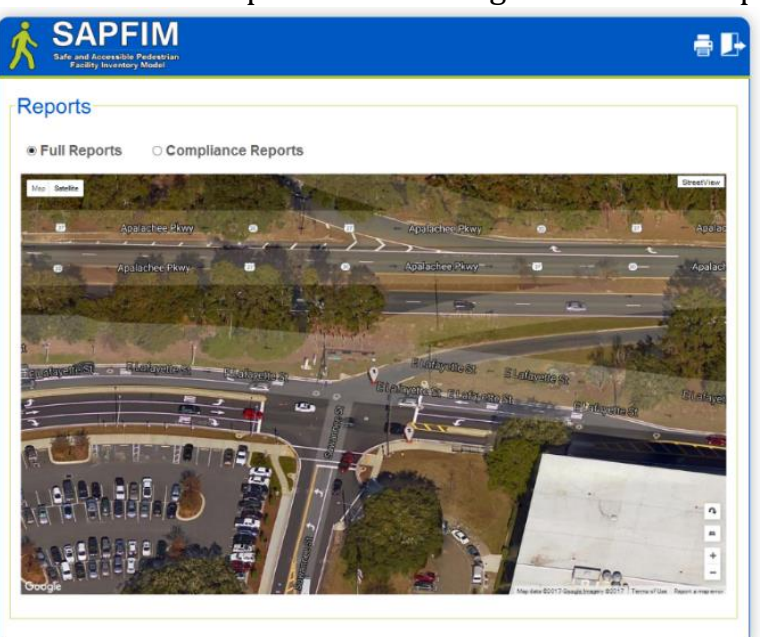

Full Reports

SAPFIM includes full reports of all the data collection fields to quickly obtain important pedestrian facility information. This feature is accessible by selecting the "Full Report" radio button on top of the page. By default, the "Full Report" is already selected. Then click on any

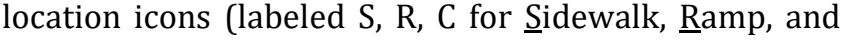
Crossing) in the map to display the full report.

Compliance Reports

SAPFIM includes compliance reports of all the data collection fields to quickly assess whether the fields are in compliance with ADA and PROWAG or not. This feature is accessible by selecting the "Compliance Report" radio button on top of the page. Then click on any location icons

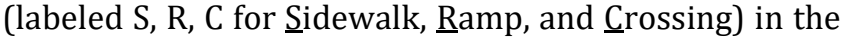
map to display the compliance report. 


\section{SAPFIM Maps}

The Google Maps function allows users to view and print a map along with the collected data. To access this information, click on any location icons (labeled S,

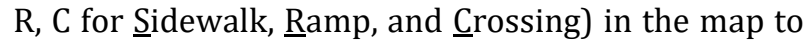
display the selected information.

\section{Data Management}

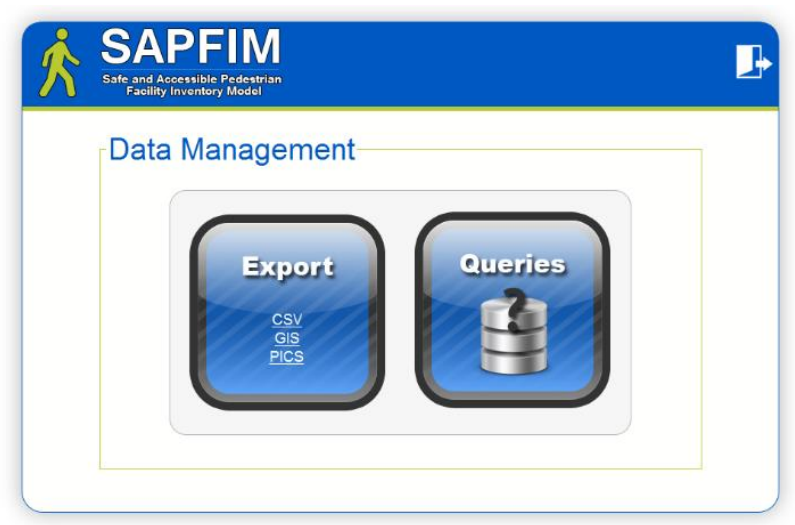

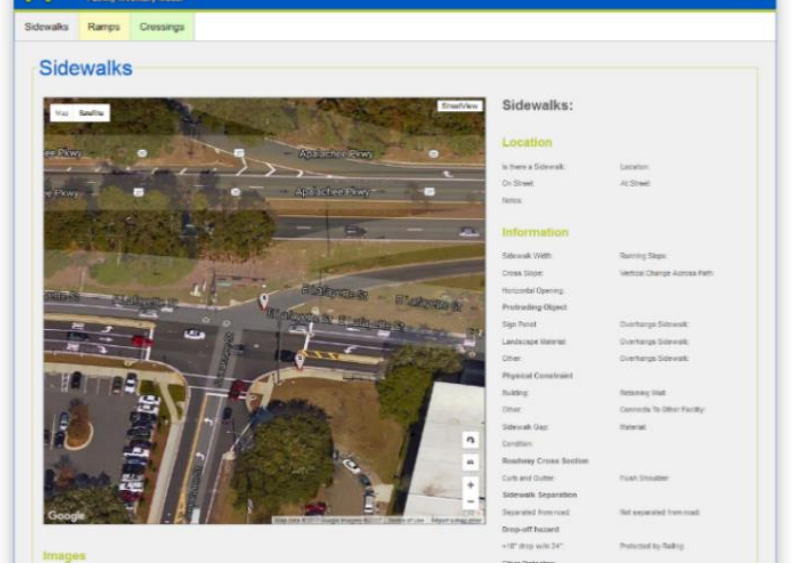

This section allows users to Export and Query the data stored in the SAPFIM database. The Export

function exports all the data in different formats: CSV (text file), GIS (shapefiles), and Pictures (jpg) with Sidewalks, Ramps, and Crossing information. The Queries section allows users to quickly retrieve information on a specific request or Query Condition (e.g., select locations where the sidewalk width is less than 36"). 